\title{
Distinguishing Beliefs about Social Inequality: Associations among Dimensions of Critical Consciousness
}

Lauren M. Alvis

West Virginia University, Imalvis@mix.wvu.edu

Follow this and additional works at: https://researchrepository.wvu.edu/etd

Part of the Developmental Psychology Commons, and the Political Science Commons

\section{Recommended Citation}

Alvis, Lauren M., "Distinguishing Beliefs about Social Inequality: Associations among Dimensions of Critical Consciousness" (2019). Graduate Theses, Dissertations, and Problem Reports. 3858.

https://researchrepository.wvu.edu/etd/3858

This Dissertation is protected by copyright and/or related rights. It has been brought to you by the The Research Repository @ WVU with permission from the rights-holder(s). You are free to use this Dissertation in any way that is permitted by the copyright and related rights legislation that applies to your use. For other uses you must obtain permission from the rights-holder(s) directly, unless additional rights are indicated by a Creative Commons license in the record and/ or on the work itself. This Dissertation has been accepted for inclusion in WVU Graduate Theses, Dissertations, and Problem Reports collection by an authorized administrator of The Research Repository @ WVU.

For more information, please contact researchrepository@mail.wvu.edu. 
Distinguishing Beliefs about Social Inequality: Associations among Dimensions of Critical Consciousness

Lauren M. Alvis, M.S.

\author{
Dissertation defense submitted to \\ the Eberly College of Arts and Sciences \\ at West Virginia University \\ in partial fulfillment of the requirements \\ for the degree of \\ Doctor of Philosophy \\ in \\ Life-Span Developmental Psychology
}

Aaron Metzger, Ph.D., Chair

Amy Gentzler, Ph.D.

Elisa Krackow, Ph.D.

Laura Wray-Lake, Ph.D.
Department of Psychology
Morgantown, West Virginia
2019

Keywords: critical consciousness, political involvement, civic engagement, political beliefs, social justice, emerging adulthood, social inequality

Copyright 2019 Lauren M. Alvis 


\begin{abstract}
Distinguishing Beliefs about Social Inequality: Associations among Dimensions of Critical Consciousness
\end{abstract}

Lauren M. Alvis

Critical consciousness researchers posit that critical reflection, which refers to a critical awareness of structural inequalities between socially constructed groups and external political efficacy beliefs (i.e., perceptions of government responsiveness) are important precursors to effective political action (Diemer et al., 2016; Watts, Diemer, \& Voight, 2011). However, little is known about emerging adults' views of social inequality and political change regarding specific marginalized groups. There are different forms of social inequality and the extent to which individuals experience these inequities is partially determined by multiple sociodemographic characteristics including race/ethnicity, sex, sexual-orientation, and gender identity (Hurst et al., 2016). Identifying potential heterogeneity in emerging adults' perceptions of these different group-based inequalities may elucidate sociocognitive factors that undergird different forms of active citizenship. Thus, the current study had three primary goals: 1) test and validate the factor structure of a new multidimensional measure of critical reflection and external political efficacy beliefs and examine the extent to which these beliefs vary across different types of group-based inequalities, 2) investigate how emerging adults' own identity characteristics (race/ethnicity, gender, sexual orientation) intersect with their group-specific critical reflection and external political efficacy beliefs, 3 ) investigate how group-specific critical reflection and external political efficacy beliefs interact to differentially predict specific forms of political action.

To address these goals, 872 college students ( $M_{\text {age }}=20.05, S D=1.20 ; 74 \%$ female) were recruited from two Pacific Coastal universities and one Mid-Atlantic university. Participants were 57\% White, 18\% Asian, 14\% Latinx/Hispanic, and 7\% Black/African American. Using self-report questionnaires, emerging adults reported on their perceptions of social inequalities that target four marginalized groups (racial/ethnic minorities, women, LGB, transgender) and their beliefs about government responsiveness toward these different marginalized groups. Additionally, emerging adults reported on their involvement in social movement (activism, political voice) and standard political behaviors (voting, news consumption, political campaigning).

Results indicated that both critical reflection and external political efficacy are multidimensional constructs that can be represented as separate and correlated group-specific constructs. The factor structure of measurement models as well as significant latent mean differences both indicated that emerging adults distinguished between race-, gender-, LGB-, and trans-based issues in their critical reflection and external political efficacy beliefs. These groupspecific beliefs further varied based on emerging adults' own identity characteristics such that emerging adults who identified with a marginalized group reported greater levels of group-based critical reflection and lower levels of group-based political efficacy compared to their dominant counterparts. In addition, emerging adults with a greater awareness of trans-based inequalities were more involved in social movement activities, especially if they also perceived the government as highly unresponsive to transgender individuals. For men, but not women, higher trans-based critical reflection was associated positively with sharing political opinions with others. In addition, White and Hispanic emerging adults, but not Asian emerging adults, who 
were more critically aware of racial inequalities and viewed the government as unresponsive to racial/ethnic minority groups were more likely to vote in political elections.

The current study builds on previous research on political development by examining complex intersections between identity and multiple dimensions of critical consciousness in emerging adulthood. Findings demonstrate the importance of disaggregating beliefs about different identity-based forms of oppression to better understand links between critical reflection, external political efficacy, and political involvement. This research offers insight specific sociopolitical beliefs that may motivate political involvement during the transition to adulthood. 


\section{ACKNOWLEDGMENTS}

I would like to thank the Eberly College of Arts and Sciences and the Department of Psychology for their financial support for this project. I would like to thank Dr. Aaron Metzger, my dissertation chair and advisor, for his guidance throughout my graduate career. I am also grateful for the support, feedback, and time from my committee members Drs. Amy Gentzler, Laura Wray-Lake, and Elisa Krackow. Additionally, I am appreciative of the support and encouragement I have received throughout my training from my friend and mentor Dr. Alexa Tullett. I am also incredibly grateful for the support I have received from my lab-mates, Benjamin Oosterhoff and Frances Romm, and undergraduate research assistants, including Danielle Kisner, Julie Gilmore, Sarah Segear, Hannah Brown, Cierra Bedard, and Melanie Quick. Finally, I would like to thank my family and friends for their continued support. 


\section{TABLE OF CONTENTS}

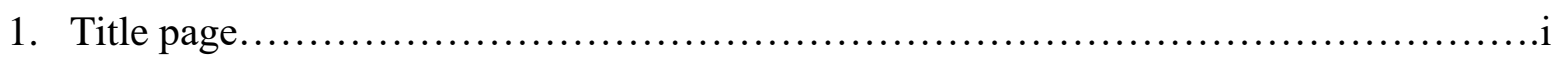

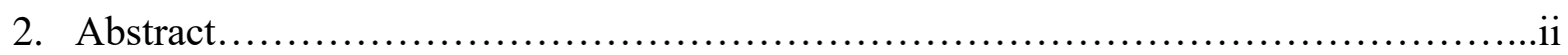

3. Acknowledgements...........................................................

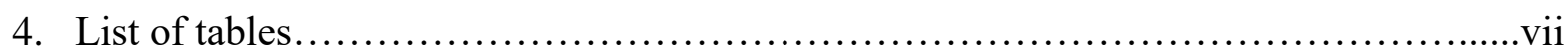

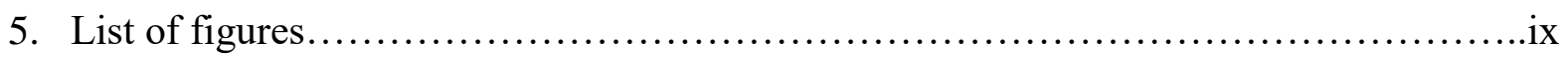

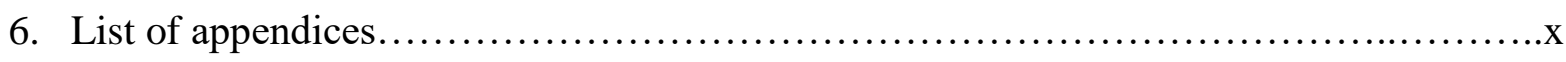

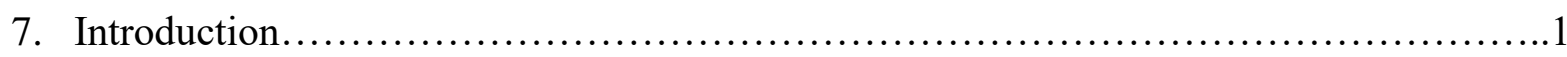

7.1 Critical Consciousness...................................................

7.2 Critical Reflection.................................................... 6

7.3 Political Efficacy....................................................13

7.4 Political Action...................................................... 15

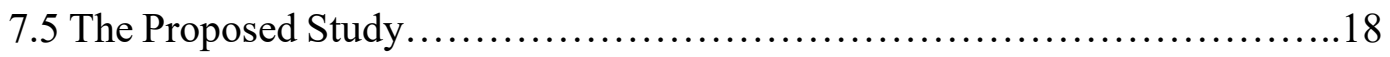

7.6.1 Research Questions.........................................19

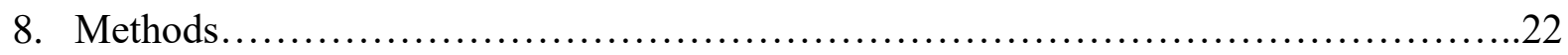

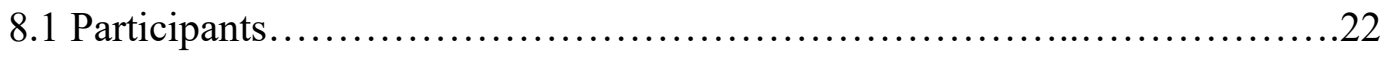

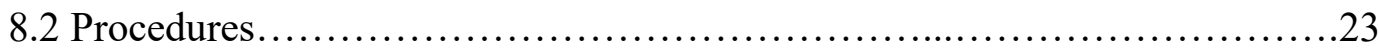

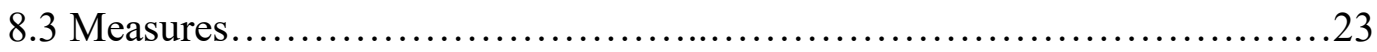

8.3.1 Demographic Information...............................23

8.3.2 Critical Reflection.....................................24

8.3.3 External Political Efficacy................................24

8.3.4 Political Action.........................................25

8.4 Data Analysis Strategy .................................................... 


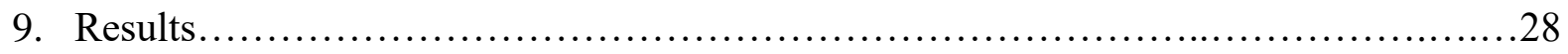

9.1 Data Cleaning and Preliminary Analyses................................28

9.2 Critical Reflection and Political Efficacy Factor Structure.....................30

9.3 Measurement Invariance and Mean Differences by Demographics.............33

9.4 Differential Associations with Political Action...............................35

9.5 Critical Reflection X Political Efficacy Interactions........................38

9.6 Three-way Interactions: Demographic Differences........................40

9.7 Summary of Main Findings.................................................43

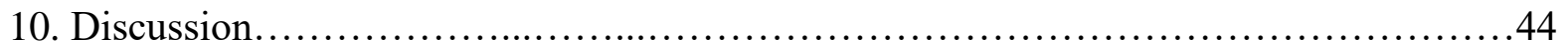

10.1 Multidimensional Models of Critical Consciousness Constructs.............45

10.2 Intersections between CC Beliefs and Emerging Adult Identity

Characteristics................................................. 48

10.3 Associations with Political Involvement.................................51

10.4 Limitations and Future Directions .......................................59

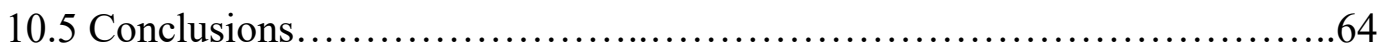

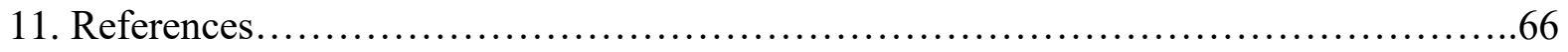

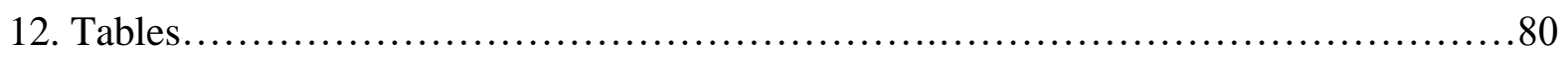

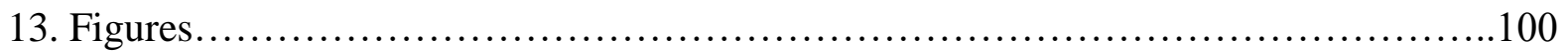

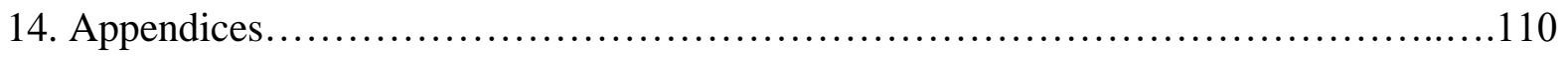




\section{LIST OF TABLES}

1. Table 1: Sample Demographics by Recruitment Location ............................80

2. Table 2: Group-Specific Critical Reflection: Perceived Inequality Subscales by

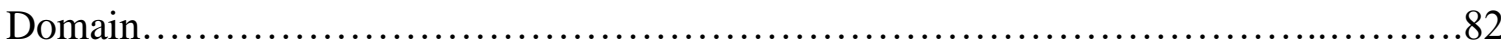

3. Table 3: Group-Specific External Political Efficacy Scales.........................85

4. Table 4: Correlations among Emerging Adult Demographic Characteristics, Critical Reflection (CR), External Political Efficacy (PE), and Political Involvement............86

5. Table 5: Means, Standard Deviations, and Bivariate Correlations among Group-Based Critical Reflection Subscales...................................................87

6. Table 6: Means, Standard Deviations, and Bivariate Correlations among External

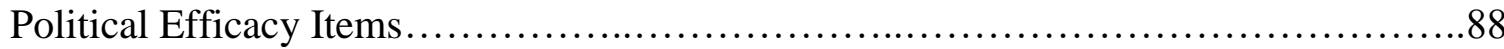

7. Table 7: Measurement Model Comparisons Testing Factor Structure of Critical Reflection and External Political Efficacy.

8. Table 8: Latent Means, Standard Deviations, and Standardized Factor Loadings of Indicator Variables Representing Subscales of Group-based Critical Reflection $(\mathrm{CR})$

9. Table 9: Correlations among Latent Variables Representing Group-based Critical Reflection (CR)

10. Table 10: Latent Means, Standard Deviations, and Standardized Factor Loadings of Indicator Variables Representing Subscales of Group-based Political Efficacy (PE).....92

11. Table 11: Correlations among Latent Variables Representing Group-based Political Efficacy (PE). 
12. Table 12: Measurement Invariance Tests for Critical Reflection and External Political Efficacy across Emerging Adult Demographics Characteristics......................94

13. Table 13: Latent Mean Differences in Critical Reflection and Political Efficacy by Emerging Adult Gender, Race/ethnicity, and Sexual Orientation......................95

14. Table 14: Unstandardized Estimates and Standard Errors of Structural Model Testing Associations among Critical Reflection and Political Involvement...................96

15. Table 15: Unstandardized Estimates and Standard Errors of Structural Model Testing Associations among External Political Efficacy and Political Involvement...............97

16. Table 16: Unstandardized Estimates and Standard Errors for Critical Reflection (CR) X Political Efficacy (PE) Interactions Predicting Political Action.......................98

17. Table 17: Model Comparisons Testing Three-Way Interactions: Group-specific CR X PE by Demographics........................................................ 99 


\section{LIST OF FIGURES}

1. Figure 1a: First-order single factor measurement model for critical reflection (Model 1a) 100

2. Figure 1b: Separate correlated four-factor measurement model for critical reflection (CR;

Model 1b)

3. Figure 1c: Higher-order latent variable measurement model for critical reflection (CR;

Model 1c)

4. Figure 2a: First-order single factor measurement model for external political efficacy (Model 2a)

5. Figure 2b: Separate correlated four-factor measurement model for external political efficacy (Model 2b)

6. Figure 2c: Higher-order latent variable measurement model for external political efficacy (Model 2c)....

7. Figure 3: Conceptual model examining group-specific interactions between critical reflection and external political efficacy as predictors of political action (RQ4)

8. Figure 4: Significant associations among critical reflection (CR), external political efficacy $(\mathrm{PE})$, and political involvement

9. Figure 5: Trans-based critical reflection by political efficacy interaction effects on activism (left) and political voice (right)

10. Figure 6: Race-based critical reflection by political efficacy interaction effects on voting for White (left) vs. Hispanic (right) emerging adults 


\section{LIST OF APPENDICES}

1. Appendix A: Demographic Information for each University used in Participant Recruitment.

2. Appendix B: Demographic Questionnaire......................................112

3. Appendix C: Critical Reflection Questionnaire.......................................118

4. Appendix D: External Political Efficacy Questionnaire..............................128

5. Appendix E: Political Involvement Questionnaire...............................130

6. Appendix F: Recruitment Location Differences in Key Study Variables.................132

7. Appendix G: Measurement Model Estimates for Model1a: Single Factor Critical

Reflection

8. Appendix H: Measurement Model Estimates for Model 1c: Higher-order Factor Critical

Reflection

9. Model I: Measurement Model Estimates for Model2a: Single Factor Political Efficacy.....

10. Model J: Measurement Model Estimates for Model 2c: Higher-order Factor Political Efficacy

11. Appendix K: Separate Single Predictor Structural Models.

12. Appendix L: Sensitivity Analyses.

13. Appendix M: Latent Profile Analysis. 
Distinguishing Beliefs about Social Inequality: Associations among Dimensions of Critical

\section{Consciousness}

Critical consciousness has traditionally been used as a framework for understanding how oppressed people recognize, navigate, and resist systemic barriers that limit their opportunity and well-being (Ginwright \& James, 2002; Prilleltensky, 2012). Many theorists discuss critical consciousness as an overarching construct that is comprised of individuals' capacity to recognize and understand structural inequalities between socially constructed groups (i.e., critical reflection), their beliefs about affecting social and political change (i.e., political efficacy), and the behaviors people may engage in to promote equality (i.e., political action; Diemer \& Rapa, 2015; Diemer, McWhirter, Ozer, \& Rapa, 2015; Watts, Diemer, \& Voight, 2011). Critical reflection, political efficacy, and political action can be considered distinct constructs that operate separately but share thematic overlap in their focus on social problems at the societal rather than individual level. To illustrate critical reflection, political efficacy, and political action, consider a company that disproportionately interviews and hires white people over people of color. In this scenario, a person with high levels of critical reflection may recognize that the hiring practices of this company are disproportionately excluding people based on race/ethnicity. This person may also believe it is possible for the source of these unjust conditions to change (political efficacy). With this critical reflection and sense of efficacy, this individual may then take political action such as boycotting the company, participating in a protest to change company policy, or writing to political administrators. A person with lower critical reflection may fail to recognize the disproportionate hiring of white people or not perceive institutionalized racism as playing a role in the hiring practices. This person may also perceive this problem as unlikely to change (i.e., low political efficacy) and therefore does not consider taking political 
action. It is also possible that someone can demonstrate high levels of critical reflection and a low sense of political efficacy. That is, levels of critical reflection and political efficacy can vary between persons as well as within persons.

Understanding the ways in which critical reflection and political efficacy intersect to predict political action can offer insight into the socio-cognitive factors underlying political activism. However, extant research on critical reflection, political efficacy, and political action has several limitations, including narrow conceptualizations of critical reflection and political efficacy, unidimensional measures that do not examine different group-based social inequalities, and limited examination of these constructs among a diverse sample of emerging adults. An important first step in investigating critical reflection and political efficacy as predictors of political action is to examine potential heterogeneity in critical reflection and efficacy beliefs across multiple group-based inequalities during emerging adulthood, a period of the lifespan particularly suited for fostering the development of critical consciousness. There are different forms of social inequality including economic, occupational, educational, and political constraints (Hurst, Gibbon, \& Nurse, 2016). The extent to which individuals experience these social inequalities is partially determined by sociodemographic characteristics including race, ethnicity, sex, sexual-orientation, and gender identity (Hurst et al., 2016). People's awareness of social inequalities and their beliefs about influencing political change may vary when reasoning about these different group-based inequities. For instance, an individual may be highly aware of inequalities based on race and ethnicity (i.e., high race-based critical reflection) and perceive to a lesser degree the barriers people face based on gender (i.e., low gender-based critical reflection). Likewise, group-specific political efficacy may manifest as perceiving the government as relatively more responsive to efforts involving women's rights issues (i.e., high gender-based 
political efficacy) and less responsive to the interests of racial and ethnic minorities (i.e., low race-based political efficacy). That is, people may perceive certain marginalized groups as having or more less political efficacy or influence on the government. However, existing measures of critical reflection and political efficacy fail to capture specificity regarding social inequalities that are based on different aspects of identity (race/ethnicity, sexual-orientation, and gender identity).

Given that power and privilege are strongly associated with multiple facets of individuals' social identity, scholars argue that making identity central is necessary when examining beliefs related to social justice (Ginwright, 2007; Ginwright \& James, 2002). Therefore, it is imperative that research examines the separate beliefs individuals have about different group-based social inequalities and investigate how group-specific critical reflection intersects with group-specific political efficacy to differentially predict engagement in specific forms of political action. The first aim of the current study is to test and validate the factor structure of a new multidimensional measure of critical reflection and political efficacy and examine the extent to which critical reflection and political efficacy beliefs vary across different types of group-based inequalities. Additionally, we aim to investigate how emerging adults' identity characteristics (race-ethnicity, gender, sexual identity) intersect with their group-specific critical reflection and political efficacy beliefs. The third goal is to examine how differences in individuals' beliefs about various types of group-based social inequality differentially predict specific forms of political action.

\section{Critical Consciousness}

Critical consciousness refers to individuals' capacity to recognize and overcome inequitable social conditions (Diemer \& Blustein, 2006; Freire, 1973; Watts, Diemer, \& Voight, 
2011). The term stems from Paulo Freire's pedagogy that aimed to promote literacy and teach Brazilian peasants how to think critically about their own oppression and act to change inequitable social conditions (Freire, 1993). It is theorized that critical reflection, which refers to a critical awareness of group-based social inequity, will unlock a sense of political efficacy, which in turn leads to action aimed at enacting change. That is, having a critical understanding of the structural causes of inequalities may allow marginalized individuals (i.e., people with social disadvantage) to feel capable of targeting the source of inequitable social conditions, thereby helping them to overcome their oppression by taking political action. Based on Freire's early work, many researchers have conceptualized critical consciousness as a broad construct comprised of critical reflection, political efficacy, and political action. However, recent empirical studies that have modeled these components of critical consciousness simultaneously suggest that critical reflection, political efficacy, and political action are separate constructs rather than indicators of a latent construct representing critical consciousness (Diemer et al., 2015; 2017). Therefore, in the current study we will focus on critical reflection, political efficacy, and political action as distinct constructs and critical consciousness will be utilized as a broader theoretical framework for examining these separate components of sociopolitical development.

Critical consciousness has a wide range of important implications for individual and societal outcomes. Reviews of research demonstrate that critical consciousness is important to marginalized individuals not only in terms of political participation but also more general positive developmental outcomes. For marginalized individuals, critical consciousness has been linked to critical thinking skills (Watts \& Abdul-Adil, 1998; Watts, Abdul-Adil, \& Pratt, 2002), better mental health (Zimmerman et al., 1999), school engagement (O’Conner, 1997; RamosZayas, 2003), and occupational attainment (Diemer, 2009; Diemer \& Blustein, 2006). Critical 
consciousness can also benefit communities as research indicates that critical consciousness plays an important role in fostering community-level change by promoting positive youth development and collective action (Berg et al., 2009; Christens \& Dolan, 2011; Ginwright, 2007; Ginwright \& James, 2002).

However, the research on critical consciousness varies in the extent to which studies examine specific components of critical consciousness or use the term critical consciousness to broadly refer to a systemic perspective on social inequality. For instance, in Diemer and Li's (2011) study, critical consciousness was composed of what the authors called sociopolitical control (equivalent to political efficacy) and political action, but not critical reflection. In another study, Diemer (2009) examined sociopolitical development, which was conceptually similar to critical consciousness, by assessing youth's awareness of and motivation to change social inequities. Watts and colleagues (2002) focused solely on the critical reflection component of critical consciousness as they examined a sample of men's critical evaluation of social problems. The differences among these studies on critical consciousness demonstrate the substantial variability in the operationalization and measurement of critical consciousness. Researchers have only recently begun to develop and validate comprehensive critical consciousness measures that are explicitly designed to assess critical reflection, political efficacy, and political action, separately (e.g., Diemer et al., 2017). However, these recently developed measures of critical consciousness constructs have yet to assess separate beliefs about different group-based inequalities.

\section{Critical Reflection}

According to Freire (1993), marginalized individuals can advance their social standing by first learning how to critically "read" their social world. With this critical reflection, they develop 
an understanding of the systemic barriers that may limit their opportunities and this understanding allows them to take more effective action aimed at redressing any unjust social conditions. For example, a member of a marginalized social group in the US who perceives educational and economic constraints that disproportionately impact their group may be better equipped and motivated to take action aimed at implementing social change compared to a marginalized individual who does not perceive their social conditions as unjust (Watts et al., 2011). While research suggests critical reflection is indeed more relevant to people who experience marginalization (e.g., racial or ethnic minority groups, women, sexual minorities; Diemer \& Blustein, 2006; Diemer et al., 2010), scholars have begun to consider that members of a dominant or majority group (e.g., white people, men, heterosexuals) who have relative privilege may also exhibit an awareness of structural inequalities (Diemer et al., 2015). For instance, critical reflection for a white person who has race-based privilege (i.e., social advantages due to being white) may stem from other aspects of their identity that is oppressed, for instance being a woman, a sexual minority, or transgender. A privileged person's critical reflection may also stem from motivation to act as an "ally" to people who experience marginalization (Diemer et al., 2015). Thus, while critical reflection is important for those who are marginalized, critical reflection does not necessarily have to result solely from an understanding of one's own oppression. Instead, critical reflection can be defined more broadly as recognizing and understanding structural inequalities that target various social groups, regardless of one's membership to those groups.

Although the term critical reflection originated in the critical consciousness literature, multiple theories on political development support the notion that recognizing social inequality and critically analyzing one's social world is foundational to sociopolitical development and 
plays a vital role in effective political action aimed at social justice (e.g., Ginwright, 2007; Speer \& Peterson, 2000; Watts et al., 1999, 2003, 2011; Westheimer \& Kahne, 2004). However, empirical research on critical reflection has several limitations. The majority of research on critical reflection has utilized samples of racial or ethnic minority or working-class adolescents. Research has not empirically investigated critical reflection as it relates to political behavior in a sample of emerging adults with varying levels of privilege and oppression. In the interest of understanding political engagement aimed at social justice, research should investigate critical reflection among people with varying levels of advantage or disadvantage, as both may serve as agents of social change.

Although most studies have only examined critical reflection in adolescence, the transitional period between adolescence and adulthood is also an important time in the lifespan to study critical reflection. The period of emerging adulthood is marked by independence of thought and cognitive growth that allows individuals to think more critically about society (Arnett 2000; Flanagan \& Levine, 2010). About two-thirds of emerging adults attend college (Kuther, 2016), which is a context that offers more opportunities for political activity through various clubs and organizations on campus (Chang, Astin, \& Kim, 2004; Flanagan \& Levine, 2010) and exposes young adults to diverse perspectives (Bowman, 2011; Jennings, 2002). These features of emerging adulthood may prompt young adults to think about other people's experiences and recognize differences in the ways in which some people are treated by society. This age period is also accompanied by greater legal opportunities to participate politically such as voting in political elections, making this an ideal period to study political action. Emerging adulthood offers a unique developmental context that may be particularly suited for the 
development of critical consciousness constructs among marginalized young adults as well as more affluent or white young adults.

Extant literature on critical reflection is also limited by a lack of consistency in terms of how critical reflection has been operationalized and measured. Until 2014, there was not a scale that was explicitly designed to measure critical reflection, therefore studies often utilized proxy measures or repurposed scales designed to measure other related constructs. For instance, research on causal attributions of poverty has examined individual (e.g., lack of motivation, laziness) versus structural (e.g., lack of educational opportunities) causes of group-based disparities (e.g., socioeconomic position of African Americans; Flanagan et al., 1997; 2014; Neville, Coleman, Falconer, \& Holmes, 2005). Given that critical reflection involves an understanding of the structural causes of social inequality, people who make more structural attributions for poverty were said to demonstrate higher levels of critical reflection (Watts et al., 2011). However, the ability to make structural attributions is only one facet of critical reflection and does not comprehensively capture whether individuals are aware of systemic group-based inequalities.

Diemer and colleagues developed a critical reflection: perceived inequality sub-scale within their 22-item Critical Consciousness Scale (CCS; Diemer et al., 2017). In the CCS, critical reflection assessed perceived inequalities which reflected youth's perceptions of race-, gender-, and socioeconomic-based inequalities (e.g., "certain racial or ethnic groups have fewer chances to get ahead"). Youth who were more perceptive of social inequalities also reported higher levels of political action. One strength of the critical reflection subscale in the CCS is that it measures consciousness of several group-based inequalities, including inequalities based on race, gender, and class. However, perceptions of these different types of group-based inequalities 
were collapsed to create a general, unidimensional measure of critical reflection. This single-axis approach has limited researchers from examining separate beliefs about specific group-based structural inequalities (Aosved, Long, \& Voller, 2009). Levels of critical reflection may vary across different group-based inequalities such that certain people may be more or less aware of inequalities that impact specific social groups. For instance, some people may demonstrate high race- and gender-based critical reflection and perceive to a lesser degree inequality that targets lesbian, gay, bisexual or transgender (LGBT) groups.

Although research has not examined the extent to which critical reflection varies across specific group-based inequalities, another critical consciousness scale was recently developed with the goal of examining individuals' consciousness of specific systemic inequalities related to racism, classism, and heterosexism (Shin et al., 2016). The Contemporary Critical Consciousness Measure (CCCM) integrated critical consciousness theory with an intersectional framework to assess critical reflection by measuring separate beliefs about institutionalized oppression based on race, class, and sexual-orientation. The CCCM differs slightly in its operationalization of critical reflection from previous research, as the CCCM items assessed not only awareness of specific structural inequalities but also attitudes toward specific inequalities (e.g., I support including sexual orientation in nondiscrimination legislation). Moreover, the authors intended to use this scale to serve as a training tool for helping counselors and psychologists identify personal biases toward social groups. However, while the goal of the measure was not specifically to investigate political activity, the development and validation of the CCCM has important implications for how researchers measure critical reflection. Through exploratory and confirmatory factor analyses and validity tests, the CCCM confirms that critical reflection is multidimensional, with distinct factors representing critical reflection related to specific forms of 
oppression (racism, classism, and heterosexism). Therefore, rather than collapsing different perceived group-based inequalities into a unidimensional measure of critical reflection, future research should take into account the multifaceted nature of critical reflection and measure separate perceptions of different group-based inequalities. When assessing perceptions of groupbased inequalities, researchers should consider additional social groups that experience marginalization.

While the CCS measured perceived inequalities based on race, gender, and class, perceived inequalities based on sexual-orientation and gender identity have not been explored (Diemer et al., 2017). The CCCM partially addressed this gap by including awareness of inequalities based on sexual-orientation but failed to include awareness of inequalities that target women and transgender people. Therefore, research has not examined individuals' perceptions of a wide range of group-based inequalities, simultaneously. Little is known about people's perceptions of structural inequalities that target LGBT groups. However, LGBT-based inequalities remain a prevalent issue in the United States today. A high percentage of LGBT individuals experience occupational discrimination such as being fired or denied employment or promotion due to their sexual identity (see Badgett et al., 2007 for a review; Tilcsik, 2011). In terms of wage gaps, LGB people earn $10-32 \%$ less than heterosexual people (Badgett et al., 2007). Less research has empirically examined transgender disparities in income, but a high percentage of the transgender population are unemployed or make less than $\$ 25,000$ per year (Badgett et al., 2007). Yet, research has not examined young adults' perceptions of the socioeconomic barriers that LGBT groups may face. Furthermore, the barriers people face based on their sexual orientation are not necessarily the same barriers people face based on their gender identity. Being a sexual minority shapes experiences with oppression differently than being 
transgender might (Stryker, 2008). Thus, it is important to assess emerging adults' perceptions of inequalities that target racial/ethnic minorities, women, LGB individuals, and transgender individuals, separately.

In addition to considering additional groups that experience marginalization, measures of critical reflection should also include a wider range of socioeconomic constraints that certain marginalized groups may experience. For instance, the CCS perceived inequality subscale assessed individuals' views of group-based inequalities in economic, occupational, and educational opportunity. However, the CCS does not include perceptions of group-based political inequalities despite the fact that racial and ethnic minority groups, women, and LGBT groups are dramatically underrepresented in elected office in the US (Dolan, 2010; Pew Research Center, 2016). In addition to inequality in political representation, many minority groups experience unique obstacles within the legal system. For example, racial and ethnic minorities often receive harsher sentences for crimes than white people under identical circumstances (Rehavi \& Starr, 2012). A high percentage of both racial and ethnic minorities and transgender people experience unjustified stops and arrests and unfair treatment by police officers (Stotzer, 2014; Weitzer \& Tuch, 2002). Also, some marginalized groups are at an elevated risk for being victims of physical and sexual violence. For instance, 1 in 4 women have experienced severe physical violence by a significant other, 1 in 5 women have been raped in their lifetime, and a high percentage of LGBT individuals are victims of verbal and sexual assault (CDC, 2016; Herek, 2007; Lombardi et al., 2002; National Coalition of Anti-Violence Programs, 2008; Xavier et al., 2013). Thus, research should investigate young adults' awareness of the economic, educational, political, legal, and assault inequalities that various groups may experience based on their identity. 
Different types of social inequalities based on various facets of identity are not uniform and these differences may be reflected in individuals' group-specific critical reflection beliefs. Differences in individuals' perceptions of the prevalence of these specific group-based inequalities may in part stem from their own experience with inequality. Given that experience with inequality is partially influenced by sociodemographic status, the degree to which people vary in their beliefs about specific group-based inequalities is likely related to their own identity status such that certain group-based inequalities may be more salient to members of certain minority groups. For example, racial or ethnic minorities may be more highly aware of racebased inequalities compared to white people while gender-based inequalities may be more salient to women than to men. Thus, it is anticipated that members of a minority group will demonstrate higher levels of critical reflection regarding inequalities that target their own social group compared to their dominant counterparts. Uncovering individuals' critical awareness of specific social inequalities and accounting for individuals' membership to specific marginalized groups can provide inside into factors that contribute to specific forms of political action. Additionally, research is needed that examines the extent to which critical reflection intersects with individuals' beliefs about the potential for changing specific inequalities (i.e., political efficacy).

\section{Political Efficacy}

Political efficacy generally refers to people's perceptions of powerfulness (or powerlessness) in the political world (Morrell, 2005). Usually, political scientists distinguish between two important facets of political efficacy: internal and external. Internal efficacy involves feeling personally competent regarding the ability to understand and effectively participate in politics (e.g., "I consider myself well qualified to participate in politics and community affairs"; Morrell, 2003). External political efficacy refers to the belief that social and 
political change is possible and that citizens have the power to influence the government to effect change. While internal political efficacy involves perceptions of one's own ability or skill in the political world, external political efficacy involves a wider lens on political change as it requires individuals think about the potential for change at a societal, rather than individual level. For instance, common items used to measure external political efficacy tap into beliefs regarding the potential for governmental structures to be influenced by citizens (i.e., government responsiveness; Gastil \& Xenos, 2010). Given that a critical consciousness framework emphasizes a systemic perspective on social inequality and political change, studying external political efficacy is particularly important. However, a comprehensive and multidimensional measure of external political efficacy is lacking.

Measures of external political efficacy typically assess people's perceptions of how responsive the government is to its citizens. Beliefs about government responsiveness capture individuals' views of citizens' potential to influence the government. That is, the belief that the government is highly responsive to its citizens suggests citizens have political efficacy or influence over political change. However, existing measures of perceived government responsiveness lack specificity with regards to the types of citizens to whom the government may be more or less responsive. For example, a typical item assessing perceived government responsiveness used in studies on critical consciousness is "The powerful leaders in government care very little about the opinions of people" (reverse coded; Diemer \& Rapa, 2015). This generalized approach may be masking important nuances and potential distinctions in individuals' external political efficacy beliefs. By making identity salient in assessments of perceived government responsiveness, we may find that external political efficacy varies when considering government responsiveness to specific marginalized groups. For instance, an 
individual may believe the government is responsive to the interests of sexual minorities and women and relatively less responsive to the interests of racial and ethnic minorities.

Research indicates that members of racial and ethnic minority groups report feeling alienated from the government and are more likely to report feeling like government officials do not care about "people like them" (Niemi \& Junn, 1998; Wray-Lake, Syvertsen, \& Flanagan, 2008). Research suggests that these racial and ethnic differences in perceptions of government responsiveness may in part be because whites are more likely to "win" political elections in the sense that the outcome of voting often favors preferences of the white majority over the preferences of racial and ethnic minorities (Hajnal, Gerber, \& Louch, 2002; Tolbert \& Hero, 1996). For example, in California, Proposition 209 was enacted which ended state affirmative action hiring and college admission programs, despite the fact that it was opposed by $70-90 \%$ of Latinxs, Blacks, and Asian Americans (Chavez, 1998). However, research has not examined the extent to which people perceive differences in how responsive the government is to various marginalized groups. Wollman and Stouder (1991) found that more situation-specific feelings of efficacy (e.g., efficacy of voting) were stronger predictors of political action than general efficacy scales. However, even situation-specific efficacy only accounted for up to $10 \%$ of the variance in political action. Capturing more specific efficacy beliefs about the potential for certain groups to influence the government can help to advance our understanding of factors that may drive engagement in different political activities.

\section{Political Action}

Political action encompasses participation in both social movement behaviors (e.g., protesting, voicing political opinions) as well as conventional or standard political behaviors (e.g., voting, participate in political campaign, keeping up with current events). Critical 
consciousness research has predominantly focused on social movement activities like participating in protests, petitions, and boycotts. These activist behaviors involve leading and organizing action to influence social and political policy (Kahne \& Westheimer, 1996). Research suggests that social movement activists are motivated by a desire to address the root causes of social problems and this critical perspective fosters more effective action aimed at community betterment (Watts, Diemer, \& Voight, 2011; Westheimer \& Kahne, 2004). While social movement involves working to change existing systems, standard political activity is considered a more mainstream form of political action whereby individuals typically work within existing social and political systems (e.g., voting). Although standard political activity has received relatively less attention in the critical consciousness literature, it remains important to study as these conventional forms of political action are foundational to maintaining a successful democracy and can also be utilized as avenues for promoting equality (Kahne \& Westheimer, 2006). For instance, one may join a political campaign or vote for a candidate whose policies could lead to positive changes regarding social inequality.

Multiple studies indicate that critical reflection (i.e., perceived inequality) is positively associated with political action such that individuals who demonstrate a greater awareness of social inequalities are also more politically active. Using a general sociopolitical participation measure that combined social movement and standard political activity, Diemer and colleagues (2017) found that critical reflection was associated positively with political action. Another study examined conventional behaviors (e.g., join a political party), voting intentions, and protest separately and found that greater critical reflection predicted greater engagement in political protest for both African American and Latinx adolescents (Diemer \& Rapa, 2015). However, associations between critical reflection and conventional and voting behaviors varied by 
ethnicity such that critical reflection was associated with more conventional activity for African American teens while critical reflection was associated with lower voting intentions for Latinx teens. These previous studies have several important implications for research on critical consciousness. First, these findings highlight the importance of examining critical reflection as a predictor of political action and demonstrate the utility of examining separate forms of political action (e.g., separating social movement involvement from standard political involvement). Second, sociodemographic differences point to the need to consider the role of identity when examining links between critical reflection and political action. By accounting for individuals' identity (e.g., ethnic/racial identity) as it intersects with group-specific critical reflection, we may find important distinctions in how critical reflection maps onto different forms of political action. For instance, research on black consciousness, which refers to an awareness among Black people of their shared marginalized or oppressed status, found that Black individuals with greater consciousness were more politically active than white people, regardless of socioeconomic status (Verba \& Nie, 1972). Similarly, critical reflection may more strongly predict political action for members of other minority groups as well, including women, LGBT individuals, and other racial/ethnic minority groups. Third, research has yet to examine the associations between critical reflection and political action among an economically and racially diverse sample of emerging adults, as these previous studies utilized samples of racial-ethnic minority adolescents. Last, few studies have examined how critical reflection may interact with individuals' beliefs about the potential to redress inequalities (i.e., external political efficacy) and how this interaction may predict specific forms of political action.

According to critical consciousness theorists, both critical reflection and political efficacy are necessary prerequisites for effective political action (Friere, 1993; Watts et al., 
2011). That is, that people who are critically aware of social inequalities and believe it is possible for social inequalities to be redressed may be more likely to take political action. As previously discussed, empirical studies that have examined separate forms of political action as outcomes of critical reflection found distinctions between social movement, standard political acts, and voting (e.g., Diemer et al., 2016; Gulevich, Sarieva, \& Nevruev, 2017). With regards to external political efficacy or perceived government responsiveness, it has been theorized that believing the government is unresponsive to citizens' interests may actually incite specifically more social movement activist behaviors (Shingles, 1981; Zimmerman, 1989). Indeed, studies have found that low perceived government responsiveness is related to greater social movement action among certain populations (e.g., Black adults, Russian and Ukrainian adults; Ennis \& Schreuer, 1987; Gulevich, Sarieva, \& Nevruev, 2017; Harris, 1999; Shingles, 1981). In contrast, findings on the link between perceived government responsiveness and standard political involvement are mixed, as some studies found a negative association between perceptions of government responsiveness and standard political acts (e.g., Gastil \& Xenos, 2010) while others have found positive links (Finkel, 1985; Zimmerman, 1989). In addition to exploring direct links between political action and both critical reflection and government responsiveness, the current study aims to investigate whether associations between critical reflection and different forms of political action vary based on one's perceptions of government responsiveness. It is anticipated that higher levels of critical reflection will be associated with greater political involvement in general. However, associations between critical reflection and specifically social movement involvement may be stronger for emerging adults who also view the government as unresponsive to minority groups (i.e., low external political efficacy), as these young adults may be particularly motivated to challenge what they view as an unjust system through acts like protest. 
In contrast, emerging adults who demonstrate high levels of critical reflection and believe the government is highly responsive (i.e., high external political efficacy) may be more likely to work within existing political systems to address the problem by engaging in higher levels of standard political acts like voting. Research is needed that investigates the intersection of critical reflection and perceived government responsiveness regarding specific group-based inequalities in order to advance our understanding of motivations that underlie unique forms of active citizenship. Additionally, making social identity salient in assessments of critical reflection and government responsiveness can allow researchers to also investigate how aspects of individuals' own identity (e.g., being a woman) intersects with specific beliefs about inequalities as it relates to different forms of political action.

\section{The Proposed Study}

Investigating the ways in which individuals understand their social and political world can provide insight into the socio-cognitive factors that drive different forms of political participation (Metzger \& Smetana, 2010). This is an important goal for research to pursue as active participation in both social movement and standard political activity is vital to the success of a democratic society (Flanagan \& Levine, 2010). The current study draws on social justice literature which emphasizes the importance of examining social identity (Ginwright \& James, 2002) and critical consciousness theory which argues that critical reflection and political efficacy are integral to effective political action (Diemer et al., 2015; Friere, 1993; Watts et al., 2011). The first goal of the current study was to create domain-specific measures of critical reflection and external political efficacy (i.e., perceived government responsiveness) and examine the multidimensional nature of these constructs. A series of measurement model comparison tests were conducted to determine whether critical reflection and external political efficacy are better 
conceptualized as overarching, unidimensional constructs entailing beliefs about various social inequalities or if they are better represented as separate but related forms of group-based critical reflection and political efficacy (i.e., race-, gender-, LGB-, and trans-based). Second, the ways in which young adults' sociodemographic characteristics (race, gender, sexual orientation) intersect with their domain-specific critical reflection and political efficacy were examined. Third, the current study aimed to advance our understanding of political development in emerging adulthood by investigating associations between critical reflection, external political efficacy, and different forms of political action. Last, the present study examined whether and how groupspecific government responsiveness beliefs moderate the associations between group-specific critical reflection and different forms of political involvement for various social groups.

\section{Research Questions}

Research Question 1. Are critical reflection and external political efficacy (i.e., perceived government responsiveness) best represented as overarching, unidimensional constructs comprised of beliefs about various social inequalities or are these constructs better represented as separate but related beliefs about specific group-based inequalities? Do levels of critical reflection and political efficacy vary across different group-based inequalities?

Hypothesis 1. Critical reflection and external political efficacy are multidimensional constructs comprised of subscales that are best modelled as separate correlated beliefs regarding specific group-based inequalities. Specifically,

a. For critical reflection, a model with four separate and correlated latent variables representing perceived race-, gender-, LGB-, and trans-based inequalities (Figure 1b) will provide a significantly better model fit compared 
to a single factor model (Figure 1a) and a higher-order factor (Figure 1c) that represent general critical reflection.

b. For external political efficacy (i.e., perceived government responsiveness), a model with four separate and correlated latent variables representing perceived government responsiveness to racial/ethnic minorities, women, LGB, and transgender people (Figure $2 b$ ) will provide a significantly better model fit compared to a single factor model (Figure 2a) and a higher-order factor (Figure 2c) that represent general government responsiveness.

Hypothesis 2. There will be significant mean level differences among race-, gender, LGB-, and trans-based critical reflection.

Hypothesis 3. There will be significant mean level differences among race-, gender-, LGB-, and trans-based government responsiveness.

Research Question 2. Do levels of domain-specific critical reflection and external political efficacy vary by sociodemographic characteristics?

Hypothesis 4. Individuals who identify with a minority group will demonstrate a greater awareness of inequalities that target their own group compared to their majority counterpart:

a. Women will report higher levels of gender-based critical reflection compared to men

b. Individuals who identify with a racial/ethnic minority group will report will higher levels of race-based critical reflection compared to white individuals c. Gay, lesbian, or bisexual individuals will report higher levels of LGB-based critical reflection compared to heterosexual individuals 
Hypothesis 5. Individuals who identify with a marginalized group will perceive the government as less responsive to groups with which they identify compared to their majority counterpart:

a. Women will report lower gender-based government responsiveness compared to men

b. Individuals who identify with a racial/ethnic minority group will report lower levels of race-based government responsiveness compared to white individuals

c. Gay, lesbian, or bisexual individuals will report lower levels of LGB-based government responsiveness compared to heterosexual individuals

Research Question 3. How are domain-specific critical reflection and perceived government responsiveness beliefs differentially associated with social movement and standard political involvement? How do these associations vary by emerging adult race, gender, and sexual orientation?

Hypothesis 6. Higher levels of critical reflection will be associated with greater engagement in both social movement and standard political activities.

Hypothesis 7. Lower levels of government responsiveness will be associated with greater engagement in social movement activities.

Research Question 4. Do the associations between domain-specific critical reflection and different forms of political action vary as a function of domain-specific government responsiveness beliefs (Figure 3)? How do sociodemographic characteristics influence these associations? 
Hypothesis 8. Domain-specific government responsiveness beliefs will moderate the association between domain-specific critical reflection and political action such that within each domain:

a. The positive association between critical reflection and social movement involvement will be significantly stronger for individuals who perceive the government as unresponsive (low government responsiveness) compared to individuals who perceive the government as highly responsive (higher government responsiveness beliefs).

b. The positive association between critical reflection and standard political involvement will be significantly stronger for individuals with higher government responsiveness beliefs compared to individuals with lower government responsiveness beliefs.

Hypothesis 9. Sociodemographic characteristics will be explored as moderators. It is anticipated that the impact domain-specific government responsiveness has on the associations between critical reflection and political action will vary based on race, gender, and sexual orientation.

\section{Method}

\section{Participants}

The sample for the current study consisted of 872 college students (ages 18-35 years, $M=$ 20.05, $S D=1.20$ ) recruited from one university in an Appalachian state and two universities in a Pacific state. University enrollment and demographic information are reported in Appendix A. Participants were primarily female (74\%) and only one participant identified as transgender. The sample was relatively evenly distributed across freshmen (31\%), sophomores (26\%), juniors 
(21\%), and seniors (24\%). Participants were primarily Caucasian/White (64\%), followed by $19 \%$ Asian American, 14\% Hispanic/Latinx, 7\% African American/Black, 2\% American Indian, 2\% Pacific Islander. Eighty-five percent of the sample identified as heterosexual, $10 \%$ identified as bisexual, and $4 \%$ identified as gay or lesbian. See Table 1 for complete sample demographic information for the total sample as well as demographic information for each recruitment site.

\section{Procedures}

The majority of participants were recruited through advertisements in Psychology classes. In order to obtain a diverse sample, emerging adults were also recruited through oncampus LGBT, diversity, and racial and ethnic minority clubs and organizations. However, only 18 participants indicated that they heard about the study through an on-campus organization. Study advertisements shown to students indicated that only college students who were 18 years or older were eligible to participate. Participants provided informed consent online before completing an online survey through the SONA system and Qualtrics. Upon completion of the survey, students were given the choice to earn extra credit toward a psychology course at their institution or be entered into a drawing to win one of ten $\$ 100$ Amazon gift cards.

\section{Measures}

Full measures with scale anchors for demographic information, critical reflection, external political efficacy, and political involvement are displayed in Appendices B through E, respectively.

Demographic information. Participants reported their gender, age, years in school, raceethnicity, sexual orientation, parents' education level, and immigration status $\left(1^{\text {st }}-, 2^{\text {nd }}-, 3^{\text {rd }}\right.$ generation). 
Critical Reflection. Perceived group-based inequality was assessed using items created for the current study and adapted items from the Critical Consciousness Scale (CCS; Diemer et al., 2017). Table 2 displays each item, with subscripts noting which items were adapted from the CCS. Four identity-based forms of critical reflection (race-, gender-, LGB-, and trans-based) were each comprised of six subscales representing perceptions of group-based inequality in economic, occupational, educational, political, legal, and assault domains. Thus, there were 19 items for each of the four forms of group-based critical reflection (76 items total). Participants were instructed to rate the extent to which they agree or disagree with each statement. Responses were given on a 5-point Likert-type scale ranging from 1 (strongly disagree) to 5 (strongly agree). Items for each type of socioeconomic constraint (economic, educational, political, legal, assault) were used to create five means representing inequality subscales for each of the four group-based critical reflection scales. Based on high inter-item correlations and conceptual overlap, the economic and occupational items were collapsed to represent a single economic domain. Cronbach's alphas for each subscale indicated adequate reliability, ranging from .68 to .91. Higher ratings indicate greater critical reflection or higher awareness of group-based inequality. A prompt was included in the survey to define certain terms to ensure that the items were interpreted similarly among participants. Racial and ethnic minority groups was defined as including individuals who identify as African American/Black, Hispanic/Latino, Asian, American Indian, or Pacific Islander (Census Bureau, 2016). Transgender was defined as an umbrella term that applies to individuals whose gender identity or expression differs from the sex they were assigned at birth (Stryker, 2008). See Appendix C.

External Political Efficacy. External political efficacy was assessed using adapted items from established measures of government responsiveness (Godfrey \& Grayman, 2014; Morrell, 
2003). Original wording of the items from previous studies were generally maintained, but items were adapted to reflect group-specificity regarding to whom the government is responsive (Table 3). Three items assessed beliefs about how responsive the government is to racial/ethnic minorities, women, LGB individuals, and transgender people, respectively. Specifically, one item measured perceptions of the government's concern for a certain group's opinions (e.g., "the powerful leaders in government care very little about the opinions of [women]" - reverse coded). Another assessed emerging adults' perceptions of whether a certain group has a say in government ("[women] don't have any say about what the government does" - reverse coded) and the third item assessed perceptions of certain groups' ability to influence the government (e.g., "[women] can successfully influence what the government does"). Responses were given on a 5-point Likert-type scale ranging from 1 (strongly disagree) to 5 (strongly agree). Higher ratings indicate stronger views of the government as more highly responsive to a certain group. See Appendix D.

Political Action. Political action was assessed using 12 items from previous research on political participation (Diemer et al., 2016; Metzger \& Ferris, 2013; Wray-Lake, Metzger, \& Syvertsen, 2017). Participants were asked "Have you ever done or plan to do the following?" on a 6-point scale: $1=I$ wouldn't do this, $2=I$ probably wouldn't do this, $3=I$ am unsure, $4=I$ probably will do this, $5=$ I will do this, $6=$ I have already done this. The political behaviors were separated into two broad categories: social movement and standard political involvement. Social movement behaviors included activism (4 items; e.g., "participate in a rally or protest for a cause", "refuse to buy something from a company that stands for things you don't like"; $\alpha=$ .77) and political voice (2 items; e.g., "share my opinions about political issues with others"). Standard political behaviors included voting (1 item; "vote in national elections"), political 
campaigning (4 items; e.g., "work or volunteer to campaign for a political candidate", "contact politicians, governments, or authorities about issues that are important to me"; $\alpha=.78$ ), and news consumption. News consumption was assessed with a single item asking participants in a typical week how often do they access information about politics and current events on TV, the radio, in the newspaper, or on news websites on a scale ranging from $1=$ never to $5=$ very often . Participants also had the option to indicate "I have no access to this information", which were treated as missing values. Higher scores indicate greater political involvement or stronger intentions to participate. The full political involvement questionnaire is displayed in Appendix E.

\section{Data Analysis Strategy}

All analyses were performed using SPSS version 24 and Mplus version 8. Models were estimated utilizing full-information maximum likelihood (FIML). First, bivariate correlations among demographic characteristics and variables of interest were examined. Demographic characteristics that were significantly associated with key study variables were included as controls in subsequent analyses. For all analyses using structural equation modeling (SEM), significant parameters were only examined upon achieving adequate model fit. Standard model fit criteria were used, including chi-square tests, root mean square error of approximation (RMSEA), and the Comparative Fit Index (CFI). Model fit was considered good if the $\chi^{2} / d f$ was less than 3.0, CFI > .95, and RMSEA <.05 and model fit was deemed adequate the chi-square ratio was less than 5.0, CFI > .90, and RMSEA < .08 (Kline, 2015; Little, 2013).

We examined the hypothesized factor structure of the measurement of critical reflection and government responsiveness, its invariance by gender, race/ethnicity, and sexual orientation, and latent mean differences within a confirmatory factor analysis (CFA) framework. To assess the dimensionality of critical reflection and political efficacy, we conducted a series of 
measurement models for each construct: 1) a unidimensional single factor model (Figures 1a and 2a), 2) separate correlated first-order four-factor model (Figures $1 \mathrm{~b}$ and $2 \mathrm{~b}$ ), and 3) higher-order factor model (Figures 1c and 2c). Models were statistically compared based on chi-square difference tests. Next, measurement invariance was tested using multiple group analysis. First, for each construct, an unconstrained multi-group model was fit across groups to serve as a baseline model against which we compared successively more restrictive models (i.e., configural model). Second, to test for metric invariance, the factor loadings were constrained to be equal across groups. If constraining the factor loadings to be equal across groups did not lead to a significantly worse model fit, the factor loadings were considered invariant across groups. Third, in addition to the constraints imposed on the factor loadings, the intercepts of the observed variables were constrained to be equal across groups. Scalar (intercept) invariance across groups was established if these additional constraints did not yield a significantly worse model fit. We relied on change in CFI to evaluate invariance, as chi-square difference tests have been found to be too sensitive to large sample sizes in invariance testing (Cheung \& Rensvold, 2002; Little, Bovaird, \& Card, 2012). Consistent with current recommendations, a change in CFI less than .01 was used as the criteria for establishing measurement invariance (Little, 2013). After establishing measurement invariance, latent mean differences in levels of domain-specific critical reflection and political efficacy by gender, race/ethnicity, and sexual orientation were tested. The latent mean of the referent group was fixed to zero and latent means for comparison groups represented deviations from the referent group mean, thus significant mean parameter estimates in the comparison group indicated the latent means were significantly different from the latent means in referent group. 
Next, two separate structural equation models tested group-specific critical reflection and government responsiveness as predictors of social movement (activism, political voice) and standard political involvement (voting, news consumption, political campaigning). Follow-up multigroup analyses were conducted to test whether the structural paths varied by race/ethnicity, gender, and sexual orientation. Then, critical reflection and government responsiveness were included in the same model as predictors of political involvement and a series of group-specific critical reflection $\mathrm{X}$ government responsiveness latent variable interactions were tested (Figure 3). Significant interaction effects were further probed and simple slopes were graphed and examined for significance. Last, follow-up multi-group analyses were performed on the full model to test whether interaction effects varied by gender, race/ethnicity, and sexual orientation. To test these 3-way interactions, the fit of an unconstrained model that freely estimated structural paths between groups was compared to the fit of a model that constrained the paths to be equal. When the unconstrained model provided a significantly better fit than the constrained model, critical ratios using a Wald's test were investigated to determine which paths differed between groups.

\section{Results}

\section{Data Cleaning and Preliminary Analyses}

Analyses were performed to assess missing data, outliers, and normality. Of the original 898 participants, twenty-five participants only completed $25 \%$ or less of the survey and were removed from all analyses due to extreme amounts of missing data on the majority of key study variables. Two additional participants were flagged for only completing $50 \%$ of the survey. Of these two cases, one was retained in the sample for completing the majority of the key study variables and one was removed for showing inattentive reporting throughout the survey and 
missingness on a large amount of key study variables. For the remaining 872 cases, mahalanobis distance scores obtained from the critical reflection, political efficacy, and political actions scales were used to test for multivariate outliers. Ten percent of participants $(n=91)$ violated mahalanobis distance. Two validity questions were built into the survey to also help identify potentially problematic cases. Twenty-three participants failed both validity questions. However, upon further investigation of survey responses of participants who were flagged as multivariate outliers and failed both validity questions, only seven participants showed inattentive reporting throughout the entire survey. Sensitivity analyses were performed to verify that these cases did not affect variable distributions. To ensure findings were not due to the inclusion of these potentially problematic cases, all analyses were conducted with and without these cases and the pattern of significant findings did not change. Although SEM is robust against assumptions of normality (Kline, 2013), for variables that were not normally distributed analyses were conducted with and without properly transformed variables. The pattern of significant findings did not vary when using transformed variables and thus, only results for the models using the untransformed variables are reported.

Additional analyses were performed to examine differences in variability based on recruitment location. Results are described in Appendix F. Table 4 displays correlations among demographic variables and key study variables. Emerging adult age was associated positively with voting and keeping up with current events. Being female was related to higher critical reflection and lower government responsiveness beliefs across domains and females also reported engaging in higher levels of social movement activities and sharing political opinions. White emerging adults reported lower levels of critical reflection and higher perceptions of government responsiveness across domains and were more likely to vote and less likely to take 
part in social movement acts. Black and Hispanic race/ethnicities were generally associated with higher critical reflection and lower government responsiveness, although being Black was not related to LGB- or trans-based government responsiveness. Being a sexual minority (LGB) was associated with higher critical reflection, lower government responsiveness, and higher levels of involvement in all political activities. Higher SES based on lower levels of financial strain and higher levels of parent education was associated with lower levels of critical reflection and higher levels of government responsiveness; however, parent education was not significantly associated with trans-based critical reflection or trans-based government responsiveness. Financial strain was not related to political involvement while higher levels of parent education were associated with more news consumption. Means, standard deviations, and bivariate correlations for critical reflection subscales and government responsiveness items are reported in Tables 5-6. All critical reflection subscales were associated positively with each other ( $\mathrm{r}$ range = $.38-.92, p s<.01$; Table 5) and all government responsiveness items were associated positively with each other $(\mathrm{r}$ range $=.14-.66, p$ s $<.01 ;$ Table 6$)$.

\section{Research Questions 1 and 2}

(1) Are critical reflection and external political efficacy (i.e., perceived government responsiveness) best represented as single overarching, unidimensional constructs comprised of beliefs about various social inequalities or are these constructs better represented as separate but related beliefs about specific groupbased inequalities? Do levels of critical reflection and political efficacy vary across different group-based inequalities?

(2) Do levels of domain-specific critical reflection and external political efficacy vary by sociodemographic characteristics? 


\section{Critical Reflection and Political Efficacy Factor Structure}

To test the multidimensional nature of the critical reflection measure, three different measurement models using confirmatory factor analysis (CFA) were tested. Means were created for each subtype of inequality (i.e., economic, educational, political, legal, and assault) and used as indicators in each measurement model. Measurement error terms for indicators for the same inequality subtype (e.g., race-based economic inequality with gender-based economic inequality) were allowed to covary to improve model fit. Model 1a tested a unidimensional, first-order single factor model representing a general critical reflection scale, with 20 observed variables representing each domain-specific critical reflection subscale as indicators (Figure 1a). Model 1b included four separate but correlated first-order latent variables representing race-based, genderbased, LGB-based, and trans-based critical reflection, with 5 mean indicators each (Figure 1b). Finally, building on model 1b, Model 1c tested a higher-order latent variable representing general critical reflection, with four first-order latent variables representing identity-based forms of critical reflection as indicators (Figure 1c). Model fit indices and comparison tests are reported in Table 7. Consistent with hypothesis 1a, results indicate that modelling critical reflection as four separate and correlated first-order latent variables (Model 1b) provided a good and significantly better model fit compared to Model 1a $\left(\Delta \chi^{2}=1769.27, d f=6, p<.001\right)$ and Model 1c $\left(\Delta \chi^{2}=174.22, d f=2, p<.001\right)$. Therefore, race-, gender-, LGB-, and trans-based critical reflection were modelled as separate latent variables in subsequent analyses. Standardized factor loadings ranged from $.54-.95$ and were all statistically significant at the .001 level (Table 8). Moderate to strong positive correlations were observed among indicators from the same domain (.34 - .85). Correlations among the four latent variables were high and ranged from $.88-.95$ (Table 9), with the strongest correlations between LGB-based and trans-based critical reflection 
$(\mathrm{r}=.95)$, followed by race-based and gender-based critical reflection $(\mathrm{r}=.91)$. Measurement estimates for Models 1a and 1c are reported in Appendix G-H.

To further investigate differences among emerging adults' views of racial, gender, LGB-, and trans-based inequalities, a series of latent mean difference tests were performed. Scaling of the latent variables was done using the effects coding method, so that latent means could be estimated and then a series of model constraints were tested to determine if constraining two latent variable means to be equal yielded a significant drop in model fit based on a chi-square difference test (Little, Slegers, \& Card, 2006). Results indicated that the latent means of nearly all group-based forms of critical reflection significantly differed from one another, with exception of gender- and LGB-based critical reflection. Specifically, emerging adults demonstrated a significantly higher awareness of race-based inequality compared to other forms of group-based inequalities, followed by trans-based inequalities. Levels of critical awareness of gender- and LGB-based inequalities were the lowest relative to perceived race- and trans-based inequalities. Latent means are reported in Table 8, with subscripts denoting significant differences.

Similar to critical reflection, the multidimensional nature of external political efficacy was tested by comparing three measurement models: single first-order factor representing general government responsiveness (Model 2a), first-order separate and correlated four-factor model with latent variables representing group-specific forms of government responsiveness (Model 2b), and a higher-order government responsiveness factor (Model 2c). In each model, three items that assessed perceptions of government responsiveness to racial/ethnic minorities, women, LGB individuals, and transgender individuals, respectively, were used as observed indicators (12 total). Errors for similar indicators were allowed to covary. Model fit indices and 
comparison tests are reported in Table 7 . Consistent with hypothesis $1 \mathrm{~b}$, results indicate that modelling political efficacy as four separate and correlated first-order latent variables (Model 2b) provided a good and significantly better model fit compared to Model 2a $\left(\Delta \chi^{2}=454.50, d f=6, p\right.$ $<.001)$ and Model $2 \mathrm{c}\left(\Delta \chi^{2}=11.99, d f=2, p<.01\right)$. Therefore, race-, gender-, LGB-, and transbased political efficacy were modelled as separate latent variables in subsequent analyses. Standardized factor loadings ranged from $.33-.86$ and were all statistically significant at the .001 level (Table 10). Moderate to strong positive correlations were observed among indicators from the same domain $(r=.30-.60)$. Correlations among the four latent variables ranged from $.70-.81$ (Table 11). Latent mean difference tests indicated that all forms of group-based government responsiveness significantly varied from one another, with emerging adults perceiving the government as most responsive to women, followed by LGB- individuals, and then ethnic/racial minorities. Emerging adults rated the government as least responsive to transgender individuals. Latent means are reported in Table 10. Measurement estimates for models $2 \mathrm{a}$ and $2 \mathrm{c}$ are reported in Appendices I-J.

\section{Measurement Invariance and Mean Differences by Demographics}

First, the factor structures of critical reflection and political efficacy were tested for equivalence across gender, sexual orientation, and racial/ethnic groups. A series of multi-group analyses tested for metric and scalar invariance across groups. Results from all measurement invariance tests are described in Table 12. The factor loadings and intercepts for critical reflection and government responsiveness were all invariant by gender (male vs female), ethnicity (Black vs Hispanic/Latinx vs Asian vs White), and sexual orientation (LGB vs heterosexual), therefore, full measurement invariance was achieved for each measure. 
Next, to test for latent mean differences by group, we set the factor means for one group, the reference group, to zero and allowed the comparison groups' factor means to be freely estimated. These freely estimated latent means then represent the difference between the factor means of the two groups and the significance of the mean difference is based on a $\mathrm{z}$ statistic (Aiken, Stein, \& Bentler, 1994). When testing mean differences between more than two groups, the reference group was changed in order to test all possible comparisons. Latent means for each group are reported in Table 13, using subscripts to denote significant mean differences by gender (men, women), race/ethnicity (Black, Hispanic, Asian, White), and sexual orientation (LGB, heterosexual). Consistent with hypotheses 4 and 5, compared to dominant groups, emerging adults who identified with a marginalized group reported higher levels of critical reflection and lower levels of political efficacy for groups that they were a member of. More specifically, females reported significantly higher levels of all forms of critical reflection and lower levels of all forms of perceived government responsiveness compared to males. Similarly, participants who identified as gay, lesbian, or bisexual reported significantly higher levels of all forms of critical reflection and lower levels of all forms of government responsiveness compared to individuals who identified as heterosexual. Significant mean differences by race/ethnicity indicated that Black, Hispanic and Asian participants had significantly higher scores on all forms of critical reflection compared to White participants. Latent means for critical reflection did not significantly differ between Black, Hispanic, and Asian participants. Ethnic differences were also found for certain domains of government responsiveness. White participants reported significantly greater levels of race-based and gender-based government responsiveness compared to Asian participants and scored higher across all forms of government responsiveness compared to Black and Hispanic participants. The Hispanic group reported significantly lower levels of 
LGB-based government responsiveness compared to the Asian group. Perceived government responsiveness means for Black participants did not significantly differ from Hispanic or Asian participants' means.

\section{Research Question 3}

How are domain-specific critical reflection and external political efficacy beliefs (i.e., perceived government responsiveness) differentially associated with social movement and standard political involvement? How do these associations vary by emerging adult race, gender, and sexual orientation?

\section{Differential Associations with Political Action}

To test associations between critical reflection, political efficacy, and political action, a series of structural equation models were performed. Five observed political involvement variables, including two types of social movement activities (activism, voicing political opinions) and three types of standard political activities (voting, news consumptions, political campaigning), were included as endogenous outcomes in each model and error term among political behaviors were allowed to covary. Emerging adult age, gender, race/ethnicity, sexual orientation, and reported levels of parent education were included as covariates. First, structural equation models tested each group-specific form of critical reflection and government responsiveness as a predictor of political involvement in separate models. Results from the separate single-predictor models indicated that all forms of group-specific critical reflection were associated positively with all forms of political involvement. Perceptions of the government as more unresponsive across all groups was associated with greater activism. Additionally, views of the government as unresponsive to racial and ethnic minorities was also associated with greater 
intentions to share political opinions, keep up with current events, and join political campaigns. See Appendix K for structural parameter estimates.

Next, a structural equation model with all four forms of critical reflection included was performed. The model with four latent variables representing perceived race-, gender-, LGB-, and trans-based inequality specified as exogenous predictors of political action provided a good fit to the data $\left(\chi^{2} / d f=3.81, \mathrm{CFI}=.96, \mathrm{RMSEA}=.06[.054, .061]\right)$. Table 14 displays the unstandardized estimates and standard errors of the structural parameters. Over and above other forms of group-based critical reflection, greater awareness of trans-based inequalities was significantly associated with greater intentions to take part in activism, share political opinions, and vote in national elections. Greater race-based critical reflection was marginally associated with more frequent news consumption $(p=.07)$. Critical reflection was not significantly associated with political campaigning. Among the covariates, higher levels of parent education and identifying as LGB (vs. heterosexual) was associated positively with social movement involvement, political voice, news consumption, and political campaigning. Older emerging adults were more likely to vote and keep up with current events compared to younger emerging adults. Compared to White participants, Asian participants were generally less politically active whereas Hispanic participants were more likely to engage in activism, share political opinions, and campaign. Black participants were less likely to vote.

A series of multi-group analyses were performed to test whether the associations between critical reflection and political action varied by emerging adult race/ethnicity, gender, and sexual orientation. Multigroup analyses were not sufficiently powered to estimate the structural models in the sample of Black emerging adults due to small $n$ in this group $(n=60)$ and the complexity of the structural models. Therefore, multi-group analyses by race/ethnicity performed on 
structural models tested for differences between Hispanic, Asian, and White participants, only.

The structural model did not significantly vary by race/ethnicity $\left(\Delta \chi^{2}(80)=96.93, p=.095\right)$.

However, there were significant differences by gender $\left(\Delta \chi^{2}(55)=88.26, p=.002\right)$. Specifically, a significant Wald comparison test $(\mathrm{Wald}=6.45, p=.04$ ) indicated that the positive association between trans-based critical reflection and political voice was only significant for emerging adult men $(B=3.07, S E=1.14, p=.007)$, not emerging adult women $(B=-.03, S E=.45, p=.95)$. Constraining the structural paths to be equal across LGB and heterosexual emerging adults also yielded a significantly worse model fit $\left(\Delta \chi^{2}(55)=73.91, p=.045\right)$, however examination of the Wald comparison tests indicated that the individual structural parameters for the associations between group-based critical reflection and political involvement were not significantly different between groups.

To test associations between external political efficacy (government responsiveness) and political action, a separate structural model included four latent variables representing perceived government responsiveness to racial/ethnic minorities, women, LGB, and transgender people as exogenous predictors of 5 forms of political action. The model provided good fit to the data $\left(\chi^{2} /\right.$ $d f=3.19, \mathrm{CFI}=.94, \mathrm{RMSEA}=.05[.046, .056])$. Unstandardized parameters and standard errors are reported in Table 15. Consistent with hypothesis 5, perceiving the government as highly unresponsive to racial and ethnic minorities (i.e., low race-based efficacy) was associated with greater activism and voicing political opinions. Additionally, views of the government as highly unresponsive to transgender individuals (low trans-based efficacy) was associated with stronger intentions to vote. In contrast, emerging adults who viewed the government unresponsive to the interests of LGB individuals (low LGB-based efficacy) were less likely to vote. Given that LGBbased government responsiveness was not significantly associated with voting at the bivariate 
level, the significance of this association may have emerged in the structural model because of multicollinearity among the independent variables which can cause a suppression effect. Thus, the association between LGB-based government responsiveness and voting should be interpreted with caution. Group-based government responsiveness was not significantly associated with news consumption or campaigning.

Follow-up multi-group analyses were performed to test whether the associations between government responsiveness and political action varied by emerging adult race/ethnicity, gender, and sexual orientation. Results indicated that the structural model did not significantly vary by race/ethnicity $\left(\Delta \chi^{2}(80)=80.70, p=.48\right)$, by gender $\left(\Delta \chi^{2}(55)=53.98, p=.51\right)$, or by sexual orientation $\left(\Delta \chi^{2}(35)=42.08, p=.19\right)$.

Next, four latent variables representing group-based critical reflection and four latent variables representing group-based government responsiveness were included in the same model, along with covariates, as predictors of political action. The model provided adequate fit to the data $\left(\chi^{2} / d f=3.19, \mathrm{CFI}=.93, \mathrm{RMSEA}=.058[.056, .060]\right.$; see Figure 4$)$. After controlling for demographics and all other forms of both critical reflection and political efficacy, trans-based critical reflection was the only significant predictor of political action. Specifically, emerging adults who demonstrated higher trans-based critical reflection were more involved in activism $(B$ $=.86, S E=.23, p<.001)$ and shared political opinions $(B=61, S E=.28, p=.031)$ more compared to emerging adults who demonstrated a lower awareness of trans-based inequalities.

\section{Research Question 4}

How does domain-specific critical reflection interact with domain-specific external efficacy beliefs to predict specific forms of political action (Figure 3)? How do sociodemographic characteristics influence these associations? 
Critical Reflection X Political Efficacy Interactions. To test whether the associations between domain-specific critical reflection and political action varied as a function of domainspecific government responsiveness, a series of models included latent variable interactions. Building on the full model which included demographic covariates and all forms of critical reflection and government responsiveness, four group-specific latent variable interaction terms representing critical reflection X political efficacy (e.g., race-based critical reflection X racebased government responsiveness) were included as predictors of political action in four separate models (Figure 3). Hereafter, the interaction term critical reflection X political efficacy will be referred to as CR X PE. Follow-up analyses were conducted to probe the interaction to aid in interpretation and simple slopes were examined. Given the complexity of these models and strong correlations among independent variables, additional follow-up sensitivity analyses were performed to test for potential suppression effects that may have been caused by multicollinearity among the IVs. A full description of these sensitivity analyses is described in Appendix L.

Race-based CR X PE was significantly associated with nearly all forms of political action, except for political campaigning (Table 16). Race-based critical reflection was associated positively with voting for young adults with low levels of race-based political efficacy (i.e., perceive low government responsiveness; $B=.49, S E=.20, p=.01$ ) but not for young adults with high levels of race-based political efficacy (i.e., perceive high government responsiveness; $B=.23, S E=.17, p=.18)$. Similarly, greater awareness of race-based inequalities was associated positively with keeping up with current events for young adults who perceived the government as unresponsive to racial/ethnic minorities $(B=.65, S E=.20, p=.001)$, but not for young adults who perceived the government as highly responsive to racial/ethnic minorities $(B=.26, S E=.19$, 
$p=.16)$. The simple slopes depicting the associations between race-based critical reflection with activism and political voice were not statistically significant at high (+1 SD) or low (-1 SD) levels of race-based government responsiveness.

Gender-based CR X PE was significantly associated with nearly all forms of political action, with the exception of voting which was marginally significant $(p=.07$; Table 16$)$. The positive association between gender-based critical reflection and political voice was significantly stronger for young adults who viewed the government as more unresponsive to women (i.e., lower gender-based efficacy; $B=.41, S E=.24, p=.08$ ) compared to young adults with higher levels of gender-based government responsiveness $(B=-.11, S E=.24, p=.65)$. However, given the simple slope at low levels of efficacy was only marginally significant at $p=.08$, effects should be interpreted with caution. Simple slopes indicated that gender-based critical reflection was not significantly associated with activism, voting, or campaigning at high or low levels of gender-based government responsiveness. The effect of gender-based CR X PE on news consumption was identified as most-likely being caused by multicollinearity leading to a suppression effect. Therefore, this effect was not interpreted. A long discussion of these sensitivity analyses is included in Appendix K.

LGB-based CR X PE was significantly associated with nearly all forms of political involvement, except for political campaigning. However, follow-up analyses indicated that although simple slopes significantly differed, LGB-based critical reflection was not significantly associated with voting, news consumption, or political voice at high or low levels of LGB-based government responsiveness. Similar to the CR X PE on news consumption described above, sensitivity analyses indicated that the significant LGB-based CR X PE interaction effect on 
activism was most-likely caused by high levels of multicollinearity leading to a suppression effect (see Appendix K for more details). Therefore, this effect was not interpreted.

Trans-based CR X PE was significantly associated with all forms of political action. Examination of simple slopes indicated that trans-based critical reflection was associated positively with activism and political voice and these associations were significantly stronger for young adults who viewed the government as unresponsive to transgender people $(B s=.80-1.02$, $S E s=.24-.30, p s<.01)$ compared to young adults who viewed the government as more responsiveness to transgender people $(B s=.39-.71, S E s=.24-.29, p s=.003-.18)$. Simple slopes are graphed in Figure 5. Specifically, while emerging adults who were more critically aware of trans-based inequalities generally engaged in greater levels of social movement activities, emerging adults who were more critically aware of trans-inequalities and perceived the government as highly unresponsive to transgender individuals were even more involved in social movement activities. The simple slopes depicting the associations between trans-based critical reflection and standard political activities (voting, news consumption, campaigning) were not statistically significant at high (+1 SD) or low (-1 SD) levels of trans-based government responsiveness.

Three-way Interactions: Demographic Differences. Finally, 3-way interactions were examined to investigate whether the effect of domain-specific political efficacy on the associations between critical reflection and political action varied by sociodemographic characteristics. A series of multigroup analyses based on sociodemographic variables (gender, race/ethnicity, sexual orientation) were conducted. Latent variable interaction models estimated in mplus use an MLR estimator which required that we base our chi-square difference testing on 
loglikelihood values and scaling correction factors (see Satorra, 2000). Model comparison tests are reported in Table 17.

The race-based CR X PE interaction model was tested for structural invariance across Hispanic, Asian, and White participants. Constraining all structural paths to be equal across racial/ethnic groups yielded a significantly worse model fit $\left(\chi^{2}(130)=168.15, p=.01\right)$, indicating that the model significantly varied by race/ethnicity. Examination of the unconstrained structural paths pointed to differences between groups with regards to the race-based interaction effects. First, the race-based CR X PE interaction term was significantly associated with voting in the White and Hispanic groups, but not in the Asian group. For White emerging adults, an analysis of simple slopes indicated that higher race-based critical reflection was significantly associated with greater intentions to vote at both high $(B=.25, S E=.12, p=.04)$ and low levels of race-based government responsiveness $(B=.49, S E=.15, p=.001)$, with low levels of racebased government responsiveness amplifying the strength of the association (Figure 6). For Hispanic emerging adults, higher race-based critical reflection was associated (marginally) with greater intentions to vote at low levels of race-based government responsiveness $(B=.55, S E=$ $.29, p=.06)$, but not at high levels of government responsiveness $(B=.28, S E=.23, p=.24$; Figure 6). Thus, results indicate that a combination of high race-based critical reflection (i.e., greater awareness of racial inequality) and low race-based efficacy (i.e., perceive government as unresponsive to racial/ethnic minorities) is related to a greater likelihood of participating in political elections for both Hispanic and White emerging adults. Additionally, the simple slope graphs point to slight differences between Hispanic and White emerging adults regarding the effect of high race-based government responsiveness. For Hispanic emerging adults, high racebased efficacy, or perceptions of the government as highly responsive to minorities seems to 
buffer against the negative effect that a low awareness of racial inequality has on voting. In contrast, White emerging adults with similarly high race-based efficacy and low race-based reflection were relatively less likely to vote.

The race-based interaction effect on activism, political voice, and political campaigning significantly differed between the White and Hispanic group based on Wald comparison tests such that the interactions were only significant in the White group (Walds $=6.67-8.55, p \mathrm{~s}=$ $.003-.009)$. However, the simple slopes were not statistically significant in the White group, meaning that even though the simple slopes significantly differed within the White group, critical reflection was not associated with activism, political voice, or campaigning for white emerging adults with either high or low levels of race-based government responsiveness. Finally, racebased CR X PE was significantly associated with news consumption for White emerging adults, but not Asian or Hispanic emerging adults. The interaction effect on news consumption did not significantly differ between White and Asian participants based on the Wald comparison test (Wald $=.2 .17, p=.34$ ) but was marginally significantly different between White and Hispanic emerging adults (Wald $=3.49, p=.06$ ). This suggests race-based government responsiveness has stronger effect on the association between critical reflection and news consumption for White emerging adults than Hispanic emerging adults. Race-based critical reflection was marginally associated with greater news consumptions for White emerging adults who perceived the government as unresponsive to racial/ethnic minorities (low race-based efficacy; $B=.53, S E=$ $.11, p=.06)$, but not for white emerging adults who perceived the government as highly responsive to racial/ethnic minorities (i.e., high race-based efficacy; $B=.06, S E=.28, p=.82$ ).

The gender-based CR X PE interaction model with structural paths constrained to be equal across males and females provided a significant drop in model fit compared to the 
unconstrained model $\left(\Delta \chi^{2}(80)=105.74, p=.02\right)$ indicating the model significantly varied by gender. The gender-based CR X PE interaction was significantly associated with activism, political voice, news consumption, and campaigning for women but not men. Gender-based critical reflection was associated positively with political voice only for women who perceived low female-based government responsiveness (low gender-based efficacy), although the slope was only marginally significant $(B=.48, S E=.27, p=.08)$. Gender-based critical reflection was not significantly associated with political voice for women with high gender-based political efficacy $(B=-.13, S E=.25, p=.60)$. Although the simple slopes significantly differed within the female group, the individual simple slopes depicting associations between gender-based critical reflection and activism, news consumption, and campaigning were not statistically significant for women at high or low levels of gender-based political efficacy. The LGB-based CR X PE interaction model as well as the trans-based CR X PE interaction model did not significantly vary by sexual orientation $\left(\Delta \chi^{2}(55)=52.62-54.02, p s=.51-.57\right)$.

\section{Summary of Main Findings}

Results indicated that both critical reflection and political efficacy are multidimensional constructs that are best represented as separate and correlated group-specific constructs. The mean and variance factor structure both indicated that emerging adults' beliefs about social inequality and political efficacy (government responsiveness) vary when reasoning about different marginalized groups and these group-specific beliefs further vary based on emerging adults' own identity characteristics. Group-specific critical reflection and political efficacy beliefs were differentially associated with social movement and standard political involvement. Over and above the effects of all forms of critical reflection and political efficacy, trans-based critical reflection was associated with greater social movement involvement (activism and 
political voice). Several group-specific critical reflection $\mathrm{X}$ efficacy interaction effects were found, which generally indicated that high critical reflection combined with views of the government as unresponsive was associated with greater political involvement. Beliefs about trans-based issues were specifically associated with social movement behaviors while beliefs about race-based issues were associated with certain standard political behaviors. Main effects and interaction effects were consistent across emerging adult sexual orientation, but race-based interactions varied by emerging adult race/ethnicity and the main effect of trans-based reflection varied between males and females.

\section{Discussion}

The current study examined emerging adults' beliefs about specific forms of group-based inequality. Building on existing measures of critical consciousness (CC) constructs, a new multidimensional assessment of critical reflection and external political efficacy was tested. Findings highlight the utility in disaggregating beliefs about different group-based inequalities. First, both the variance and mean structure of critical reflection and political efficacy point to differences across group-specific forms of critical reflection and external political efficacy or government responsiveness beliefs. This was demonstrated through measurement model comparison tests indicating the separate correlated factor model fit the data best and through mean difference tests across group-specific forms of critical reflection and external efficacy. Mean differences demonstrated that emerging adults' beliefs about systemic inequality and political change vary when reasoning about different marginalized groups. There is also evidence emerging adults' own identity characteristics may influence their mean level of critical reflection and external efficacy beliefs about different marginalized groups. Current findings also indicated group-specific beliefs were differentially associated with emerging adults' involvement in social 
movement (activism, sharing political opinions) and standard political activities (voting, keeping up with current events). In addition, the current study demonstrates that critical reflection and external political efficacy are unique constructs that interact to potentially stimulate specific types of political action; findings also hint at potential differences in these associations based on race/ethnicity and gender. Thus, the current study offers insight into specific sociocognitive beliefs that may motivate emerging adults to become involved in different types of political activities.

\section{Multidimensional Models of Critical Consciousness Constructs}

Comparing two multidimensional measurement models of critical consciousness constructs to a unidimensional single factor model provided strong evidence for the multidimensional structure of critical reflection and external political efficacy. Although the higher-order model provided good fit to the data and thus could be empirically justified, the correlated separate factor model provided the best model fit. Results are somewhat consistent with Shin and colleagues' (2016) measurement work on the Contemporary Critical Consciousness Measure (CCCM) which found that critical consciousness is comprised of separate beliefs about specific systems of oppression. While critical reflection in the CCCM represents an awareness of and attitudes toward racism, classism, and sexism separately as well as generally, the current study demonstrated that both critical reflection and external political efficacy can be modeled as four separate beliefs regarding race-, gender-, LGB-, and trans-based issues. The current study is the first to date that has assessed separate beliefs about groupspecific forms of external political efficacy.

Previous research that has examined the measurement of multidimensional constructs has demonstrated that empirical differences between measurement models of multidimensional 
constructs are often small. Therefore, researchers should augment their interpretation of statistical comparisons with conceptual rationale, theory, and practical study goals when choosing the most appropriate model (Brunner et al., 2012; Reise, 2012; Wray-Lake et al., 2017). Thus, in addition to the statistical evidence pointing to the separate and correlated factor model as the better fit, previous research and theory provides strong conceptual rationale for modeling group-specific forms of critical consciousness beliefs as distinct constructs in future research. Social justice scholars who have attempted to integrate intersectionality into psychological research argue that it is important to recognize both race, gender, as well as sexuality in relation to systems that perpetuate inequality as these different systems of oppression (i.e., systemic racism, sexism, heterosexism, cissexism) are unique but also mutually influential and intertwined (Cole, 2009; Nash, 2008). Based on intersectional scholarship (Shields, 2008; Crenshaw, 1989), it would be inappropriate to assess individuals' beliefs about one system of oppression without accounting for their beliefs about other related oppressive systems. Thus, an intersectionality framework provides support for measuring beliefs about multiple forms of oppression, simultaneously.

Furthermore, it is important to treat beliefs about different group-based inequalities as separate (but related) dimensions of critical reflection and political efficacy given that different social groups have unique histories and experiences with inequality and social change in the United States. For instance, although racial and ethnic minorities technically gained the right to vote (Fifteenth Amendment, 1870) before women gained the right to vote (Nineteenth Amendment, 1920), Jim Crow Laws and other amendments that followed the fifteenth amendment effectively disenfranchised racial/ethnic minority voters until the Voting Rights Act of 1965. Moreover, despite some progress toward equality, racial and ethnic minorities today still 
face barriers such as voter suppression when trying to exercise their right to vote that women are less likely to encounter (Combs, 2016; Hahnal, Lajevardi, \& Nielson, 2017). The history of social and political change toward equality (or in some cases, toward inequality) markedly differs for different marginalized groups and these unique histories feed into and shape systems of oppression that currently exist in America. By using a multidimensional assessment of critical consciousness beliefs, the current study was able to demonstrate that emerging adults indeed perceive differences in how systemic inequalities affect different marginalized groups, as evinced by significant mean differences.

Previous research on critical consciousness beliefs has primarily collapsed perceptions of different group-based inequalities into a single axis measure or relied on unidimensional assessments that fail to capture specificity regarding the target of oppression (e.g., Deimer \& Rapa, 2016). Current findings suggest that a single-axis or unidimensional approach likely masks important nuance and distinctions in critical consciousness beliefs, as latent mean differences indicated that emerging adults distinguish between race-, gender-, LGB-, and trans-based issues in both their critical reflection and political efficacy beliefs. On average, emerging adults perceived the highest levels of inequality among racial and ethnic minorities, followed by transgender individuals. In contrast, emerging adults viewed transgender individuals as having the least amount of influence on the government, followed by racial and ethnic minorities. While participants reported similar levels of perceived inequality for women and LGB individuals, they viewed the government as most responsive to women compared to other marginalized groups. Consistent with hypotheses, findings support the notion that critical consciousness beliefs vary when reasoning about different marginalized groups, which provides further evidence for 
disaggregating group-specific forms of critical reflection and political efficacy beliefs in future research.

Furthermore, the mean differences found in the current study provide insight into the types of social justice issues that emerging adults view as most prevalent in today's society. The timeliness of these data can shed light on the specific social issues that this generation of young adults may be more likely to pursue in future political activities. Taken together, the current study indicates that emerging adults do not view inequality across different marginalized groups uniformly and they also perceive differences in the potential for certain groups to influence the government. This is an important finding, as scholars argue that although marginalized groups may share some experiences of oppression (e.g., poverty), there is a great deal of variability with regards to the prevalence and quality of these group-based inequalities (Young, 1990).

\section{Intersections between CC Beliefs and Emerging Adult Identity Characteristics}

The current study is an important first step toward demonstrating that emerging adults recognize nuance in the ways that certain groups of people are treated in America. Moreover, findings indicate critical reflection and views of government responsiveness may be related to one's own experiences with oppression. While self-reported experiences with marginalization or oppression were not assessed, the current study did examine mean level differences in domainspecific critical reflection and political efficacy beliefs between individuals who identified with a marginalized group (Black, Hispanic, Asian, female, gay, lesbian, bisexual) vs dominant group (White, male, heterosexual). Consistent with hypotheses, individuals who identified with a marginalized group demonstrated a greater awareness of inequalities that target their own group compared to their dominant counterparts (e.g., women reported higher gender-based critical reflection scores than men). However, findings differed slightly from initial hypotheses in that 
marginalized emerging adults were also more critically aware of other forms of group-based inequalities. Specifically, compared to men and heterosexuals, women and sexual minorities (LGB) reported a greater awareness of all forms of inequality and also perceived the government as more unresponsive to all groups (i.e., lower political efficacy), respectively. Black, Hispanic, and Asian emerging adults also reported higher scores across all forms of critical reflection compared to White individuals. Black and Hispanic emerging adults viewed the government as more unresponsive to all marginalized groups compared to White emerging adults. Asian emerging adults perceived lower race-based and female-based government responsiveness compared to White emerging adults and greater LGB-based government responsiveness compared to Hispanic emerging adults.

Potentially, the experience of being marginalized because of their own identity may make emerging adults more attuned to the plight of others with different identity characteristics that make them targets of oppression and systemic inequality. For instance, a study found that sexual minorities reported lower levels of racial colorblindness (i.e., less denial or minimization of race or racism) and demonstrated a greater capacity to understand the experiences of racial minorities (i.e., racial empathy) compared to heterosexuals (Kleinman, Spanierman, \& Smith, 2015). Indirect effects suggested that sexual minority individuals' experiences with heterosexism fostered greater empathy for other marginalized groups which in turn lead to greater recognition of racism (Kleiman, Spanierman, \& Smith, 2015). In addition, emerging adults who identify with groups that have been historically oppressed may be exposed to more overt conversations about group-based inequality within family and peer contexts that facilitate a greater understanding of oppressive systems. Research on racial socialization has found that in racial/ethnic minority families, parents often engage in explicit conversations aimed at fostering an understanding of 
racism, oppression, and privilege to help teach their children how to anticipate and navigate obstacles related to their racial minority status (Hughes et al., 2006; Quintana \& Vera, 1999). Given that systems of oppression are intertwined and connected (Crenshaw, 1989), conversations about power and privilege in the context of race may also include messages about other systems of oppression such as sexism and heterosexism. For example, Black/African American parents sometimes discuss how people treat Black boys and Black girls differently in America, which may foster awareness of both racial and gendered inequalities (Reid \& Comas-Diaz, 1990; Thomas \& King, 2007). While racial and ethnic minority parents are more likely to explicitly emphasize and teach an awareness of racial inequalities, racial socialization for White parents often involves a more passive process whereby White parents answer questions when prompted by their child and teach more general or colorblind messages about equality (Hughes et al,, 2006; Katz \& Kofkin, 1997). Thus, the messages racial/ethnic minority youth receive may make them more prepared to recognize the role identity plays in influencing experiences of power and oppression whereas White youth may receive relatively less guidance regarding how to recognize the ways in which identity intersects with inequality.

Peer and family support also may play an important role in fostering critical consciousness for women. For example, research has found that compared to men, women perceive more support for challenging sexism from their family and peers, which is associated with greater critical reflection (Diemer et al., 2006). Studies also show that compared to men, women report more supportive attitudes toward equal rights for women and for sexual minorities (LGB; Eagly et al., 2004). These gender differences were partially explained by differences in social dominance orientation (SDO; i.e., preference for group-based hierarchy) and egalitarianism (i.e., preference for group-based equality). Men were more motivated to maintain 
group-based hierarchy and were then less supportive of women and gay/lesbian rights whereas women demonstrated lower SDO and a greater preference for equality which in turn was associated with greater support of equal rights for women and LGB individuals. Thus, women's motivation to reduce group-based hierarchy may make them more perceptive of the existence of unjust group-based inequities compared to men.

\section{Associations with Political Involvement}

An additional goal of the current study was to examine how group-specific forms of critical reflection and political efficacy were differentially associated with social movement and standard political involvement. It was hypothesized that a greater critical awareness of groupbased inequality would be associated with greater involvement in both types of political activities while viewing the government as unresponsive (i.e., low political efficacy) would be associated specifically with greater social movement involvement. At the bivariate level, all forms of critical reflection were associated positively with all types of political engagement and all forms of perceived government responsiveness were associated negatively with social movement as anticipated. However, structural equation models indicated that after controlling for all other forms of critical reflection and government responsiveness by including them in the same model, only trans-based critical reflection emerged as a significant predictor of specifically social movement activity, including both activist behaviors like protest and voicing political opinions. This finding suggests that emerging adults' critical beliefs about inequalities that target transgender individuals are particularly important for emerging adults' political activism over and above the influence of race-, gender-, and LGB-based critical reflection and political efficacy beliefs. In addition, the association between trans-based critical reflection and political voice was significant for men, not women, suggesting men who were more critically aware of 
transgender-based inequalities were more likely to share their political opinions with others. Although men were generally less critically aware of trans-based inequalities than women, there was more variability in trans-based critical reflection for men $(\mathrm{SD}=.73)$ compared to women $(\mathrm{SD}=.66)$. Thus, findings may be tapping into individual differences among men regarding $\mathrm{CC}$ and political involvement such that men who do demonstrate a relatively higher awareness of transgender issues may be particularly politically opinionated or possess unique characteristics that lead to increased political voice. However, more research is needed to examine potential mechanisms that may explain these gender differences.

Furthermore, certain types of group-based critical reflection and government responsiveness beliefs significantly interacted to predict political involvement. Although groupspecific interactions were differentially associated with different forms of political involvement, critical reflection $\mathrm{X}$ efficacy interaction effects generally demonstrated a similar pattern such that views of the government as unresponsive combined with high levels of critical reflection (i.e., greater awareness of inequality) were associated with greater political involvement. Emerging adults who are critically aware of a specific groups' experiences with oppression may be even more motivated to get politically involved if they also perceive an injustice within the political system or government. It is possible that an awareness of systemic oppression on its own (i.e., without low external political efficacy) may not be enough to motivate high levels of political involvement. Alternatively, high levels of critical reflection may motivate other forms of civic engagement. For instance, being aware of certain group-based inequalities like racial inequality in poverty may motivate some people to volunteer or donate to charity rather than engaging in political acts such as protest or voting. However, recognizing that this group not only has fewer chances to get ahead in society, but also must work against a political system that is ignoring 
their interests may increase the likelihood that critical reflection beliefs will facilitate involvement in political activities, which may be viewed as a more effective means for addressing inequalities that are perceived to exist in both society and the government.

These results demonstrate that critical reflection and political efficacy are distinct components of critical consciousness that interact to predict specific forms of political involvement, which offers clarity regarding associations among dimensions of critical consciousness. Although critical consciousness theorists have postulated that critical reflection and political efficacy may interact to predict action, previous research has not found external critical reflection $\mathrm{X}$ external political efficacy interactions in predicting political engagement (Diemer \& Rapa, 2015). One potential explanation is that previous studies relied on single axis measures of critical reflection and external political efficacy that lack specificity regarding the targeted group. Additionally, they examined these associations in a sample of lower SES Hispanic and Black adolescents whereas the current study utilized a sample of emerging adults with varying levels of SES and different racial/ethnic backgrounds (White, Hispanic, Black, Asian). Emerging adulthood is met with cognitive maturation that allows for more critical views on society and is accompanied by increased opportunities for political participation (Flanagan \& Levine, 2010). This is particularly true in college contexts where students are exposed to diverse perspectives and on-campus clubs and organizations that may offer additional opportunities for political involvement (Jennings, 2002). Thus, features of emerging adulthood may foster increased complexity in critical consciousness that may lead critical reflection beliefs to be more closely aligned with emerging adults' external political efficacy beliefs.

These findings advance our understanding of sociocognitive factors that may undergird specific forms of political engagement in emerging adulthood by shedding light on sets of group- 
specific CC beliefs that are differentially associated with social movement and standard political or mainstream forms of political action. Specifically, the positive association between transbased critical reflection and social movement involvement was significantly stronger for emerging adults who also perceived the government as unresponsive to transgender individuals (lower trans-based efficacy). A similar interaction pattern was found for race-based beliefs but with different outcomes such that a combination of high race-based critical reflection and low race-based government responsiveness was associated with emerging adults' engagement in mainstream conventional political acts such as voting and news consumption. Thus, the use of a multidimensional assessment of critical consciousness beliefs yielded greater specificity regarding the direct and interactive links between critical reflection, political efficacy, and political involvement.

The trans-based critical reflection by government responsiveness interaction effect is consistent with study hypotheses. It had been posited that a critical understanding of inequality faced by a particular group combined with an awareness that this group has little influence on the government would be particularly likely to motivate young adults to engage in acts that seek to challenge and change the system, like activism. Indeed, above and beyond beliefs about other marginalized groups, emerging adults with a critical awareness of trans-based inequalities were more politically involved in activism and expressing their political opinions, especially if they also perceived the government as unresponsive to transgender individuals. These findings point to beliefs about trans-based issues as particularly important for driving activist behaviors in emerging adulthood, relative to beliefs about other social issues. An examination of the history of social movements on behalf of trans-rights in relation to the history of social movements for other marginalized groups may help to explicate this association. 
Historically, there have been a host of large social movements fighting for equal rights. The Women's Rights Movement is cited as beginning in 1848, which focused on women's suffrage until 1920 (Lorber, 2001). Then a resurgence of women's rights movements occurred in 1960 's, often referred to as the second wave of feminism. Examples of current social movements on behalf of gendered issues include Time's Up and \#MeToo, many of which were represented at the famously attended Women's March in 2017 and 2018. The Civil Rights Movement fought for equal rights on behalf of racial/ethnic minorities beginning in the late 1940's and smaller movements such as the Chicano (i.e., Mexican-American) Civil Rights Movement began in the 1960’s (Kenneth, 2001; Rosales, 1997). More modern fights for racial equality include Black Lives Matter (BLM) which began in 2013 and fights against violence and systemic racism toward Black people (Garza, 2014). The Immigrant Rights Movement received mainstream attention in 2006 through massive organized protests led by Latinx groups fighting for immigration reform; many of these activists continue to fight against policies rooted in racist and anti-immigrant ideologies today (Barreto, Manzano, Ramirez, \& Rim, 2009; Johnson \& Hing, 2007). Scholars of social movements have argued that LGB civil rights have been at the centerstage in American politics over the past 30 years, with transgender rights only gaining recognition in the early 2000's creating LGBT movements (Kollman \& Waites, 2009). However, historians articulate that LGBT movements have predominantly centered on issues related to sexual orientation whereas issues related to gender identity have received far less attention (Stryker, 2008). While gay and lesbian rights movements have become mainstream and led to progress in LGB rights (e.g., same-sex marriage legalized in 2015), trans-activism receives less visibility and resources (Currah, 2008; Stryker, 2008). Despite some progress over recent years, the trans-community has experienced massive setbacks such as the exclusion of transgender 
people from federal non-discrimination protections, public restroom bans, and military bans

(ACLU, 2017; Movement Advancement Project, 2017; see Stryker, 2008 for a review).

Therefore, emerging adults who are critically aware of the obstacles transgender individuals face in America and recognize the history of their exclusion from mainstream movements, policies, and government may feel particularly compelled to take part in social movement activities.

Rather than working within the system to redress these inequalities through mainstream forms of political participation (e.g., voting), emerging adults who are critically aware of trans-based inequalities may be drawn to political protests and other forms of activism, which work outside of conventional political organizations with the goal of initiating systematic change.

In contrast, race-based critical reflection $\mathrm{X}$ political efficacy interactions were associated with more conventional forms of political involvement. Higher critical awareness of racial inequalities was associated with greater voting intentions and news consumption but only for emerging adults who also perceived the government as unresponsive to racial and ethnic minorities. These interactions were slightly contrary to current study hypothesis $8 \mathrm{~b}$, as it was anticipated that high levels of critical reflection combined with high levels of political efficacy (i.e., government viewed as highly responsive) would motivate emerging adults to work within existing systems through mainstream acts like voting. Instead, emerging adults' participation in conventional behaviors seem to be motivated by a combination of high race-based reflection and low levels of race-based government responsiveness. Given the long history of activism and social movements on behalf of racial equality and the attention current protests about racial issues receive in the media (Bonilla \& Rosa, 2015; Carney, 2016), racially conscious emerging adults may feel less of a responsibility to engage in activism as a primary strategy for redressing racial inequality. Instead, emerging adults who are critically aware of racial inequality and view 
the government as unresponsive to racial/ethnic minorities may feel that it possible to work within the system to redress such inequalities through acts like voting. While it seems counterintuitive that viewing the system as unresponsive to minorities would be related to an increased likelihood of working within that system on behalf of these issues, it is possible that racially conscious emerging adults view current political officials (i.e., the Trump administration) as the problematic source of low race-based responsiveness and are therefore motivated to vote for different representatives who might be more responsive to racial issues.

Findings may also be due in part to emerging adults' perceptions of the progress that has been made regarding racial equality in America. With historical victories such as the Civil Rights Act of 1964 ending segregation and banning employment discrimination and the Regents of the University of California v. Bakke (Affirmative Action) in 1978 allowing colleges to accept more racial minority applicants, emerging adults may feel that the US government has demonstrated the capacity to pass policies that seek to redress racial inequalities. Moreover, although racial and ethnic minorities are still underrepresented in positions of political leadership, there has been a documented increase in the number of racial/ethnic minorities elected to office in recent years which may lead emerging adults to view voting as a viable option for addressing systemic racial inequality. For example, since 2001 there has been an $84 \%$ increase in the number of non-white congress members (Pew Research Center, 2018). This stands in contrast to the continued vast underrepresentation of transgender individuals. To date, there are only four openly transgender state legislatures and zero openly transgender individuals have served in office at the national level (Victory Institute, 2018). Thus, while emerging adults who are aware of trans-issues may not believe working within the system will yield progress, emerging adults who are motivated to act on behalf of racial inequalities may see mainstream avenues as at least a possibility based on 
their perceptions of the progress that has been made for minorities, even if they are wary of the current governments' responsiveness to race-based issues.

The race-based CR X PE interaction was further qualified by a 3-way interaction with emerging adult race/ethnicity. First, race-based government responsiveness moderated the association between race-based critical reflection and news consumption for White emerging adults only, but not for Hispanic or Asian emerging adults. Second, race-based government responsiveness moderated the association between race-based critical reflection and voting, but only for White and Hispanic participants, not for Asian participants. Thus, for both White and Hispanic emerging adults, a combination of high critical awareness of racial inequality and perceptions of the government as unresponsive to racial/ethnic minorities (low race-based efficacy) may motivate participation in political elections. For White emerging adults only, high race-based critical reflection and low government responsiveness is also associated with keeping up with current events. Moreover, further examination of the interaction effects on voting potentially points to a slightly different process for White and Hispanic emerging adults at high levels of race-based government responsiveness and low levels of race-based reflection. For Hispanic emerging adults, high levels of race-based political efficacy (i.e., view government as highly responsive to racial/ethnic minorities) seemed to buffer against the negative effects of low race-based critical awareness on voting. In contrast, for White emerging adults, high race-based government responsiveness does not seem to compensate for low levels of race-based reflection regarding participation in political elections. Instead, White emerging adults only demonstrated relatively higher levels of participation in elections if they had high race-based critical reflection, regardless of their race-based government responsiveness beliefs. Therefore, while a combination of high race-based critical reflection and low race-based government responsiveness 
is related to optimal voting behavior for both White and Hispanic emerging adults, it may also be especially important for racial and ethnic minorities who lack a critical awareness of racial inequality to at least feel a strong sense of race-based efficacy.

One potential explanation that voting is slightly lower among White emerging adults with high race-based government responsiveness and low race-based reflection compared to Hispanic emerging adults with similar levels of race-based $\mathrm{CC}$ is that these White emerging adults may not feel compelled to act on behalf of another racial group if this group is viewed as equal to their own group. That is, perceptions of racial equality both in society (low race-based CR) and in government responsiveness (high race-based PE) may circumvent any feelings of need or desire to act as an ally to racial/ethnic minorities, as their CC beliefs indicate they do not view racial and ethnic minorities as a target of injustice. In contrast, high race-based government responsiveness has more relevance to Hispanic emerging adults' political behaviors given their minority status. Research shows that individuals are more likely to be politically involved when they believe their own group can achieve its goals (i.e., strong group efficacy) because these collective group efficacy beliefs are related to their own internal political efficacy beliefs (Zomeren, Saguy, \& Schellhaas, 2012). Thus, perceptions of how responsive the government is to a group with which Hispanic individuals identify may bolster their own feelings of internal political efficacy and in turn facilitate political participation. So, although Hispanic emerging adults who feel equal in society may be generally less motivated to participate in political elections, they may participate slightly more if they at least believe that government might listen to the interests of their own ethnic group. 


\section{Limitations and Future Directions}

The current study provides several novel contributions to research on political development in emerging adulthood and is one of the first to examine emerging adults' perceptions of different group-based inequalities and beliefs regarding the political efficacy of different social groups. However, findings should be considered in light of certain limitations. The measures utilized in the current study were collected via self-report, and this measurement strategy is susceptible to social-desirability bias. Thus, emerging adults may have over-reported their awareness of group-based inequalities and their political involvement. The current study utilized cross-sectional and correlational data, therefore causal inferences about the associations found in the current study cannot be made. Longitudinal data is needed to determine the temporal order and potential bidirectionality of these associations to further elucidate the developmental processes underlying critical consciousness in emerging adulthood. Although critical reflection and political efficacy beliefs are hypothesized to incite political involvement, theorists have argued that political involvement may also in turn shape critical consciousness beliefs (Watts et al., 2011).

This study recruited participants primarily through psychology courses at universities, which may have subjected the data to selection bias. The majority of participants opted to earn extra credit toward a psychology class which may reflect greater academic motivation. This may be one reason the sample was comprised almost entirely of students who reported earning B's or higher (88\%). Moreover, current findings may not generalize to all emerging adults. Given the sample consisted of students currently enrolled in a university, findings cannot be generalized to emerging adults not enrolled in college, which represents about one-third of emerging adults (Kuther, 2016). College contexts may be uniquely suited to foster CC for students, given the 
increased opportunities to interact with diverse others (Chang, Astin, \& Kim, 2004; Gurin, Dey, Hurtado, \& Gurin, 2002) and options for courses on diversity or social justice related issues (e.g., women's studies; Bowman, 2011). Thus, future research should explore the development of critical consciousness among emerging adults who entered the workforce after high school instead of attending college and emerging adults who already graduated college, as little is known about political development in these populations. Moreover, future research should also seek to examine $\mathrm{CC}$ among a more geographically diverse sample. Although participants were recruited from universities located in two different geographic regions of the United States (Pacific Coastal and mid-Atlantic), the current sample is not nationally representative.

Future studies should examine complex associations among dimensions of critical consciousness in a sample with greater diversity with regards to race and ethnicity. Although the percentage of Hispanic participants in current samples was similar to the demographics of the recruited schools and the percentage of Black and Asian participants was actually higher than that of recruited schools, certain multi-group analyses were unable to include Black participants due to small sample sizes and the complexity of the structural models. Multi-group analyses may also have been underpowered to detect significant associations within the Hispanic and Asian groups in the complex latent variable interaction multi-group models due to the small sample size in those groups relative to the number of parameters estimated in the models. However, it should be noted that although racial/ethnic diversity was somewhat limited for the complex analyses that were conducted, model fit indices across groups were adequate and full measurement invariance across all groups was achieved. An additional strength is that this is one of the first studies to examine associations between critical consciousness beliefs and political action among a sample of racially privileged or White emerging adults, as previous research has 
only examined these associations in minority adolescents. Future research should also try to obtain a more balanced sample in terms of gender and sexuality, as the current sample was primarily cis female and heterosexual. The small number of participants who identified as LGBT prevented us from examining potentially important within-group differences between gay, lesbian, bisexual, and transgender individuals and limited our ability to examine unique intersections of identity (e.g., Hispanic gay male).

Although we were unable to examine differences between gay, lesbian, bisexual, and transgender individuals, a strength of the current study is that we assessed beliefs about LGBand trans-based issues separately. Despite the strong correlation between LGB- and trans-based critical reflection, significant mean level differences and differential associations with political action indicated that emerging adults indeed distinguish between these groups when reasoning about systemic inequality and political efficacy. Future research should consider examining beliefs about inequalities that target lesbian women, gay men, and bisexual men and women separately, as these intersections of identity are theorized to lead to qualitatively different experiences with oppression (Purdie-Vaughns \& Eibach, 2008). Furthermore, while the measure developed in the current study builds on previous work by including a more comprehensive list of different types of inequalities (economic, educational, political, legal, assault/violence) based on multiple facets of identity (race/ethnicity, gender identity, sexual orientation), it is not an exhaustive list. Future research should consider assessing beliefs about inequalities that target groups based on immigration status and disability status, as well. An additional next step for research to pursue would be to examine differences in the subtypes of inequality across different forms of group-based critical reflection. For example, emerging adults may perceive racial/ethnic 
minorities as experiencing the most inequality, but potentially only in certain domains (e.g., economic and legal constraints).

Findings from the current study yield many additional questions for future research to pursue. The development of a new multidimensional measure of critical consciousness beliefs is an important first step toward integrating an intersectional framework into research on political development. Thus, researchers should strive to examine how facets of group-specific critical consciousness beliefs may relate to political involvement differently among emerging adults with different intersections of identity. In addition, another fruitful direction for researchers to pursue would be to investigate other potential sources of variation in critical consciousness. Consistent with previous research, the current study focused on social identity characteristics and political activity as correlates of social beliefs. However, other research has demonstrated that perceptions of society are heavily influenced by other social status indicators such as educational and occupational attainment (e.g., Schoon et al., 2010) and by personality characteristics (e.g., social dominance orientation, Pratto et al., 1994). Contextual factors such as school or neighborhood climate and exposure to diversity may also foster unique beliefs about specific types of inequality (Bowman, 2011; Greene \& Kamimura, 2003).

In addition to exploring sources of critical consciousness, future research can utilize this new multidimensional critical consciousness measure to examine links between specific sets of critical consciousness beliefs and other developmental outcomes. Research has demonstrated that critical consciousness is related to positive developmental outcomes for marginalized individuals including decreased substance use (Windsor et al., 2014), mental health (Zimmerman et al., 1999), and academic achievement (O’Connor, 1997). Using a multidimensional assessment of separate CC beliefs, researchers can further uncover how dimensions of CC may promote 
positive outcomes for not only marginalized individuals but also individuals who may be motivated to act as an ally to marginalized groups. A hopeful implication of the current findings is that it may be beneficial to facilitate $\mathrm{CC}$ among people with privilege, so they can act as agents of social change using their advantages and resources to fight for justice on behalf of marginalized groups. This hypothesis builds on previous CC conceptualizations which primarily put the responsibility on the already marginalized to redress their own oppression (e.g., Diemer et al. 2014; Ginwright and James 2002). Relatedly, research can work towards identifying important skills or assets that may empower critically conscious individuals to initiate and maintain political involvement. Little is known about the consequences for various groups who demonstrate high levels of critical reflection combined with a low sense of external political efficacy, especially if these beliefs intersect with their own identity. For some individuals, prolonged political involvement with continued critical reflection and perceptions of low potential for change may lead to burn out or stress, unless paired with certain developmental assets like resilience (Zimmerman et al., 1999).

Current findings also have important implications for interventions. In the counseling field, many psychologists have begun to utilize critical consciousness measures for prevention work and to identify biases among professionals, so that counselors and social workers are better equipped to work with marginalized populations with an understanding of the systemic forces that inextricably shape marginalized individuals' circumstances and experiences (Pitner \& Sakamoto, 2005; Shin et al. 2016). Thus, the new multidimensional measure of critical consciousness beliefs can be used to identify and target individuals who may need to undergo training or an intervention on multicultural awareness (Thomas et al., 2014). In addition, present results can inform civic educators and service learning programs that aim to foster political 
participation. Findings suggest that it may be important to both foster an awareness of specific group-based inequalities and, also help individuals to recognize that certain groups of people have little influence on the government. Additional research is needed to determine the direction of these associations though, as it may also be that involvement in political activities fosters a deeper understanding of social issues.

\section{Conclusions}

Overall, present findings suggest that critical reflection and political efficacy constitute conceptually distinct dimensions of critical consciousness and are both best measured by individual constructs that capture specific beliefs about different social issues. This new measurement approach allows for greater specificity in research seeking to understand critical consciousness and related developmental processes. The present study was the first to consider the extent to which emerging adults' perceptions of different marginalized groups vary in the context of critical consciousness beliefs. Differences in emerging adults' group-specific critical consciousness beliefs may predict emerging adults' level of political involvement as well as the form that involvement may take. Elucidating complex associations among multiple facets of critical consciousness will provide valuable insight into the developmental processes that may support political involvement during the transition to adulthood. Finally, gender and race/ethnicity differences emerged in certain models which hint at the possibility that these political developmental processes may vary based on identity characteristics. Findings urge researchers to continue to investigate the complex intersections between social identity characteristics and dimensions of sociopolitical development. 


\section{References}

ACLU. (2017). Past LGBT nondiscrimination and Anti-LGBT Bills across the country. Retrieved January 01, 2018, from https://www.aclu.org/other/past-lgbt$\underline{\text { nondiscrimination-and-anti-lgbt-bills-across-country }}$

Aiken, L. S., Stein, J. A., \& Bentler, P. M. (1994). Structural equation analyses of clinical subpopulation differences and comparative treatment outcomes: Characterizing the daily lives of drug addicts. Journal of Consulting and Clinical Psychology, 62(3), 488.

Aosved, A. C., Long, P. J., \& Voller, E. K. (2009). Measuring sexism, racism, sexual prejudice, ageism, classism, and religious intolerance: The intolerant schema measure. Journal of Applied Social Psychology, 39(10), 2321-2354.

Arnett, J. J. (2000). Emerging adulthood: A theory of development from the late teens through the twenties. American Psychologist, 55(5), 469-480. https://doi.org/10.1037//0003066X.55.5.469

Badgett, M., Lau, H., Sears, B., \& Ho, D. (2007). Bias in the workplace: Consistent evidence of sexual-orientation and gender identity discrimination. The Williams Institute, (June), 1-8. Retrieved from http://escholarship.org/uc/item/5h3731xr;jsessionid=8D8B7F2F93649A5C36B473C5051 $\underline{221 \mathrm{EC}}$

Barreto, M. A., Manzano, S., Ramirez, R., \& Rim, K. (2009). Mobilization, participation, and solidaridad: Latino participation in the 2006 immigration protest rallies. Urban Affairs Review, 44(5), 736-764. 
Berg, M., Coman, E., \& Schensul, J. J. (2009). Youth action research for prevention: A multilevel intervention designed to increase efficacy and empowerment among urban youth. American Journal of Community Psychology, 43, 345-359.

doi 10.1007/s10464-009- 9231-2

Bonilla, Y., \& Rosa, J. (2015). \#Ferguson: Digital protest, hashtag ethnography, and the racial politics of social media in the United States. American Ethnologist, 42(1), 4-17.

Bowman, N. A. (2011). Promoting participation in a diverse democracy: A meta-analysis of college diversity experiences and civic engagement. Review of Educational Research, 81(1), 29-68.

Brunner, M., Nagy, G., \& Wilhelm, O. (2012). A tutorial on hierarchically structured constructs. Journal of Personality, 80(4), 796-846. doi: 10.1111/j.1467-6494.2011.00749.x

Carney, N. (2016). All lives matter, but so does race: Black lives matter and the evolving role of social media. Humanity \& Society, 40(2), 180-199.

CDC (2016). The National Intimate Partner and Sexual Violence Survey. Retrieved from https://www.cdc.gov/violenceprevention/nisvs/index.html

Census Bureau (2016). Current Population Survey. Retrieved from https://www.census.gov/programs-surveys/cps.html

Chang, M. J., Astin, A. W., \& Kim, D. (2004). Cross-racial interaction among undergraduates: Some consequences, causes, and patterns. Research in Higher Education, 45(5), 529-553.

Chavez, L. (1998). The color bind: California's battle to end affirmative action. Univ of California Press. 
Cheung, G. W., \& Rensvold, R. B. (2002). Evaluating goodness-of-fit indexes for testing measurement invariance. Structural equation modeling, 9(2), 233-255.

Christens, B. D. \& Dolan, T. (2011). Interweaving youth development, community development, and social change through youth organizing. Youth \& Society, 43(2), 528-548.

Combs, B. H. (2016). Black (and brown) bodies out of place: Towards a theoretical understanding of systematic voter suppression in the United States. Critical Sociology, 42(4-5), 535-549.

Crenshaw, Kimberle' Williams. 1989. "Demarginalizing the Intersection of Race and Sex: A Black Feminist Critique of Antidiscrimination Doctrine, Feminist Theory and Antiracist Politics.” University of Chicago Legal Forum 1989.

Currah, P. (2008). Stepping back, looking outward: Situating transgender activism and transgender studies - Kris Hayashi, Matt Richardson, and Susan Stryker frame the movement. Sexuality Research and Social Policy, 5(1), 93-105.

Cole, E. R. (2009). Intersectionality and research in psychology. American psychologist, 64(3), 170.

Diemer, M.A. (2009). Pathways to occupational attainment among poor youth of color: The role of sociopolitical development. The Counseling Psychologist, 37(1), 6-35.

Diemer, M. A., \& Blustein, D. L. (2006). Critical consciousness and career development among urban youth. Journal of Vocational Behavior, 68(2), 220-232. https://doi.org/10.1016/j.jvb.2005.07.001

Diemer, M. A., \& Li, C. H. (2011). Critical consciousness development and political participation among marginalized youth. Child Development, 82(6), 1815-1833. https://doi.org/10.1111/j.1467-8624.2011.01650.x 
Diemer, M. A., Kauffman, A., Koenig, N., Trahan, E., \& Hsieh, C. A. (2006). Challenging racism, sexism, and social injustice: Support for urban adolescents' critical consciousness development. Cultural Diversity and Ethnic Minority Psychology, 12(3), 444.

Diemer, M. A., McWhirter, E. H., Ozer, E. J., \& Rapa, L. J. (2015). Advances in the conceptualization and measurement of critical consciousness. Urban Review, 47(5), 809823. https://doi.org/10.1007/s11256-015-0336-7

Diemer, M. A., \& Rapa, L. J. (2015). Unraveling the complexity of critical consciousness, political efficacy, and political action among marginalized adolescents. Child Development, 87(1), 221-238. https://doi.org/10.1111/cdev.12446

Diemer, M. A., Rapa, L. J., Park, C. J., \& Perry, J. C. (2014). Development and validation of the critical consciousness scale. Youth \& Society. doi:10.1177/0044118X14538289.

Diemer, M. A., Rapa, L. J., Voight, A. M., \& McWhirter, E. H. (2016). Critical consciousness: A developmental approach to addressing marginalization and oppression. Child Development Perspectives, 10(4), 216-221. https://doi.org/10.1111/cdep.12193

Diemer, M. A., Rapa, L. J., Park, C. J., \& Perry, J. C. (2017). Development and validation of the Critical Consciousness Scale. Youth \& Society, 49(4), 461-483.

Diemer, M. A., Wang, Q., Moore, T., Gregory, S. R., Hatcher, K. M., \& Voight, A. M. (2010). Sociopolitical development, work salience, and vocational expectations among low socioeconomic status African American, Latin American, and Asian youth. Developmental Psychology, 46(3), 619-635.

Dolan, K. (2010). The impact of gender stereotyped evaluations on support for women candidates. Political Behavior, 32(1), 69-88. 
Eagly, A. H., Diekman, A. B., Johannesen-Schmidt, M. C., \& Koenig, A. M. (2004). Gender gaps in sociopolitical attitudes: A social psychological analysis. Journal of personality and social psychology, 87(6), 796.

Ennis, J. G., \& Schreuer, R. (1987). Mobilizing weak support for social movements: The role of grievance, efficacy, and cost. Social Forces, 66(2), 390-409.

Finkel, S. E. (1985). Reciprocal effects of participation and political efficacy: A panel analysis. American Journal of Political Science, 29(4), 891-913.

Flanagan, C., \& Levine, P. (2010). Civic engagement and the transition to adulthood. The Future of Children, 20(1), 159-179.

Flanagan, C., Ingram, P., Gallay, E. M., \& Gallay, E. E. (1997). Why are people poor? Social conditions and adolescents' interpretation of the "social contract.". Social and Emotional Adjustment and Family Relations in Ethnic Minority Families, 53-62.

Flanagan, C. A., Kim, T., Pykett, A., Finlay, A., Gallay, E. E., \& Pancer, M. (2014). Adolescents' theories about economic inequality: Why are some people poor while others are rich?. Developmental Psychology, 50(11), 2512.

Freire, P. (1973). Education for critical consciousness. New York, NY: Continuum.

Freire, P. (1993). Pedagogy of the oppressed. New York, NY: Continuum.

Garza, A. (2014). A herstory of the\# BlackLivesMatter movement. Are all the women still white, 23-28. https://news.northseattle.edu/sites/news.northseattle.edu/files/blacklivesmatter_Herstory. pdf 
Gastil, J., \& Xenos, M. (2010). Of attitudes and engagement: Clarifying the reciprocal relationship between civic attitudes and political participation. Journal of Communication, 60(2), 318-343. https://doi.org/10.1111/j.1460-2466.2010.01484.x

Ginwright, S. A. (2007). Black youth activism and the role of critical social capital in black community organizations. American Behavioral Scientist, 51(3), 403-418. https://doi.org/10.1177/0002764207306068

Ginwright, S., \& James, T. (2002). From assets to agents of change: Social justice, organizing, and youth development. New Directions for Student Leadership, 2002(96), 27-46.

Godfrey, E. B., \& Grayman, J. K. (2014). Teaching citizens: The role of open classroom climate in fostering critical consciousness among youth. Journal of Youth and Adolescence, 43(11), 1801-1817.

Greene, S. R., \& Kamimura, M. (2003, November). Ties that bind: enhanced social awareness development through interactions with diverse peers. In Annual Meeting of the association for the study of higher education (pp. 213-228).

Gulevich, O., Sarieva, I., \& Nevruev, A. (2017). How do social beliefs affect political action motivation? The cases of Russia and Ukraine. Group Processes \& Intergroup Relations, 20(3), 382-395. https://doi.org/10.1177/1368430216683531

Gurin, P., Dey, E., Hurtado, S., \& Gurin, G. (2002). Diversity and higher education: Theory and impact on educational outcomes. Harvard educational review, 72(3), 330-367.

Hajnal, Z. L., Gerber, E. R., \& Louch, H. (2002). Minorities and direct legislation: Evidence from California ballot proposition elections. The Journal of Politics, 64(1), 154-177.

Hajnal, Z., Lajevardi, N., \& Nielson, L. (2017). Voter identification laws and the suppression of minority votes. The Journal of Politics, 79(2), 363-379. 
Harris, F.C. (1999). Will the circle be unbroken? The erosion and transformation of AfricanAmerican civic life. In Robert Fullinwider (Ed), Civil society, democracy, and civic renewal, 317-338. New York, NY: Roman and Littlefield.

Herek, G. M. (2007). Confronting sexual stigma and prejudice: Theory and practice. Journal of Social Issues, 63(4), 905-925.

Hughes, D., Rodriguez, J., Smith, E. P., Johnson, D. J., Stevenson, H. C., \& Spicer, P. (2006). Parents' ethnic-racial socialization practices: A review of research and directions for future study. Developmental psychology, 42(5), 747.

Hurst, C. E., Gibbon, H. M. F., \& Nurse, A. M. (2016). Social inequality: Forms, causes, and consequences. New York and London: Routledge.

Jennings, M.K. (2002). Generation units and the student protest movement in the United States: An intra- and inter-generational analysis. Political Psychology, 23, 303-324.

Johnson, K. R., \& Hing, B. O. (2007). The immigrant rights marches of 2006 and the prospects for a new civil rights movement. Harv. CR-CLL Rev., 42, 99.

Kahne, J., \& Westheimer, J. (1996). In the service of what. Phi Delta Kappan, 77(9), 592-599.

Kahne, J., \& Westheimer, J. (2006). The limits of political efficacy: Educating citizens for a democratic society. Political Science \& Politics, 39(2), 289-296. https://doi.org/10.1017/S1049096506060471

Katz, P. A., \& Kofkin, J. A. (1997). Race, gender, and young children. Developmental psychopathology: Perspectives on adjustment, risk, and disorder, 21, 51-74.

Kenneth, A. (2001). Social movements and policy implementation: The Mississippi civil rights movement and the war on poverty, 1965 to 1971. American Sociological Review, 66, 7195. 
Kleiman, S., Spanierman, L. B., \& Smith, N. G. (2015). Translating oppression: Understanding how sexual minority status is associated with White men's racial attitudes. Psychology of Men \& Masculinity, 16(4), 404.

Kline, R. B. (2015). Principles and practice of structural equation modeling. Guilford Publications

Kline, P. (2013). Handbook of psychological testing. London and New York: Routledge.

Kollman, K., \& Waites, M. (2009). The global politics of lesbian, gay, bisexual and transgender human rights: An introduction. Contemporary politics, 15(1), 1-17.

Kuther, T. L. (2016). Lifespan development: Lives in context. Thousand Oaks, CA: SAGE Publications.

Little, T.D. (2013). Longitudinal structural equation modeling. New York, NY: The Guilford.

Little, T. D., Bovaird, J. A., \& Card, N. A. (Eds.). (2012). Modeling contextual effects in longitudinal studies. New York and London: Psychology Press.

Little, T. D., Slegers, D. W., \& Card, N. A. (2006). A non-arbitrary method of identifying and scaling latent variables in SEM and MACS models. Structural Equation Modeling: A Multidisciplinary Journal, 13, 59-72. doi: 10.1207/s15328007sem1301_3

Lombardi, E. L., Wilchins, R. A., Priesing, D., \& Malouf, D. (2002). Gender violence: Transgender experiences with violence and discrimination. Journal of homosexuality, 42(1), 89-101.

Lorber, J. (2001). Gender inequality. Los Angeles, CA: Roxbury.

Metzger, A., \& Ferris, K. (2013). Adolescents' domain-specific judgments about different forms of civic involvement: Variations by age and gender. Journal of adolescence, 36(3), 529538. 
Metzger, A., \& Smetana, J. G. (2010). Social cognitive development and adolescent civic engagement. Handbook of research on civic engagement in youth, 221-248.

Morrell, M. E. (2005). Deliberation, democratic decision-making and internal political efficacy. International Electronic Journal of Elementary Education, 7(3), 301-318. https://doi.org/10.1007/s

Morrell, M. E. (2003). Survey and experimental evidence for a reliable and valid measure of internal political efficacy. The Public Quarterly, 67(4), 589-602.

Movement Advancement Project (2017). Non-discrimination laws. Retrieved January 1, 2018, from http://www.lgbtmap.org/equality-maps/non_discrimination_laws

Nash, J. C. (2008). Re-thinking intersectionality. Feminist review, 89(1), 1-15.

National Coalition of Anti-Violence Programs. (2008). Lesbian, Gay, Bisexual, and Transgender Domestic Violence in 2007. Retrieved December 02, 2017, from https://avp.org/wpcontent/uploads/2017/04/2007_NCAVP_DV_Report.pdf

Neville, H. A., Coleman, M. N., Falconer, J. W., \& Holmes, D. (2005). Color-blind racial ideology and psychological false consciousness among African Americans. Journal of Black Psychology, 31(1), 27-45.

Niemi, R.J., \& Junn, J. (1998). Civic education: What makes students learn. New Haven, CT: Yale University Press.

O’Connor, C. (1997). Dispositions toward (collective) struggle and educational resilience in the inner city: A case analysis of six African-American high school students. American Educational Research Journal, 34(4), 593-632.

Pew Research Center. (2016, January 27). Faith and the 2016 Campaign. Retrieved December 02, 2017, from http://www.pewforum.org/2016/01/27/faith-and-the-2016-campaign 
Pew Research Center (2018): Growing racial and ethnic diversity in congress. Retrieved from https://www.pewresearch.org/fact-tank/2019/02/08/for-the-fifth-time-in-a-row-the-newcongress-is-the-most-racially-and-ethnically-diverse-ever/ft_19-0129_minoritiescongress_bar/

Pitner, R. O., \& Sakamoto, I. (2005). The role of critical consciousness in multicultural practice: Examining how its strength becomes its limitation. American Journal of Orthopsychiatry, $75,684-694$.

Pratto, F., Sidanius, J., Stallworth, L. M., \& Malle, B. F. (1994). Social dominance orientation: A personality variable predicting social and political attitudes. Journal of personality and social psychology, 67(4), 741.

Prilleltensky, I. (2012). Wellness as fairness. American Journal of Community Psychology, 49(12), 1-21.

Purdie-Vaughns, V., \& Eibach, R. P. (2008). Intersectional invisibility: The distinctive advantages and disadvantages of multiple subordinate-group identities. Sex Roles, 59(56), 377-391.

Quintana, S. M., \& Vera, E. M. (1999). Mexican American children's ethnic identity, understanding of ethnic prejudice, and parental ethnic socialization. Hispanic Journal of Behavioral Sciences, 21(4), 387-404.

Ramos-Zayas, A. Y. (2003). National performances: The politics of race, class and space in Puerto Rican Chicago. Chicago, IL: University of Chicago Press.

Rehavi, M. M., \& Starr, S. B. (2012). Racial disparity in federal criminal charging and its sentencing consequences. The Social Science Research Network, 12-002. doi:10.2139/ssrn.1985377 
Reid, P. T., \& Comas-Diaz, L. (1990). Gender and ethnicity: Perspectives on dual status. Sex roles, 22(7-8), 397-408.

Reise, S. P. (2012). The rediscovery of bifactor measurement models. Multivariate Behavioral Research, 47, 667-696. doi: 10.1080/00273171.2012.715555

Rosales, F. A. (1997). Chicano! The history of the Mexican American civil rights movement. Arte Publico Press.

Satorra, A. (2000). Scaled and adjusted restricted tests in multi-sample analysis of moment structures. In Innovations in multivariate statistical analysis (pp. 233-247). Springer, Boston, MA.

Schoon, I., Cheng, H., Gale, C. R., Batty, G. D., \& Deary, I. J. (2010). Social status, cognitive ability, and educational attainment as predictors of liberal social attitudes and political trust. Intelligence, 38(1), 144-150.

Shields, S. A. (2008). Gender: An intersectionality perspective. Sex roles, 59(5-6), 301-311.

Shin, R. Q., Ezeofor, I., Smith, L. C., Welch, J. C., \& Goodrich, K. M. (2016). The development and validation of the critical consciousness scale Journal of Counseling Psychology. Journal of Counseling Psychology, (January), 1-14. https://doi.org/http://dx.doi.org/10.1037/cou0000137

Shingles, R. D. (1981). Black consciousness and political participation: The missing link. The American Political Science Review, 75(1), 76-91.

Speer, P. W. \& Peterson, N. A. (2000). Psychometric properties of an empowerment scale: Testing cognitive, emotional, and behavioral domains. Social Work Research, 24(2), 109118. 
Stotzer, R. L. (2014). Law enforcement and criminal justice personnel interactions with transgender people in the United States: A literature review. Aggression and violent behavior, 19(3), 263-277.

Stryker, S. (2008). Transgender history. Berkeley, CA: Seal Press.

Thomas, A. J., \& King, C. T. (2007). Gendered racial socialization of African American mothers and daughters. The Family Journal, 15(2), 137-142.

Thomas, A. J., Barrie, R., Brunner, J., Clawson, A., Hewitt, A., Jeremie-Brink, G., \& RoweJohnson, M. (2014). Assessing critical consciousness in youth and young adults. Journal of Research on Adolescence, 24(3), 485-496.

Tilcsik, A. (2011). Pride and prejudice: Employment discrimination against openly gay men in the United States. American Journal of Sociology, 117(2), 586-626. https://doi.org/10.1086/661653

Tolbert, X. \& Hero, R. (1996). Race/Ethnicity and direct democracy: An analysis of California's illegal immigration initiative. Journal of Politics, 58(1996), 806-818.

Verba, S., \& Nie, N. H. (1972). Participation in America: Political democracy and social equality. New York, NY: Harper \& Row.

Victory Institute. (2018). Out for America. Retrieved from https://outforamerica.org/

Watts, R. J., \& Abdul-Adil, J. K. (1998). Promoting critical consciousness in young, AfricanAmerican men. Journal of Prevention \& Intervention in the Community, 16(1-2), 63-86.

Watts, R. J., Abdul-Adil, J. K., \& Pratt, T. (2002). Enhancing critical consciousness in young African American men: A psychoeducational approach. Psychology of Men \& Masculinity, 3(1), 41-52. 
Watts, R. J., Diemer, M. A., \& Voight, A. M. (2011). Critical consciousness: Current status and future directions. In C. A. Flanagan \& B. D. Christens (Eds.), Youth civic development: Work at the cutting edge. New Directions for Child and Adolescent Development, (pp. 43-57).

Watts, R. J., Griffith, D. M., \& Abdul-Adil, J. (1999). Sociopolitical development as an antidote for oppression — Theory and action. American Journal of Community Psychology, 27(2), 255-271. https://doi.org/10.1023/A:1022839818873

Watts, R. J., Williams, N. C., \& Jagers, R. J. (2003). Sociopolitical development. American Journal of Community Psychology, 31(1-2), 185-194. https://doi.org/10.1023/A:1023091024140

Weitzer, R., \& Tuch, S. A. (2002). Perceptions of racial profiling: Race, class, and personal experience. Criminology, 40(2), 435-456.

Westheimer, J., \& Kahne, J. (2004). Educating the "good" citizen: Political choices and pedagogical goals. PS: Political Science \& Politics, 37(2), 241-247.

Windsor, L., Pinto, R. M., Benoit, E., Jessell, L., \& Jemal, A. (2014). Community Wise: The development of an anti-oppression model to promote individual and community health. Journal of social work practice in the addictions, 14(4), 402-420.

Wollman, N., \& Stouder, R. (1991). Believed efficacy and political activity: A test of the specificity hypothesis. The Journal of social psychology, 131(4), 557-566.

Wray-Lake, L., Metzger, A., \& Syvertsen, A. K. (2017). Testing multidimensional models of youth civic engagement: Model comparisons, measurement invariance, and age differences. Applied Developmental Science, 21(4), 266-284. 
Wray-Lake, L., Syvertsen, A. K., \& Flanagan, C. A. (2008). Contested citizenship and social exclusion: Adolescent Arab American immigrants' views of the social contract. Applied Development Science, 12(2), 84-92.

Xavier, J., Bradford, J., Hendricks, M., Safford, L., McKee, R., Martin, E., \& Honnold, J. A. (2013). Transgender health care access in Virginia: A qualitative study. International Journal of Transgenderism, 14(1), 3-17.

Young, I. (1990). Five Faces of Oppression. In A. E. Cudd \& R. O. Andreasen (Eds.), Feminist theory: A philosophical anthology (pp. 91-104). Oxford, UK Malden, Massachusetts: Blackwell.

Zimmerman, M. A., Ramirez-Valles, J., \& Maton, K. I. (1999). Resilience among urban African American male adolescents: A study of the protective effects of sociopolitical control on their mental health. American Journal of Community Psychology, 27(6), 733-751. https://doi.org/10.1023/A:1022205008237

Zimmerman, M. A. (1989). The relationship between political efficacy and citizen participation: Construct validation studies. Journal of Personality Assessment, 53(3), 554-566. https://doi.org/10.1207/s15327752jpa5303_12

Zomeren, M. Van, Saguy, T., \& Schellhaas, F. M. H. (2012). Believing in "making a difference" to collective efforts: Participative efficacy beliefs as a unique predictor of collective action. Group Processes \& Intergroup Relations, 16(5), 618-634. https://doi.org/10.1177/1368430212467476 
Table 1

Sample Demographics by Recruitment Location

\begin{tabular}{|c|c|c|c|c|}
\hline & \multicolumn{4}{|c|}{$\mathbf{N}(\%) / M(S D)$} \\
\hline & $\begin{array}{c}\text { WVU } \\
\mathbf{N}=\mathbf{5 0 3}\end{array}$ & $\begin{array}{c}\text { UCLA } \\
\mathbf{N}=334 \\
\end{array}$ & $\begin{array}{l}\text { MSMU } \\
\mathbf{N}=35\end{array}$ & $\begin{array}{c}\text { Total } \\
\mathbf{N}=872 \\
\end{array}$ \\
\hline Age & $19.58(1.80)$ & $20.77(1.98)$ & $19.97(2.77)$ & $20.05(1.20)$ \\
\hline \multicolumn{5}{|l|}{ Years in School } \\
\hline First Year & $228(45)$ & $24(7)$ & $15(43)$ & $267(31)$ \\
\hline Second & $159(32)$ & $40(12)$ & $7(20)$ & $206(24)$ \\
\hline Third & $72(14)$ & $106(32)$ & $4(11)$ & $182(21)$ \\
\hline Fourth & $39(8)$ & $159(48)$ & $7(20)$ & $205(24)$ \\
\hline Five or more & $5(1)$ & $5(2)$ & $2(6)$ & $10(1)$ \\
\hline Sex (assigned at birth): Female & $386(77)$ & $208(67)$ & $33(100)$ & $642(74)$ \\
\hline \multicolumn{5}{|l|}{ Gender Identity } \\
\hline Male & $112(22)$ & $102(33)$ & $0(0)$ & $221(25)$ \\
\hline Female & $383(77)$ & $209(67)$ & $32(97)$ & $639(74)$ \\
\hline Transgender (female to male) & $1(<1)$ & 0 & 0 & $1(<1)$ \\
\hline Gender non-conforming/queer & $4(1)$ & $1(<1)$ & $1(3)$ & $6(<1)$ \\
\hline \multicolumn{5}{|l|}{ Ethnicity } \\
\hline Caucasian/White & $446(89)$ & $98(32)$ & $3(9)$ & $553(64)$ \\
\hline Hispanic/Latinx & $25(5)$ & $59(19)$ & $23(70)$ & $117(14)$ \\
\hline Asian American & $20(4)$ & $126(41)$ & $8(24)$ & $163(19)$ \\
\hline African American/Black & $33(7)$ & $25(8)$ & $4(12)$ & $62(7)$ \\
\hline American Indian/Native American & $6(1)$ & $4(1)$ & $3(9)$ & $13(2)$ \\
\hline Pacific Islander & $4(1)$ & $7(2)$ & $1(3)$ & $13(2)$ \\
\hline Other & $15(3)$ & $45(15)$ & $1(3)$ & $64(7)$ \\
\hline \multicolumn{5}{|l|}{ Sexual Orientation } \\
\hline Straight/heterosexual & $432(87)$ & $277(89)$ & $27(82)$ & $739(85)$ \\
\hline Bisexual & $46(9)$ & $20(6)$ & $6(18)$ & $85(10)$ \\
\hline Gay or lesbian & $18(4)$ & $11(4)$ & 0 & $35(4)$ \\
\hline Other & $3(1)$ & $3(1)$ & 0 & $6(.7)$ \\
\hline \multicolumn{5}{|l|}{ Immigration Status } \\
\hline Born Outside of US & $27(5)$ & $74(24)$ & $2(6)$ & $109(13)$ \\
\hline Parent(s) Born Outside of US & $55(11)$ & $232(75)$ & $19(58)$ & $325(38)$ \\
\hline $\begin{array}{r}\text { Grandparent(s) Born Outside of } \\
\text { US }\end{array}$ & $110(22)$ & $250(80)$ & $26(79)$ & 407 (47) \\
\hline \multicolumn{5}{|l|}{ Mother Education Level } \\
\hline Some Middle or High School & $6(<1)$ & $35(11)$ & $8(24)$ & $52(6)$ \\
\hline Completed High School & $108(22)$ & $44(14)$ & $7(21)$ & $163(19)$ \\
\hline Some College & $112(22)$ & $64(21)$ & $8(24)$ & $187(22)$ \\
\hline Completed College/Technical & $160(32)$ & $95(30)$ & $6(18)$ & $266(31)$ \\
\hline Graduate Degree & $113(23)$ & $70(22)$ & $3(9)$ & $193(22)$ \\
\hline \multicolumn{5}{|l|}{ Father Education Level } \\
\hline Some Middle or High School & $17(1)$ & $45(14)$ & $7(21)$ & $73(8)$ \\
\hline
\end{tabular}




\begin{tabular}{r|c|c|c|c} 
Completed High School & $131(26)$ & $42(14)$ & $7(21)$ & $185(21)$ \\
Some College & $85(17)$ & $47(15)$ & $5(15)$ & $140(16)$ \\
Graduate Degree & $112(22)$ & $84(30)$ & $4(12)$ & $205(24)$ \\
Completed College/Technical & $150(30)$ & $84(30)$ & $3(9)$ & $242(28)$ \\
Financial Strain & & & & \\
"Hard time buying necessities" & $20(4)$ & $15(5)$ & $8(24)$ & $45(5)$ \\
"Just enough for necessities" & $111(22)$ & $99(32)$ & $12(36)$ & $230(27)$ \\
"no problem buying necessities, & $281(56)$ & $149(50)$ & $9(27)$ & $449(52)$ \\
sometimes more" & & & & \\
"enough money to buy anything & $87(17)$ & $48(15)$ & $4(12)$ & $141(16)$ \\
we want" & & & & \\
Grades & $89(38)$ & $148(47)$ & $5(15)$ & $350(40)$ \\
Mostly As & $173(35)$ & $112(36)$ & $12(36)$ & $306(35)$ \\
Some As and Bs & $75(15)$ & $31(10)$ & $7(21)$ & $115(13)$ \\
Mostly Bs & $56(11)$ & $15(5)$ & $8(24)$ & $82(10)$ \\
Some Bs and Cs & $4(1)$ & $4(1)$ & 0 & $8(1)$ \\
Mostly Cs & $3(1)$ & 0 & 0 & $3(.3)$ \\
\hline Some Cs and Ds & $3(1)$ & &
\end{tabular}


Table 2

Group-Specific Critical Reflection: Perceived Inequality Subscales by Domain

\begin{tabular}{lll}
\hline Race/ethnicity-based & Gender-based & TGB-based \\
\hline & Economic/Occupational Constraints (24 items)
\end{tabular}

1. Certain racial or ethnic minority ahead $^{\text {CCS }}$

2. White people often get paid more than racial and ethnic minorities for the same work

3. A high percentage of racial and ethnic minorities are unemployed because of discrimination good jobs ${ }^{\mathrm{CCS}}$

5. Racial or ethnic minorities have fewer chances to get job promotions ${ }^{\mathrm{CCS}}$

6. Certain racial and ethnic minority jobs in highly prestigious fields like medicine, technology, science, and engineering groups have fewer chances to get

4. Certain racial and ethnic minority groups have fewer chances to get groups have fewer chances to get
Gay, lesbian, and bisexual people have fewer chances to get ahead

Men often get paid more than women for the same work

Straight people often get paid more than gay, lesbian, and bisexual people for the same work

A high percentage of women are unemployed because of discrimination

Women have fewer chances to get good jobs ${ }^{\mathrm{CCS}}$

Women fewer chances to get job promotions ${ }^{\mathrm{CCS}}$

Women have fewer chances to get jobs in highly prestigious fields like medicine, technology, science, and engineering
A high percentage of gay, lesbian, and bisexual people are unemployed because of discrimination

Gay, lesbian, and bisexual people have fewer chances to get good jobs

Gay, lesbian, and bisexual people have fewer chance to get job promotions

Gay, lesbian, and bisexual people have fewer chances to get jobs in highly prestigious fields like medicine, technology, science, and engineering
Transgender people have fewer chances to get ahead

Cisgender (i.e., people whose gender identity matches the sex they were assigned at birth) people often get paid more than transgender people for the same work

A high percentage of transgender people are unemployed because of discrimination

Transgender people have fewer chances to get good jobs

Transgender people have fewer chances to get job promotions

Transgender people have fewer chances to get jobs in highly prestigious fields like medicine, technology, science, and engineering

\section{Educational Constraints (12 items)}

7. Certain racial or ethnic minority groups have fewer chances to get a good education ${ }^{\mathrm{CCS}}$

8. Certain racial and ethnic minority groups have fewer chances to get a doctorate degree (e.g., $\mathrm{PhD}, \mathrm{MD}$ )
Women have fewer chances to get a good education ${ }^{\mathrm{CCS}}$

Women have fewer chances to get a doctorate degree (e.g., PhD, MD)
Gay, lesbian, and bisexual people have fewer chances to get a good education

Gay, lesbian, and bisexual people have fewer chances to get a doctorate degree (e.g., PhD, MD)
Transgender people have fewer chances to get a good education

Transgender people have fewer chances to get a doctorate degree (e.g., PhD, MD) 
9. In public schools, racial and ethnic minority groups are always treated fairly by teachers - reverse
In public schools, boys and girls are always treated fairly by teachers - reverse
In public schools, LGB students are always treated fairly by teachers reverse
In public schools, transgender people are always treated fairly by teachers - reverse
10. Certain racial and ethnic minority groups have fewer chances to be elected into political office

11. Certain racial and ethnic minority groups are underrepresented as candidates in political elections

12. Certain racial and ethnic minority groups have little political power

\section{Political Constraints (12 items)}

Women have fewer chances
to be elected into political

office

Women are underrepresented as candidates in political elections

Women have little political power
Gay, lesbian, and bisexual people have fewer chances to be elected into political office

Gay, lesbian, and bisexual people are underrepresented as candidates in political elections

Gay, lesbian, and bisexual people have little political power
Transgender people have fewer chances to be elected into political office

Transgender people are underrepresented as candidates in political elections

Transgender people have little political power
13. The legal system is applied to all racial and ethnic groups fairly reverse

14. A high percentage of certain racial and ethnic minority groups are treated unfairly by police officers

15. Racial and ethnic minority groups face more legal obstacles because of their race or ethnicity

16. Racial and ethnic minorities not adequately protected by antidiscrimination laws in the US

\section{Legal treatment/Legal Rights}

The legal system is applied to The legal system is applied to gay, men and women fairly reverse

A high percentage of women are treated unfairly by police officers

Women face more legal obstacles because of their gender

Women are not adequately protected by anti-

discrimination laws in the US lesbian, and bisexual people fairly reverse

A high percentage of LGB people are treated unfairly by police officers

LGB people face more legal obstacles because of their sexual orientation

LGB people are not adequately protected by anti-discrimination laws in the US
The legal system is applied to transgender people fairly - reverse

A high percentage of transgender people are treated unfairly by police officers

Transgender people face more legal obstacles because of their gender identity

Transgender people are not adequately protected by antidiscrimination laws in the US

\section{A high percentage of racial and ethnic minorities are sexually assaulted \\ 18. A high percentage of racial and ethnic minorities are physically} assaulted

\section{Assault \& Harassment}

A high percentage of women are sexually assaulted

A high percentage of women are physically assaulted
A high percentage of LGB people are sexually assaulted

A high percentage of LGB people are physically assaulted
A

A high percentage of transgender people are sexually assaulted

A high percentage of transgender people are physically assaulted 
19. A high percentage of racial and ethnic minorities are victims of domestic violence

A high percentage of women are victims of domestic

violence
A high percentage of LGB people are victims of domestic violence
A high percentage of transgender people are victims of domestic violence

Note. CCS subscript indicates item was adapted from the Critical Consciousness Scale (Diemer et al., 2017). All other items were written by first author. 
Table 3

Group-Specific External Political Efficacy Scales

Government Responsiveness:

\begin{tabular}{|c|c|c|c|c|}
\hline & To racial-ethnic minorities & To women & To LGB & To transgender \\
\hline 1. & $\begin{array}{l}\text { The powerful leaders in } \\
\text { government care very little } \\
\text { about the opinions of racial } \\
\text { and ethnic minorities - } \\
\text { reversed }\end{array}$ & $\begin{array}{l}\text { The powerful leaders in } \\
\text { government care very little } \\
\text { about the opinions of } \\
\text { women - reversed }\end{array}$ & $\begin{array}{l}\text { The powerful leaders in } \\
\text { government care very little } \\
\text { about the opinions of LGB } \\
\text { people - reversed }\end{array}$ & $\begin{array}{l}\text { The powerful leaders in } \\
\text { government care very little } \\
\text { about the opinions of } \\
\text { transgender people - } \\
\text { reversed }\end{array}$ \\
\hline 2. & $\begin{array}{l}\text { Certain racial-ethnic minority } \\
\text { groups don't have any say } \\
\text { about what the government } \\
\text { does - reversed }\end{array}$ & $\begin{array}{l}\text { Women don't have any } \\
\text { say about what the } \\
\text { government does - } \\
\text { reversed }\end{array}$ & $\begin{array}{l}\text { LGB people don't have any } \\
\text { say about what the } \\
\text { government does - reversed }\end{array}$ & $\begin{array}{l}\text { Transgender people don't } \\
\text { have any say about what } \\
\text { the government does - } \\
\text { reversed }\end{array}$ \\
\hline 3. & $\begin{array}{l}\text { Racial and ethnic minority } \\
\text { groups can successfully } \\
\text { influence what the } \\
\text { government does }\end{array}$ & $\begin{array}{l}\text { Women can successfully } \\
\text { influence what the } \\
\text { government does }\end{array}$ & $\begin{array}{l}\text { LGB people can } \\
\text { successfully influence what } \\
\text { the government does }\end{array}$ & $\begin{array}{l}\text { Transgender people can } \\
\text { successfully influence } \\
\text { what the government does }\end{array}$ \\
\hline
\end{tabular}


Table 4

Correlations among Emerging Adult Demographic Characteristics, Critical Reflection (CR), External Political Efficacy (PE), and Political Involvement.

\begin{tabular}{|c|c|c|c|c|c|c|c|c|c|c|c|c|c|c|c|c|c|c|c|c|c|c|}
\hline & 1 & 2 & 3 & 4 & 5 & 6 & 7 & 8 & 9 & 10 & 11 & 12 & 13 & 14 & 15 & 16 & 17 & 18 & 19 & 20 & 21 & 22 \\
\hline \multicolumn{23}{|l|}{ 1. Age } \\
\hline 2. Gender & $-.13^{* *}$ & & & & & & & & & & & & & & & & & & & & & \\
\hline 3. Black & .05 & .03 & & & & & & & & & & & & & & & & & & & & \\
\hline 4. White & $-.19^{* *}$ & .05 & $-.32^{* *}$ & & & & & & & & & & & & & & & & & & & \\
\hline 5. Asian & $.12^{* *}$ & $-.07^{*}$ & $-.13^{* *}$ & $-.54^{* *}$ & & & & & & & & & & & & & & & & & & \\
\hline 6. Hispanic & .04 & .03 & $-.11^{* *}$ & $-.45^{* *}$ & $-.18^{* *}$ & & & & & & & & & & & & & & & & & \\
\hline 7. Other & $.10^{* *}$ & $-.08^{*}$ & -.06 & $-.25^{* *}$ & $-.10^{* *}$ & $-.08^{*}$ & & & & & & & & & & & & & & & & \\
\hline 8. Sex. Orient. & -.02 & .06 & .01 & -.05 & -.01 & $.11^{* *}$ & -.04 & & & & & & & & & & & & & & & \\
\hline 9. Strain & $-.11^{* *}$ & .03 & $-.10^{* *}$ & $.15^{* *}$ & -.00 & $-.17^{* *}$ & .04 & -.03 & & & & & & & & & & & & & & \\
\hline 10. Parent Edu & $-.07^{*}$ & -.03 & -.04 & $.16^{* *}$ & .05 & $-.30^{* *}$ & .05 & -.03 & $.35^{* *}$ & & & & & & & & & & & & & \\
\hline \multicolumn{23}{|c|}{ Critical Reflection } \\
\hline 11. Race-CR & .05 & $.28^{* *}$ & $.13^{* *}$ & $-.27^{* *}$ & $.12^{* *}$ & $.17^{* *}$ & -.02 & $.26^{* *}$ & $-.12^{* *}$ & $-.09^{*}$ & & & & & & & & & & & & \\
\hline 12. Gend-CR & .02 & $.34^{* *}$ & $.12^{* *}$ & $-.24^{* *}$ & $.11^{* *}$ & $.17^{* *}$ & -.05 & $.27^{* *}$ & $-.13^{* *}$ & $-.09^{*}$ & $.89^{* *}$ & & & & & & & & & & & \\
\hline 13. LGB-CR & .03 & $.29^{* *}$ & $.10^{* *}$ & $-.23^{* *}$ & $.12^{* *}$ & $.15^{* *}$ & -.04 & $.27^{* *}$ & $-.10^{* *}$ & $-.07^{*}$ & $.87^{* *}$ & $.89^{* *}$ & & & & & & & & & & \\
\hline 14. Trans-CR & .06 & $.28^{* *}$ & $.10^{* *}$ & $-.22^{* *}$ & $.09^{* *}$ & $.17^{* *}$ & -.01 & $.33^{* *}$ & $-.08^{*}$ & -.06 & $.87^{* *}$ & $.84^{* *}$ & $.94^{* *}$ & & & & & & & & & \\
\hline \multicolumn{23}{|l|}{ Political Efficacy } \\
\hline 15. Race-PE & -.03 & $-.23^{* *}$ & $-.09^{* *}$ & $.19^{* *}$ & -.06 & $-.13^{* *}$ & -.02 & $-.18^{* *}$ & $.10^{* *}$ & $.10^{* *}$ & $-.66^{* *}$ & $-.60^{* *}$ & $-.57^{* *}$ & $-.55^{* *}$ & & & & & & & & \\
\hline 16. Gend-PE & .04 & $-.31^{* *}$ & $-.09^{* *}$ & $.14^{* *}$ & -.06 & $-.12^{* *}$ & .07 & $-.17^{* *}$ & $.14^{* *}$ & $.11^{* *}$ & $-.55^{* *}$ & $-.62^{* *}$ & $-.56^{* *}$ & $-.51^{* *}$ & $.62^{* *}$ & & & & & & & \\
\hline 17. LGB-PE & .02 & $-.18^{* *}$ & -.06 & $.12^{* *}$ & -.02 & $-.14^{* *}$ & .05 & $-.17^{* *}$ & $.11^{* *}$ & $.09^{* *}$ & $-.46^{* *}$ & $-.47^{* *}$ & $-.51^{* *}$ & $-.46^{* *}$ & $.62^{* *}$ & $.61^{* *}$ & & & & & & \\
\hline 18. Trans-PE & -.01 & $-.19^{* *}$ & -.06 & $.09^{* *}$ & -.01 & $-.10^{* *}$ & .04 & $-.23^{* *}$ & $.08^{*}$ & .02 & $-.53^{* *}$ & $-.50^{* *}$ & $-.55^{* *}$ & $-.57^{* *}$ & $.61^{* *}$ & $.58^{* *}$ & $.69^{* *}$ & & & & & \\
\hline \multicolumn{23}{|l|}{ Political Involv. } \\
\hline 19. Vote & $.11^{* *}$ & .04 & $-.07^{*}$ & $.07^{*}$ & $-.10^{* *}$ & $.08^{*}$ & -.02 & $.12^{* *}$ & .04 & .04 & $.13^{* *}$ & $.10^{* *}$ & $.12^{* *}$ & $.17^{* *}$ & -.02 & .00 & .01 & $-.08^{*}$ & & & & \\
\hline 20. Campaign & -.01 & .06 & .03 & -.03 & $-.10^{* *}$ & $.11^{* *}$ & .05 & $.18^{* *}$ & .01 & .05 & $.21^{* *}$ & $.22^{* *}$ & $.25^{* *}$ & $.26^{* *}$ & $-.13^{* *}$ & $-.11^{* *}$ & -.06 & $-.09^{* *}$ & $.33^{* *}$ & & & \\
\hline 21. Soc move. & .06 & $.16^{* *}$ & .06 & $-.08^{*}$ & $-.07^{*}$ & $.14^{* *}$ & .03 & $.27^{* *}$ & -.03 & .02 & $.43^{* *}$ & $.39^{* *}$ & $.42^{* *}$ & $.46^{* *}$ & $-.28^{* *}$ & $-.21^{* *}$ & $-.18^{* *}$ & $-.22^{* *}$ & $.41^{* *}$ & $.64^{* *}$ & & \\
\hline 22. Voice & -.01 & $.09^{*}$ & .03 & -.05 & $-.10^{* *}$ & $.12^{* *}$ & .06 & $.25^{* *}$ & -.01 & .04 & $.29^{* *}$ & $.27^{* *}$ & $.28^{* *}$ & $.32^{* *}$ & $-.19^{* *}$ & $-.12^{* *}$ & $-.11^{* *}$ & $-.15^{* *}$ & $.39^{* *}$ & $.58^{* *}$ & $.65^{* *}$ & \\
\hline 23. News Cons. & $.10^{* *}$ & -.03 & .01 & .01 & $-.08^{*}$ & .03 & $.08^{*}$ & $.10^{* *}$ & .06 & $.07^{*}$ & $.13^{* *}$ & $.09^{* *}$ & $.12^{* *}$ & $.13^{* *}$ & $-.07^{*}$ & -.04 & -.02 & -.05 & $.29^{* *}$ & $.40^{* *}$ & $.38^{* *}$ & $.43^{* *}$ \\
\hline
\end{tabular}

Notes: $* \mathrm{p}<.05, * * \mathrm{p}<.01$. Gender coded $0=$ male, $1=$ female. Sexual orientation coded $0=$ heterosexual, $1=$ gay, lesbian, or bisexual. Strain $=$ Financial Strain. Gend $=$ Gender. 
Table 5

Means, Standard Deviations, and Bivariate Correlations among Group-Based Critical Reflection Subscales.

\begin{tabular}{|c|c|c|c|c|c|c|c|c|c|c|c|c|c|c|c|c|c|c|c|c|c|}
\hline & $M$ & $S D$ & 1 & 2 & 3 & 4 & 5 & 6 & 7 & 8 & 9 & 10 & 11 & 12 & 13 & 14 & 15 & 16 & 17 & 18 & 19 \\
\hline \multicolumn{22}{|l|}{ Race-based CR } \\
\hline 1. Economic & 3.52 & 0.94 & - & & & & & & & & & & & & & & & & & & \\
\hline 2. Educational & 3.31 & 0.94 & $.79 * *$ & - & & & & & & & & & & & & & & & & & \\
\hline 3. Political & 3.68 & 0.90 & $.81^{* *}$ & $.70^{* *}$ & - & & & & & & & & & & & & & & & & \\
\hline 4. Legal & 3.79 & 0.92 & $.78^{* *}$ & $.73^{* *}$ & $.74^{* *}$ & - & & & & & & & & & & & & & & & \\
\hline 5. Assault/Vio & 3.70 & 0.84 & $.65^{* *}$ & $.54^{* *}$ & $.60^{* *}$ & $.67^{* *}$ & - & & & & & & & & & & & & & & \\
\hline \multicolumn{22}{|l|}{ Gender-based CR } \\
\hline 6. Economic & 3.26 & 0.92 & $.85^{* *}$ & $.70^{* *}$ & $.70^{* *}$ & $.71^{* *}$ & $.62^{* *}$ & - & & & & & & & & & & & & & \\
\hline 7. Educational & 2.80 & 0.86 & $.67^{* *}$ & $.77^{* *}$ & $.56^{* *}$ & $.59^{* *}$ & $.50^{* *}$ & $.74^{* *}$ & - & & & & & & & & & & & & \\
\hline 8. Political & 3.47 & 0.88 & $.71 * *$ & $.60^{* *}$ & $.82^{* *}$ & $.64^{* *}$ & $.55^{* *}$ & $.75^{* *}$ & $.57^{* *}$ & - & & & & & & & & & & & \\
\hline 9. Legal & 3.12 & 0.88 & $.68^{* *}$ & $.67^{* *}$ & $.63^{* *}$ & $.76^{* *}$ & $.61^{* *}$ & $.78^{* *}$ & $.71^{* *}$ & $.63^{* *}$ & - & & & & & & & & & & \\
\hline 10. Assault/Vio & 4.05 & 0.81 & $.57^{* *}$ & $.44^{* *}$ & $.52^{* *}$ & $.60^{* *}$ & $.76^{* *}$ & $.56^{* *}$ & $.39^{* *}$ & $.52^{* *}$ & $.51^{* *}$ & & & & & & & & & & \\
\hline \multicolumn{22}{|l|}{ LGB-based CR } \\
\hline 11. Economic & 3.11 & 0.89 & $.80 * *$ & $.64^{* *}$ & $.67^{* *}$ & $.66^{* *}$ & $.57^{* *}$ & $.81^{* *}$ & $.67^{* *}$ & $.64^{* *}$ & $.69^{* *}$ & $.48^{* *}$ & & & & & & & & & \\
\hline 12. Educational & 2.85 & 0.83 & $.64^{* *}$ & $.76^{* *}$ & $.55^{* *}$ & $.59^{* *}$ & $.49^{* *}$ & $.65^{* *}$ & $.81^{* *}$ & $.52^{* *}$ & $.66^{* *}$ & $.38^{* *}$ & $.76^{* *}$ & & & & & & & & \\
\hline 13. Political & 3.68 & 0.83 & $.70 * *$ & $.57^{* *}$ & $.82^{* *}$ & $.67^{* *}$ & $.60^{* *}$ & $.67^{* *}$ & $.52^{* *}$ & $.79^{* *}$ & $.59^{* *}$ & $.56^{* *}$ & $.73^{* *}$ & $.57^{* *}$ & & & & & & & \\
\hline 14. Legal & 3.42 & 0.89 & $.70 * *$ & $.68^{* *}$ & $.68^{* *}$ & $.80^{* *}$ & $.63^{* *}$ & $.72^{* *}$ & $.66^{* *}$ & $.62^{* *}$ & $.82^{* *}$ & $.55^{* *}$ & $.77^{* *}$ & $.70^{* *}$ & $.69^{* *}$ & & & & & & \\
\hline 15. Assault/Vio & 3.66 & 0.89 & $.62 * *$ & $.51^{* *}$ & $.56^{* *}$ & $.63^{* *}$ & $.80^{* *}$ & $.60^{* *}$ & $.51^{* *}$ & $.55^{* *}$ & $.60^{* *}$ & $.72^{* *}$ & $.61^{* *}$ & $.53^{* *}$ & $.59^{* *}$ & $.67^{* *}$ & & & & & \\
\hline \multicolumn{22}{|l|}{ Trans-based CR } \\
\hline 16. Economic & 3.41 & 0.91 & $.81^{* *}$ & $.66^{* *}$ & $.69^{* *}$ & $.71^{* *}$ & $.61^{* *}$ & $.76^{* *}$ & $.61^{* *}$ & $.62^{* *}$ & $.65^{* *}$ & $.53^{* *}$ & $.88^{* *}$ & $.70^{* *}$ & $.74^{* *}$ & $.76^{* *}$ & $.65^{* *}$ & & & & \\
\hline 17. Educational & 3.05 & 0.89 & $.65^{* *}$ & $.76^{* *}$ & $.56^{* *}$ & $.61^{* *}$ & $.50^{* *}$ & $.62^{* *}$ & $.76^{* *}$ & $.51^{* *}$ & $.63^{* *}$ & $.41^{* *}$ & $.71^{* *}$ & $.90^{* *}$ & $.58^{* *}$ & $.69^{* *}$ & $.55^{* *}$ & $.75^{* *}$ & & & \\
\hline 18. Political & 3.86 & 0.83 & $.69 * *$ & $.56^{* *}$ & $.80^{* *}$ & $.67^{* *}$ & $.58^{* *}$ & $.62^{* *}$ & $.48^{* *}$ & $.74^{* *}$ & $.53^{* *}$ & $.55^{* *}$ & $.65^{* *}$ & $.52^{* *}$ & $.91^{* *}$ & $.66^{* *}$ & $.58^{* *}$ & $.75^{* *}$ & $.59^{* *}$ & & \\
\hline 19. Legal & 3.56 & 0.90 & $.69 * *$ & $.67^{* *}$ & $.67^{* *}$ & $.81^{* *}$ & $.63^{* *}$ & $.69^{* *}$ & $.62^{* *}$ & $.61^{* *}$ & $.78^{* *}$ & $.56^{* *}$ & $.72^{* *}$ & $.66^{* *}$ & $.68^{* *}$ & $.92^{* *}$ & $.69^{* *}$ & $.79^{* *}$ & $.71^{* *}$ & $.70^{* *}$ & \\
\hline 20. Assault/Vio & 3.70 & 0.91 & $.61^{* *}$ & $.52^{* *}$ & $.56^{* *}$ & $.62^{* *}$ & $.75^{* *}$ & $.58^{* *}$ & $.48^{* *}$ & $.55^{* *}$ & $.56^{* *}$ & $.69^{* *}$ & $.58^{* *}$ & $.51^{* *}$ & $.58^{* *}$ & $.64^{* *}$ & $.92^{* *}$ & $.66^{* *}$ & $.56^{* *}$ & $.59^{* *}$ & $.70^{* *}$ \\
\hline
\end{tabular}

Notes: $* \mathrm{p}<.05, * * \mathrm{p}<.01$ 
Table 6

Means, Standard Deviations, and Bivariate Correlations among External Political Efficacy Items

\begin{tabular}{|c|c|c|c|c|c|c|c|c|c|c|c|c|c|}
\hline & $\mathrm{M}$ & SD & 1. & 2. & 3. & 4. & 5. & 6. & 7. & 8. & 9. & 10. & 11. \\
\hline \multicolumn{14}{|l|}{ Race-based PE } \\
\hline 1. Opinion & 2.67 & 1.12 & & & & & & & & & & & \\
\hline 2. Have a say & 2.89 & 1.14 & $.63^{* *}$ & & & & & & & & & & \\
\hline 3. Influence & 3.24 & 1.01 & $.18^{* *}$ & $.22^{* *}$ & & & & & & & & & \\
\hline \multicolumn{14}{|c|}{ Gender-based PE } \\
\hline 4. Opinion & 2.91 & 1.13 & $.66^{* *}$ & $.48^{* *}$ & $.15^{* *}$ & & & & & & & & \\
\hline 5. Have a say & 3.65 & .99 & $.41^{* *}$ & $.45^{* *}$ & $.26^{* *}$ & $.59^{* *}$ & & & & & & & \\
\hline $\begin{array}{l}\text { 6. Influence } \\
\text { LGB-based PE }\end{array}$ & 3.62 & .92 & $.18^{* *}$ & $.16^{* *}$ & $.47^{* *}$ & $.26^{* *}$ & $.37^{* *}$ & & & & & & \\
\hline 7. Opinion & 2.71 & 1.03 & $.63^{* *}$ & $.45^{* *}$ & $.15^{* *}$ & $.61^{* *}$ & $.37^{* *}$ & $.20^{* *}$ & & & & & \\
\hline 8. Have a say & 3.38 & .98 & $.39^{* *}$ & $.46^{* *}$ & $.27^{* *}$ & $.41^{* *}$ & $.51^{* *}$ & $.30^{* *}$ & $.52^{* *}$ & & & & \\
\hline 9. Influence & 3.23 & .93 & $.14^{* *}$ & $.21^{* *}$ & $.46^{* *}$ & $.12^{* *}$ & $.26^{* *}$ & $.43^{* *}$ & $.18^{* *}$ & $.38^{* *}$ & & & \\
\hline \multicolumn{14}{|l|}{ Trans-based PE } \\
\hline 10. Opinion & 2.45 & 1.02 & $.58^{* *}$ & $.45^{* *}$ & $.15^{* *}$ & $.61^{* *}$ & $.37^{* *}$ & $.16^{* *}$ & $.68^{* *}$ & $.40^{* *}$ & $.15^{* *}$ & & \\
\hline 11. Have a say & 3.14 & 1.05 & $.37^{* *}$ & $.50^{* *}$ & $.27^{* *}$ & $.40^{* *}$ & $.50^{* *}$ & $.26^{* *}$ & $.43^{* *}$ & $.58^{* *}$ & $.32^{* *}$ & $.52^{* *}$ & \\
\hline 12. Influence & 2.99 & .99 & $.16^{* *}$ & $.21^{* *}$ & $.45^{* *}$ & $.16^{* *}$ & $.24^{* *}$ & $.37^{* *}$ & $.20^{* *}$ & $.31^{* *}$ & $.51^{* *}$ & $.22^{* *}$ & $.39^{* *}$ \\
\hline
\end{tabular}

Notes. $* p<.05, * * p<.01$ 
Table 7

Measurement Model Comparisons Testing Factor Structure of Critical Reflection and External Political Efficacy

\begin{tabular}{lccccccc}
\hline & $\chi^{2}$ & df & $\Delta \chi^{2}$ & $\Delta$ df & p value & RMSEA 90\% CI [ ] & CFI \\
\hline Critical Reflection & & & & & & & \\
\hline Model 1a: Single-Factor & 2604.45 & 140 & & & & $.142[.137, .147]$ & .897 \\
Model 1b: Separate Correlated Four-Factor & $\mathbf{7 3 4 . 7 4}$ & $\mathbf{1 3 4}$ & $\mathbf{1 8 6 9 . 7 0 8}$ & $\mathbf{6}$ & $<.0001$ & $\mathbf{. 0 7 2}[.067, .077]$ & $\mathbf{. 9 7 5}$ \\
Model 1c: Second-order factor & 901.51 & 136 & 166.764 & 2 & $<.0001$ & $.080[.075, .085]$ & .968 \\
\hline External Political Efficacy & & & & & & \\
Model 2a: Single-Factor & 568.23 & 42 & & & & $.120[.111, .129]$ & .890 \\
Model 2b: Separate Correlated Four-Factor & $\mathbf{1 0 3 . 2 6}$ & $\mathbf{3 6}$ & $\mathbf{4 6 4 . 9 7}$ & $\mathbf{6}$ & $<.0001$ & $\mathbf{. 0 4 6}[.036, .057]$ & $\mathbf{. 9 8 6}$ \\
Model 2c: Second-order factor & 115.87 & 38 & 12.62 & 2 & .002 & $.048[.039, .059]$ & .984 \\
\hline
\end{tabular}


Table 8

Latent Means, Standard Deviations, and Standardized Factor Loadings of Indicator Variables Representing Subscales of Group-based Critical Reflection (CR).

\begin{tabular}{lcccc}
\hline & Race CR & Gender CR & LGB CR & Trans CR \\
\hline & \multicolumn{4}{c}{ Latent Means (SD) } \\
\cline { 2 - 5 } Indicators & $3.60(.75)_{\mathrm{a}}$ & $3.34(.68)_{\mathrm{b}}$ & $3.34(.69)_{\mathrm{b}}$ & $3.52(.71)_{\mathrm{d}}$ \\
\cline { 2 - 5 } & \multicolumn{4}{c}{ Factor Loadings } \\
Economic & .95 & .93 & .90 & .93 \\
Educational & .84 & .79 & .79 & .81 \\
Political & .84 & .79 & .80 & .79 \\
Legal & .87 & .84 & .86 & .86 \\
Assault & .65 & .54 & .66 & .67 \\
\hline
\end{tabular}


Table 9

Correlations among Latent Variables Representing Group-based Critical Reflection (CR).

\begin{tabular}{|c|c|c|c|}
\hline & 2 & 3 & 4 \\
\hline 1. Race-based CR & $.91 * * *$ & $.89 * * *$ & $.88 * * *$ \\
\hline 2. Gender-based CR & & $.91 * * *$ & $.87 * * *$ \\
\hline 3. LGB-based CR & & & $.95 * * *$ \\
\hline 4. Trans-based CR & & & \\
\hline
\end{tabular}

Note. $* * * \mathrm{p}<.001$ 
Table 10

Latent Means, Standard Deviations, and Standardized Factor Loadings of Indicator Variables Representing Subscales of Group-based Political Efficacy (PE).

\begin{tabular}{lcccc}
\hline & \multicolumn{1}{c}{ Race PE } & Gender PE & LGB PE & Trans PE \\
\cline { 2 - 5 } & \multicolumn{4}{c}{ Latent Means (SD) } \\
\cline { 2 - 5 } Indicators & $2.93(.68)_{\mathrm{a}}$ & $3.40(.66)_{\mathrm{b}}$ & $3.11(.61)_{\mathrm{c}}$ & $2.86(.65)_{\mathrm{d}}$ \\
\cline { 2 - 5 } Item 1 (opinions) & .70 & .71 & .63 & .62 \\
Item 2 (have a say) & .82 & .83 & .84 & .86 \\
Item 3 (Influence) & .33 & .40 & .40 & .41 \\
\hline
\end{tabular}


Table 11

Correlations among Latent Variables Representing Group-based Political Efficacy (PE).

\begin{tabular}{|c|c|c|c|}
\hline & 2 & 3 & 4 \\
\hline 1. Race-based PE & $.71 * * *$ & $.70 * * *$ & $.70 * * *$ \\
\hline 2. Gender-based PE & & $.72 * * *$ & $.69 * * *$ \\
\hline 3. LGB-based PE & & & $.81 * * *$ \\
\hline 4. Trans-based PE & & & \\
\hline
\end{tabular}

Note. $* * * \mathrm{p}<.001$ 
Table 12

Measurement Invariance Tests for Critical Reflection and External Political Efficacy across Emerging Adult Demographics Characteristics.

\begin{tabular}{|c|c|c|c|c|}
\hline \multicolumn{5}{|c|}{ Critical Reflection } \\
\hline & $\chi^{2}$ & df & CFI & $\triangle \mathrm{CFI}$ \\
\hline \multicolumn{5}{|c|}{ By Race (Black, Hispanic, Asian, White) } \\
\hline Configural & 1288.07 & 536 & .966 & \\
\hline Factorial Invariance & 1341.91 & 584 & .966 & .000 \\
\hline Intercept Invariance & 1449.73 & 632 & .963 & .003 \\
\hline \multicolumn{5}{|c|}{ By Gender (male vs. female) } \\
\hline Configural & 837.90 & 268 & .974 & \\
\hline Factorial Invariance & 863.35 & 284 & .974 & .001 \\
\hline Intercept Invariance & 979.33 & 300 & .969 & .002 \\
\hline \multicolumn{5}{|c|}{ By Sexual Orientation (heterosexual vs. LGB) } \\
\hline Configural & 892.70 & 268 & .972 & \\
\hline Factorial Invariance & 924.57 & 284 & .971 & .001 \\
\hline Intercept Invariance & 1009.47 & 300 & .968 & .003 \\
\hline \multicolumn{5}{|c|}{ External Political Efficacy } \\
\hline & $\chi^{2}$ & df & CFI & $\Delta \mathrm{CFI}$ \\
\hline \multicolumn{5}{|c|}{ By Race (Black, Hispanic, Asian, White) } \\
\hline Configural & 212.57 & 144 & .985 & \\
\hline Factorial Invariance & 246.72 & 168 & .982 & .003 \\
\hline Intercept Invariance & 306.30 & 192 & .974 & .008 \\
\hline \multicolumn{5}{|c|}{ By Gender (male vs. female) } \\
\hline Configural & 167.393 & 70 & .978 & \\
\hline Factorial Invariance & 178.001 & 78 & .978 & .000 \\
\hline Intercept Invariance & 218.862 & 86 & .970 & .008 \\
\hline \multicolumn{5}{|c|}{ By Sexual Orientation (heterosexual vs. LGB) } \\
\hline Configural & 144.81 & 70 & .984 & \\
\hline Factorial Invariance & 169.82 & 78 & .980 & .004 \\
\hline Intercept Invariance & 213.92 & 86 & .972 & .008 \\
\hline
\end{tabular}


Table 13

Latent Mean Differences in Critical Reflection and Political Efficacy by Emerging Adult Gender, Racelethnicity, and Sexual Orientation.

\begin{tabular}{|c|c|c|c|c|c|c|c|c|}
\hline & \multicolumn{2}{|c|}{ Gender } & \multicolumn{4}{|c|}{$\underline{\text { Race/Ethnicity }}$} & \multicolumn{2}{|c|}{$\underline{\text { Sexual Orientation }}$} \\
\hline & Women & Men & Hispanic & Black & Asian & White & LGB & Heterosexual \\
\hline \multicolumn{9}{|l|}{ Critical Reflection } \\
\hline Race-based & $3.7(0.69)_{\mathrm{a}}$ & $3.28(0.81)_{\mathrm{b}}$ & $3.93(0.71)_{\mathrm{abc}}$ & $3.96(0.7)_{\mathrm{abc}}$ & $3.81(0.71)_{\mathrm{abc}}$ & $3.4(0.71)_{\mathrm{d}}$ & $4.11(0.62)_{\mathrm{a}}$ & $3.51(0.74)_{b}$ \\
\hline Gender-based & $3.46(0.59)_{\mathrm{a}}$ & $2.96(0.72)_{\mathrm{b}}$ & $3.64(0.63)_{\mathrm{abc}}$ & $3.65(0.63)_{\mathrm{abc}}$ & $3.51(0.65)_{\mathrm{abc}}$ & $3.18(0.63)_{\mathrm{d}}$ & $3.82(0.54)_{a}$ & $3.25(0.66)_{b}$ \\
\hline LGB-Based & $3.45(0.63)_{\mathrm{a}}$ & $3.03(0.72)_{\mathrm{b}}$ & $3.62(0.67)_{\mathrm{abc}}$ & $3.6(0.67)_{a b c}$ & $3.53(0.66)_{\mathrm{abc}}$ & $3.19(0.66)_{\mathrm{d}}$ & $3.85(0.58)_{a}$ & $3.26(0.67)_{b}$ \\
\hline Trans-Based & $3.62(0.66)_{a}$ & $3.2(0.73)_{\mathrm{b}}$ & $3.82(0.68)_{\mathrm{abc}}$ & $3.77(0.67)_{\mathrm{abc}}$ & $3.66(0.68)_{\mathrm{abc}}$ & $3.37(0.69)_{\mathrm{d}}$ & $4.14(0.58) \mathrm{a}$ & $3.41(0.68)_{b}$ \\
\hline 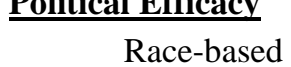 & & & & $268(066)$ & & & $266(062)$ & $208(067)$ \\
\hline $\begin{array}{r}\text { Kace-based } \\
\text { Gender-based }\end{array}$ & $3.28(0.63)_{a}$ & $\begin{array}{l}3.1 /(0.08)_{b} \\
3.75(0.62)_{b}\end{array}$ & $\begin{array}{l}2.08(0.01)_{\mathrm{abc}} \\
3.23(0.67)_{\mathrm{abc}}\end{array}$ & $\begin{array}{l}2.08(0.00)_{\mathrm{abc}} \\
3.14(0.69)_{\mathrm{abc}}\end{array}$ & $\begin{array}{l}2.18(0.05) \mathrm{abc} \\
3.29(0.66)_{\mathrm{abc}}\end{array}$ & $\begin{array}{l}3.08(0.00)_{\mathrm{d}} \\
3.48(0.63)_{\mathrm{d}}\end{array}$ & $\begin{array}{l}2.00(0.02) \mathrm{a} \\
3.18(0.73)_{\mathrm{a}}\end{array}$ & $3.44(0.65)_{b}$ \\
\hline LGB-Based & $3.06(0.61)_{\mathrm{a}}$ & $3.26(0.6)_{\mathrm{b}}$ & $2.92(0.65)_{\mathrm{ab}}$ & $2.94(0.54)_{\mathrm{ab}, \mathrm{c}}$ & $3.05(0.57)_{\mathrm{c}, \mathrm{d}}$ & $3.17(0.61)_{\mathrm{c}, \mathrm{d}}$ & $2.9(0.69)_{a}$ & $3.14(0.6)_{\mathrm{b}}$ \\
\hline Trans-Based & $2.79(0.64)_{\mathrm{a}}$ & $3.04(0.6)_{\mathrm{b}}$ & $2.69(0.57)_{\mathrm{ab}}$ & $2.69(0.63)_{\mathrm{ab}, \mathrm{c}}$ & $2.8(0.63)_{\mathrm{c}, \mathrm{d}}$ & $2.91(0.65)_{\mathrm{c}, \mathrm{d}}$ & $2.5(0.68)_{\mathrm{a}}$ & $2.91(0.62)_{b}$ \\
\hline
\end{tabular}

Note. Means with different subscripts indicate significant mean differences between groups. Standard deviations are reported in parentheses. 
Table 14

Unstandardized Estimates and Standard Errors of Structural Model Testing Associations among Critical Reflection and Political Involvement

\begin{tabular}{|c|c|c|c|c|c|c|c|c|c|c|}
\hline & \multicolumn{4}{|c|}{$\underline{\text { Social Movement }}$} & \multicolumn{6}{|c|}{$\underline{\text { Standard Political Involvement }}$} \\
\hline & \multicolumn{2}{|c|}{ Activism } & \multicolumn{2}{|c|}{ Political Voice } & \multicolumn{2}{|c|}{ Voting } & \multicolumn{2}{|c|}{ News Consumption. } & \multicolumn{2}{|c|}{ Campaign } \\
\hline & $B$ & $S E$ & $B$ & $S E$ & $B$ & $S E$ & $B$ & $S E$ & $B$ & $S E$ \\
\hline \multicolumn{11}{|l|}{ Covariates } \\
\hline Parent Education & $.08 *$ & .03 & $.11 *$ & .04 & $.06^{+}$ & .03 & $.08 *$ & .03 & $.09 * *$ & .03 \\
\hline Age & .02 & .02 & -.02 & .02 & $.06 * *$ & .02 & $.05 * *$ & .02 & -.02 & .02 \\
\hline Gender (female) & .16 & .09 & .05 & .12 & .03 & .09 & $-.15^{+}$ & .09 & -.06 & .09 \\
\hline Black & .00 & .15 & .01 & .19 & $-.45 * *$ & .15 & -.12 & .15 & .04 & .15 \\
\hline Hispanic & $.27 *$ & .12 & $.35 *$ & .16 & .07 & .12 & .03 & .12 & $.32 *$ & .13 \\
\hline Asian & $-.32 * *$ & .11 & $-.40 * *$ & .13 &.$- .40 * * *$ & .10 & $-.36 * * *$ & .10 & $-.31 * *$ & .11 \\
\hline Other & .16 & .19 & $.42^{+}$ & .24 & -.30 & .18 & .27 & .18 & .27 & .19 \\
\hline LGB & $.47 * * *$ & .12 & $.70 * * *$ & .15 & .18 & .11 & $.22^{+}$ & .11 & $.36^{* *}$ & .12 \\
\hline \multicolumn{11}{|l|}{ Critical Reflection } \\
\hline Race-based & .22 & .17 & .22 & .21 & .09 & .16 & $.29^{+}$ & .16 & -.17 & .17 \\
\hline Gender-based & -.00 & .19 & -.13 & .25 & -.13 & .18 & -.24 & .19 & .03 & .20 \\
\hline LGB-based & -.45 & .28 & -.26 & .36 & -.45 & .27 & .08 & .27 & .23 & .29 \\
\hline Trans-based & $.92 * * *$ & .24 & $.68 *$ & .31 & $.68 * *$ & .23 & .07 & .23 & .28 & .24 \\
\hline
\end{tabular}

Note. $* * * \mathrm{p}<.001, * * \mathrm{p}<.01, * \mathrm{p}<.05$ 
Table 15

Unstandardized Estimates and Standard Errors of Structural Model Testing Associations among External Political Efficacy and Political Involvement

\begin{tabular}{|c|c|c|c|c|c|c|c|c|c|c|}
\hline & \multicolumn{4}{|c|}{ Social Movement } & \multicolumn{6}{|c|}{ Standard Political Involvement } \\
\hline & \multicolumn{2}{|c|}{ Activism } & \multicolumn{2}{|c|}{ Political Voice } & \multicolumn{2}{|c|}{ Voting } & \multicolumn{2}{|c|}{ News Consum. } & \multicolumn{2}{|c|}{ Campaign } \\
\hline & $B$ & $S E$ & $B$ & $S E$ & $B$ & $S E$ & $B$ & $S E$ & $B$ & $S E$ \\
\hline \multicolumn{11}{|l|}{ Covariates } \\
\hline Parent Education & $.09 *$ & .03 & $.11 *$ & .04 & .05 & .03 & $.09 * *$ & .03 & $.09 * *$ & .04 \\
\hline Age & $.03^{+}$ & .02 & -.00 & .03 & $.07 * * *$ & .02 & $.06 * *$ & .02 & -.01 & .02 \\
\hline Gender (female) & $.35 * * *$ & .09 & .21 & .12 & .11 & .09 & -.11 & .09 & .03 & .10 \\
\hline Black & .17 & .16 & .15 & .20 & $-.36 *$ & .15 & -.06 & .15 & .09 & .16 \\
\hline Hispanic & $.43 * *$ & .13 & $.47 * *$ & .16 & .15 & .12 & .10 & .12 & $.40 * *$ & .13 \\
\hline Asian & $-.19^{+}$ & .11 & $-.29 *$ & .14 & $-.34 * *$ & .10 & $-.31 * *$ & .11 & $-.24 *$ & .11 \\
\hline Other & .21 & .2 & $.46^{+}$ & .25 & -.23 & .19 & $.31^{+}$ & .19 & .29 & .20 \\
\hline LGB & $.80 * * *$ & .12 & $.95 * * *$ & .15 & $.33 * *$ & .11 & $.33 * *$ & .12 & $.52 * * *$ & .12 \\
\hline \multicolumn{11}{|l|}{ Political Efficacy } \\
\hline Race-based & $-.47 * * *$ & .13 & $-.42 * *$ & .15 & .01 & .11 & -.15 & .12 & -.16 & .12 \\
\hline Gender-based & .05 & .13 & .16 & .15 & .05 & .11 & -.08 & .12 & -.11 & .12 \\
\hline LGB-based & .21 & .17 & .19 & .21 & $.35 *$ & .15 & .10 & .16 & .22 & .16 \\
\hline Trans-based & -.09 & .17 & -.11 & .21 & $-.36 *$ & .15 & .07 & .16 & -.09 & .16 \\
\hline
\end{tabular}


Table 16

Unstandardized Estimates and Standard Errors for Critical Reflection (CR) X Political Efficacy (PE) Interactions Predicting Political Action

\begin{tabular}{|c|c|c|c|c|c|c|c|c|c|c|}
\hline & \multicolumn{4}{|c|}{ Social Movement } & \multicolumn{6}{|c|}{ Standard Political Involvement } \\
\hline & \multicolumn{2}{|c|}{ Activism } & \multicolumn{2}{|c|}{ Political Voice } & \multicolumn{2}{|c|}{ Voting } & \multicolumn{2}{|c|}{ News Consum. } & \multicolumn{2}{|c|}{ Campaign } \\
\hline & $B$ & $S E$ & $B$ & $S E$ & $B$ & $S E$ & $B$ & $S E$ & $B$ & $S E$ \\
\hline Race-based CR X PE & $-.12 * *$ & .04 & $-.21 * * *$ & .04 & $-.13 * * *$ & .04 & $-.20 * * *$ & .03 & -.06 & .04 \\
\hline Gender-based CR X PE & $-.15 * *$ & .05 & $-.26 * * *$ & .05 & $-.08^{+}$ & .05 & $-.16 * * *$ & .04 & $-.15 * *$ & .05 \\
\hline LGB-based CR X PE & $-.14 * *$ & .05 & $-.21 * * *$ & .05 & $-.11 * *$ & .04 & $-.18 * * *$ & .04 & -.06 & .05 \\
\hline Trans-based CR X PE & $-.15 * * *$ & .04 & $-.21 * * *$ & .05 & $-.10 * *$ & .04 & $-.19 * * *$ & .04 & $-.09^{+}$ & .05 \\
\hline
\end{tabular}

Note. $* * * \mathrm{p}<.001, * * \mathrm{p}<.01, * \mathrm{p}<.05$ 
Table 17

Model Comparisons Testing Three-Way Interactions: Group-specific CR X PE by Demographics

\begin{tabular}{|c|c|c|c|c|}
\hline & $\begin{array}{l}\text { Loglikelihood } \\
\text { Value }\end{array}$ & df & $\begin{array}{c}\text { Scaling } \\
\text { Correction }\end{array}$ & $\Delta \chi^{2}(\mathrm{df})$ \\
\hline \multicolumn{5}{|c|}{ Race-based CR X PE By Race/Ethnicity } \\
\hline Constrained & -26042.42 & 274 & & \\
\hline Unconstrained & -25963.45 & 404 & .9393 & $\Delta \chi^{2}(130)=168.15, p=.01$ \\
\hline \multicolumn{5}{|c|}{ Gender-based CR X PE By Gender } \\
\hline Constrained & -29271.61 & 276 & & \\
\hline Unconstrained & -29219.14 & 356 & .9926 & $\Delta \chi^{2}(80)=105.74, p=.02$ \\
\hline \multicolumn{5}{|c|}{ LGB-based CR X PE By Sexual Orientation } \\
\hline Constrained & -29381.78 & 242 & & \\
\hline Unconstrained & -29360.48 & 297 & .7885 & $\Delta \chi^{2}(55)=54.02, p=.51$ \\
\hline
\end{tabular}




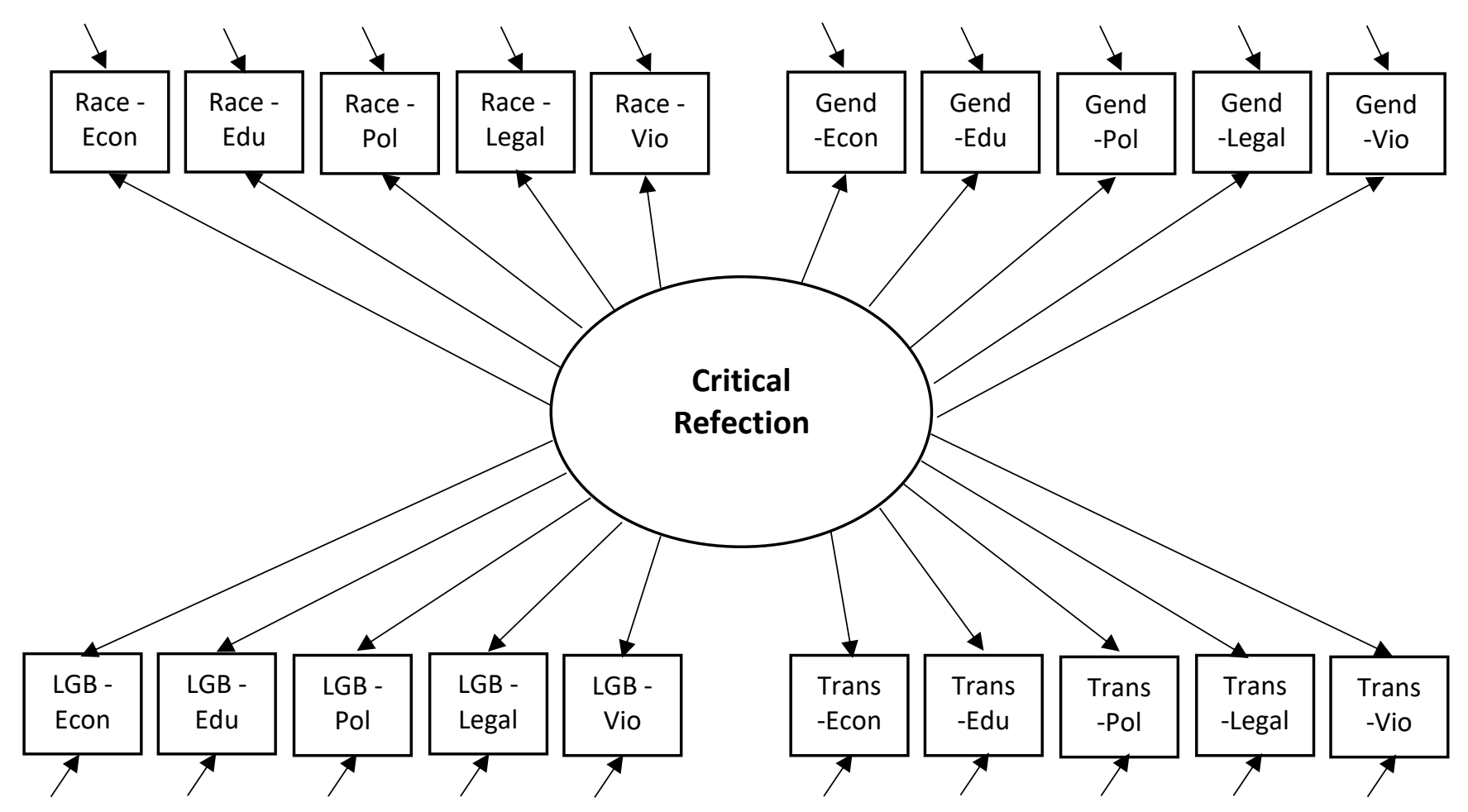

Figure 1a. First-order single factor measurement model for critical reflection (Model 1a).

Econ $=$ Economic constraints. Edu $=$ Educational constraints. Pol = Political constraints. Leg = Legal barriers. Vio = Violence/Assault. 

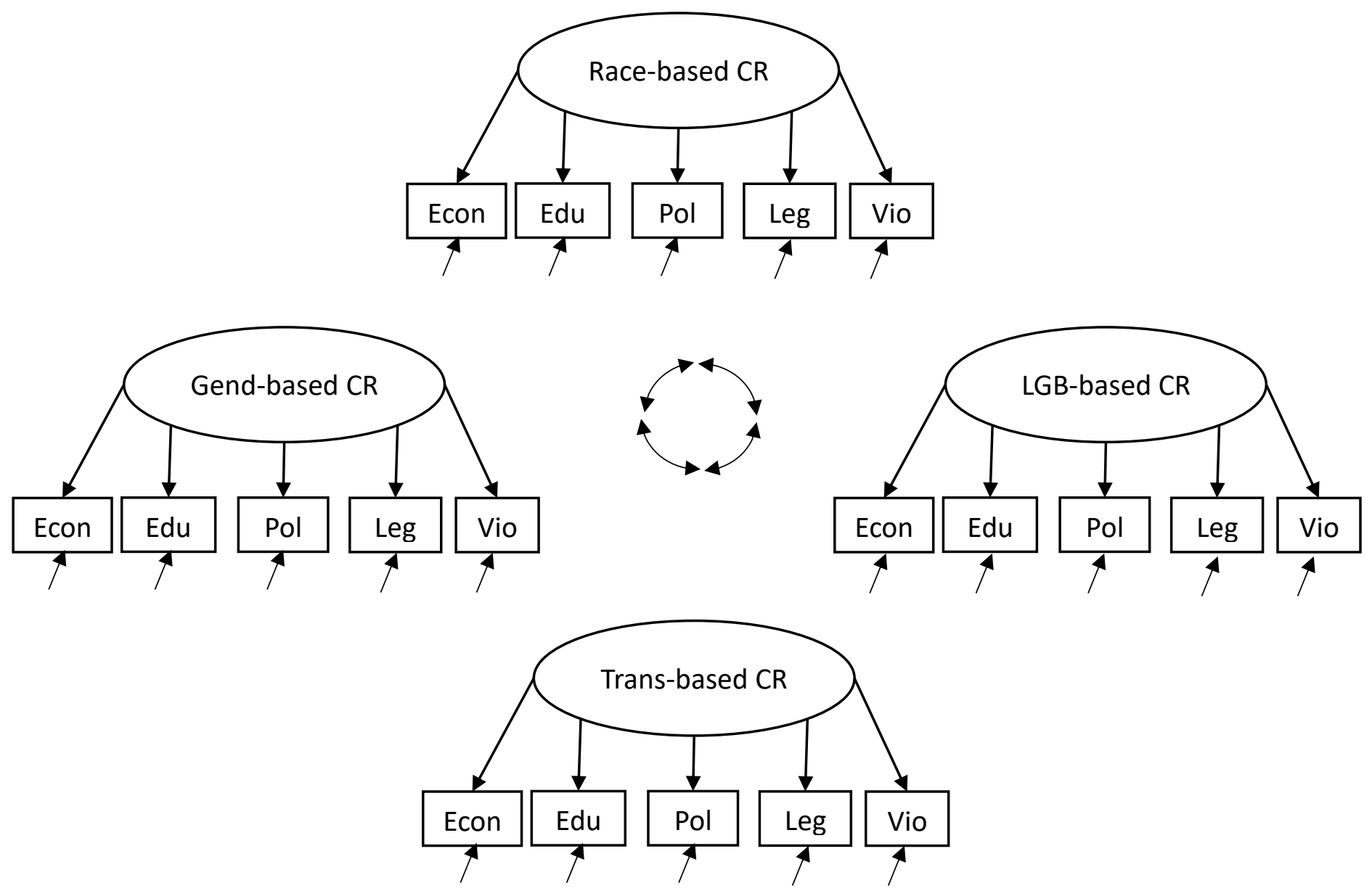

Figure 1 b. Separate correlated four-factor measurement model for critical reflection (CR; Model 1b). 


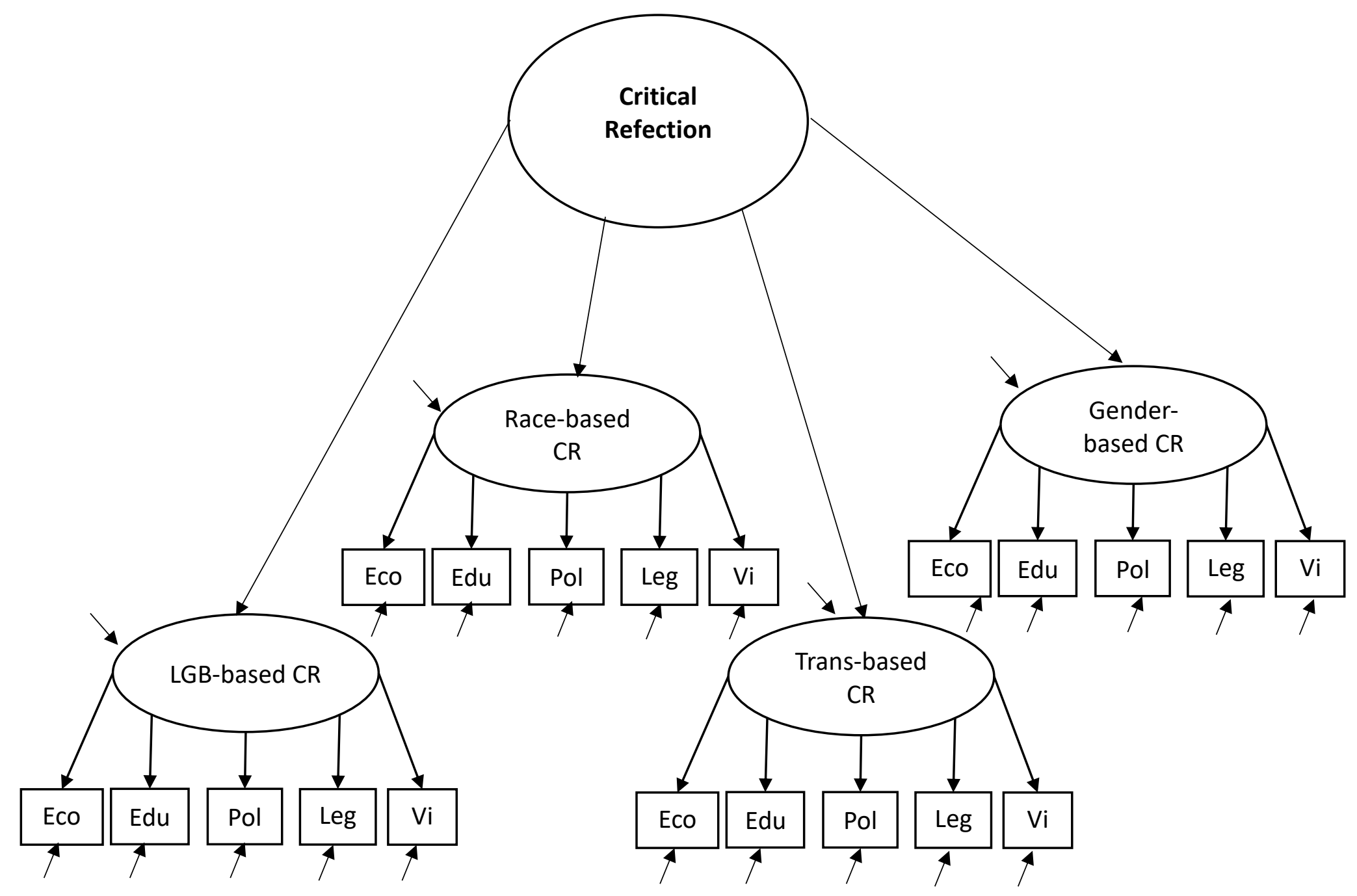

Figure 1c. Higher-order latent variable measurement model for critical reflection (CR; Model 1c). 


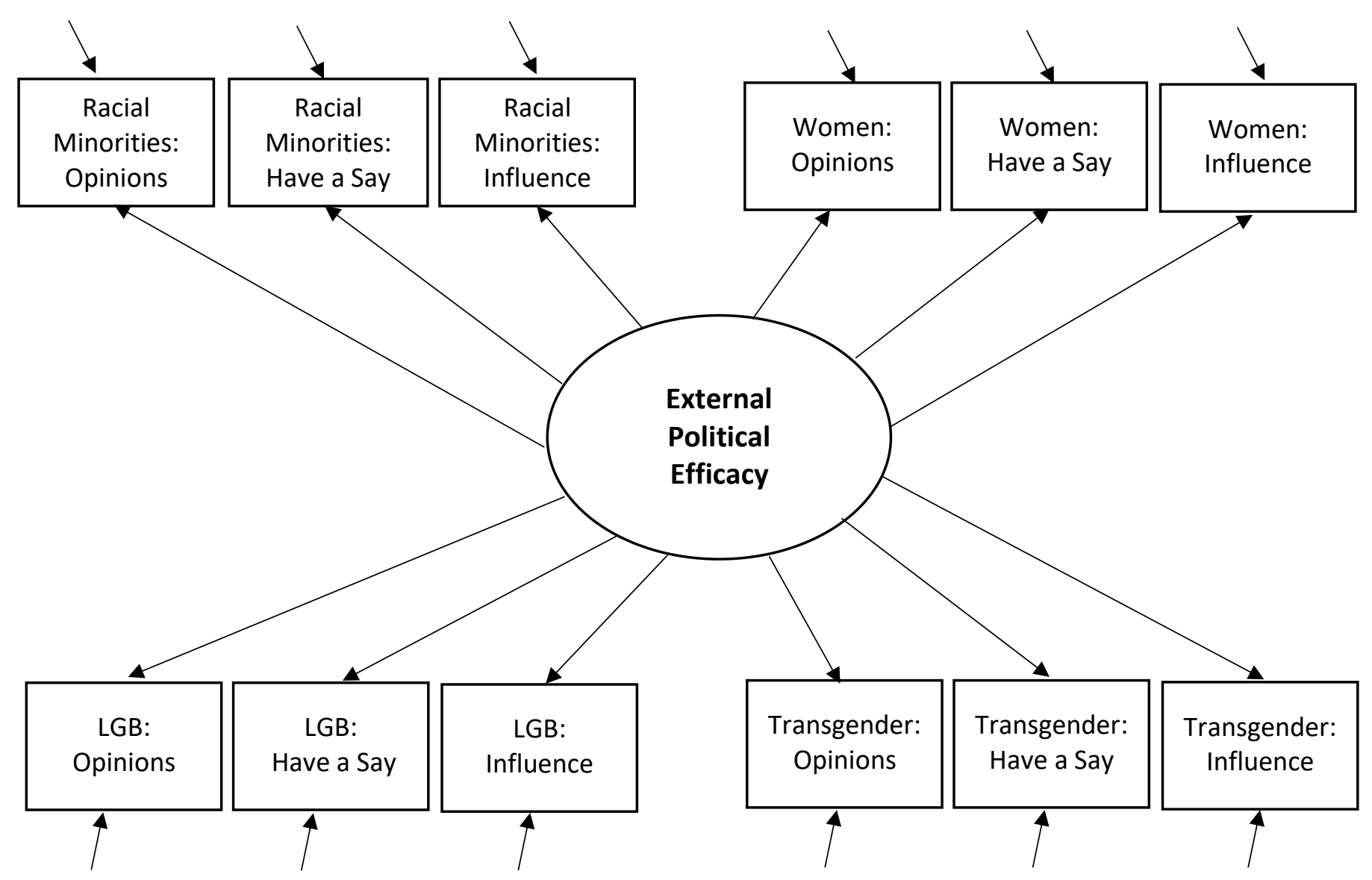

Figure 2a. First-order single factor measurement model for external political efficacy (Model 2a). 

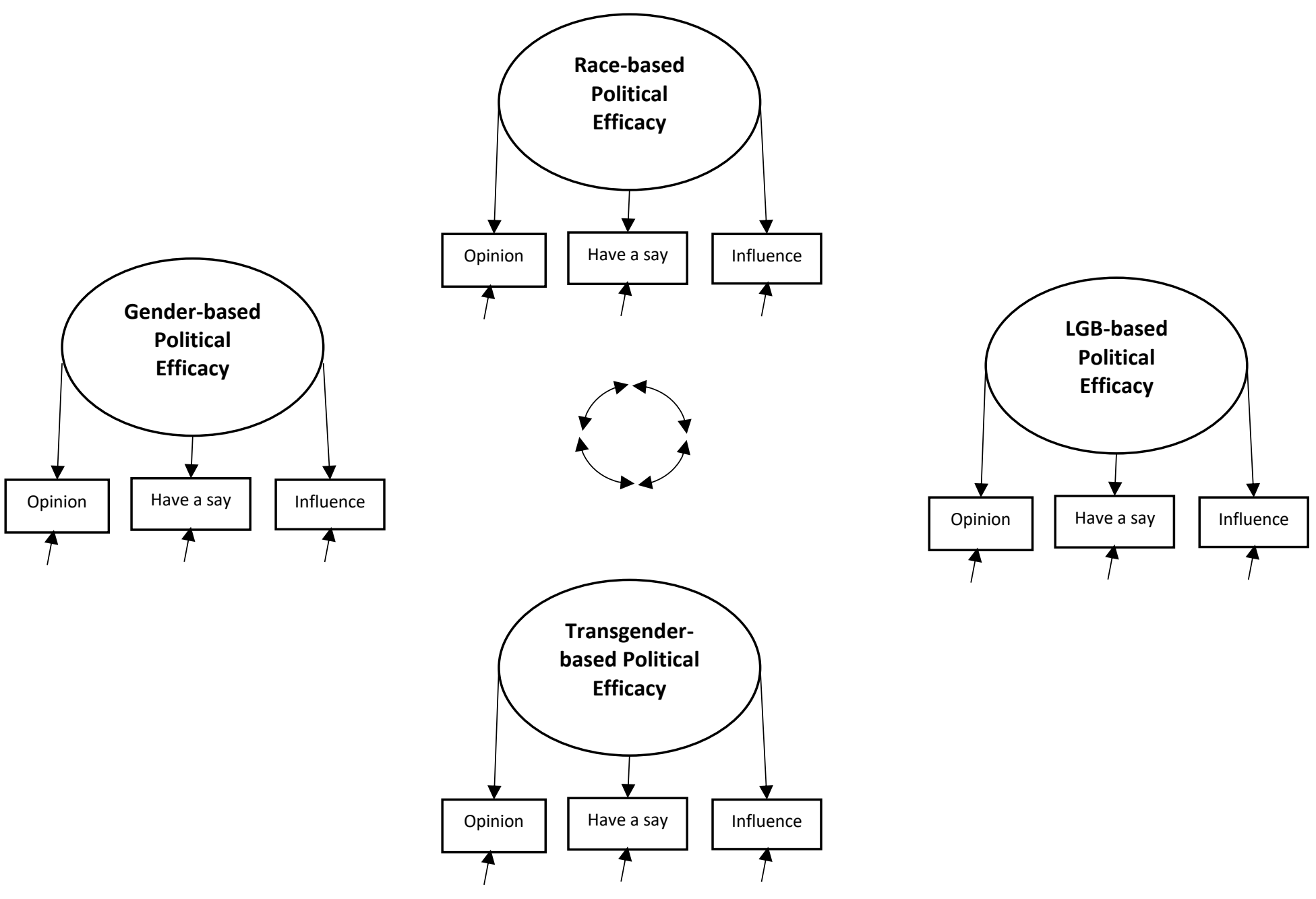

Figure $2 b$. Separate correlated four-factor measurement model for external political efficacy (Model 2b). 


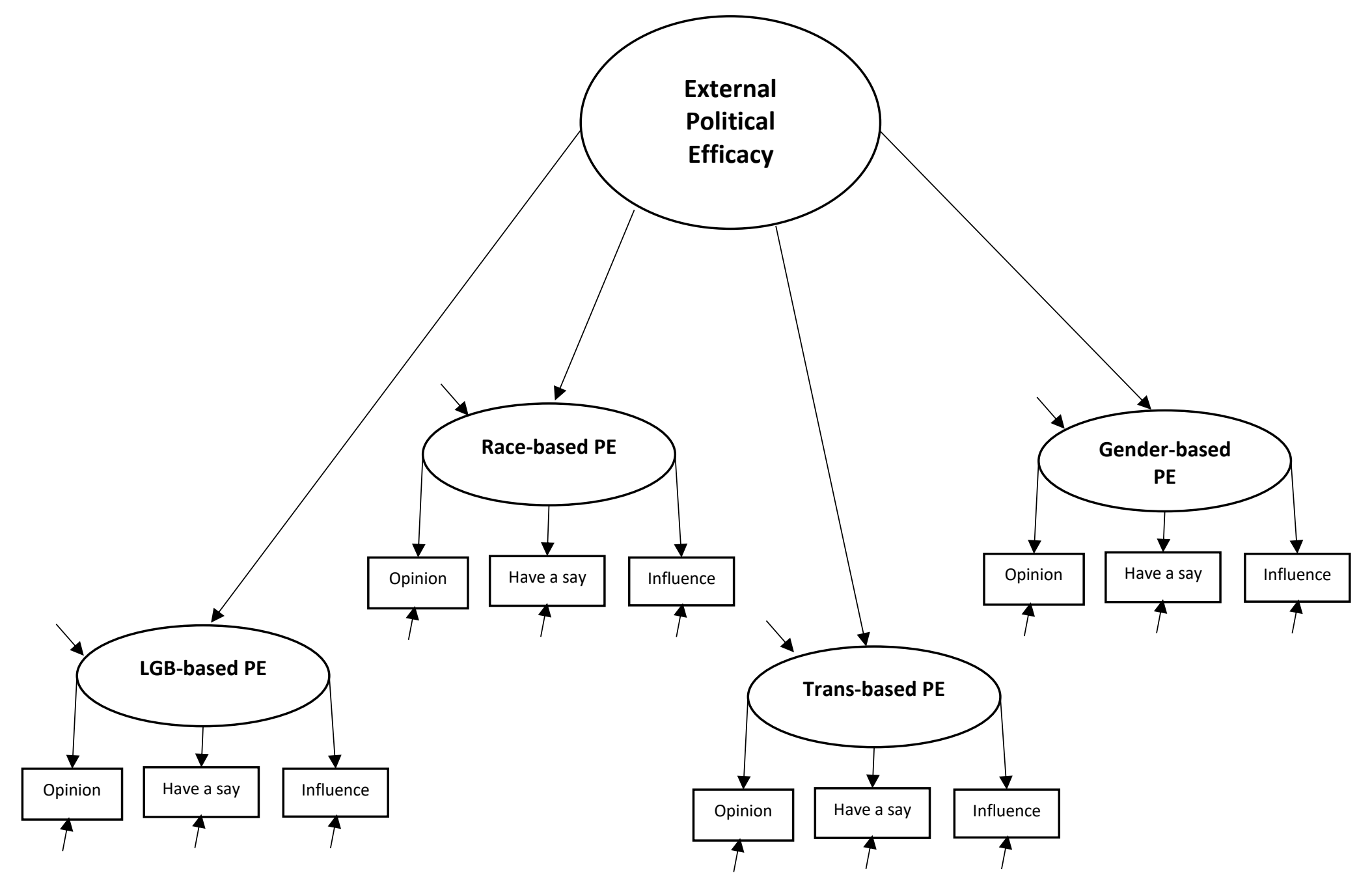

Figure 2c. Higher-order latent variable measurement model for external political efficacy (Model 2c). 


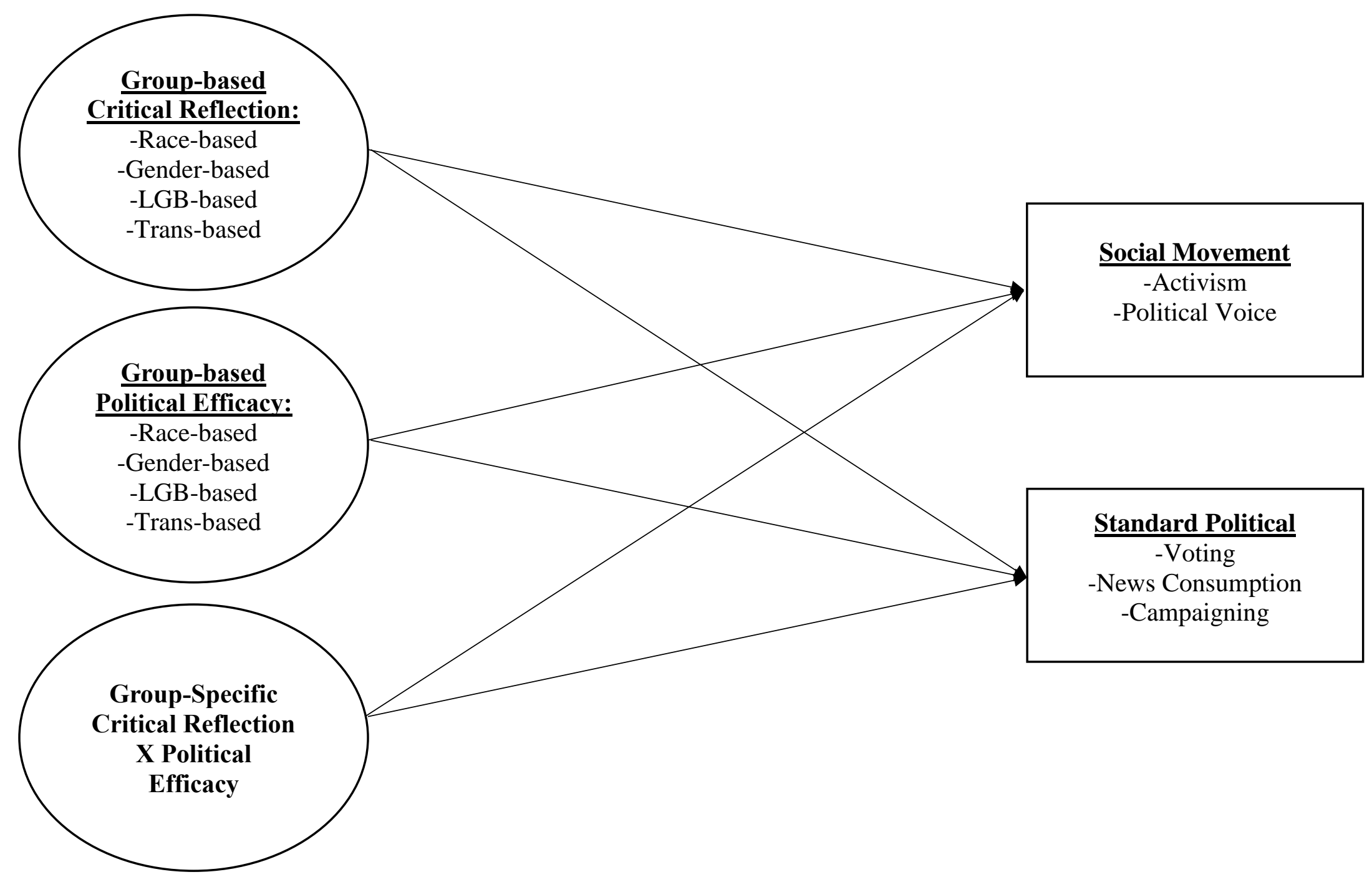

Figure 3. Conceptual model examining group-specific interactions between critical reflection and external political efficacy as predictors of political action (RQ4). 


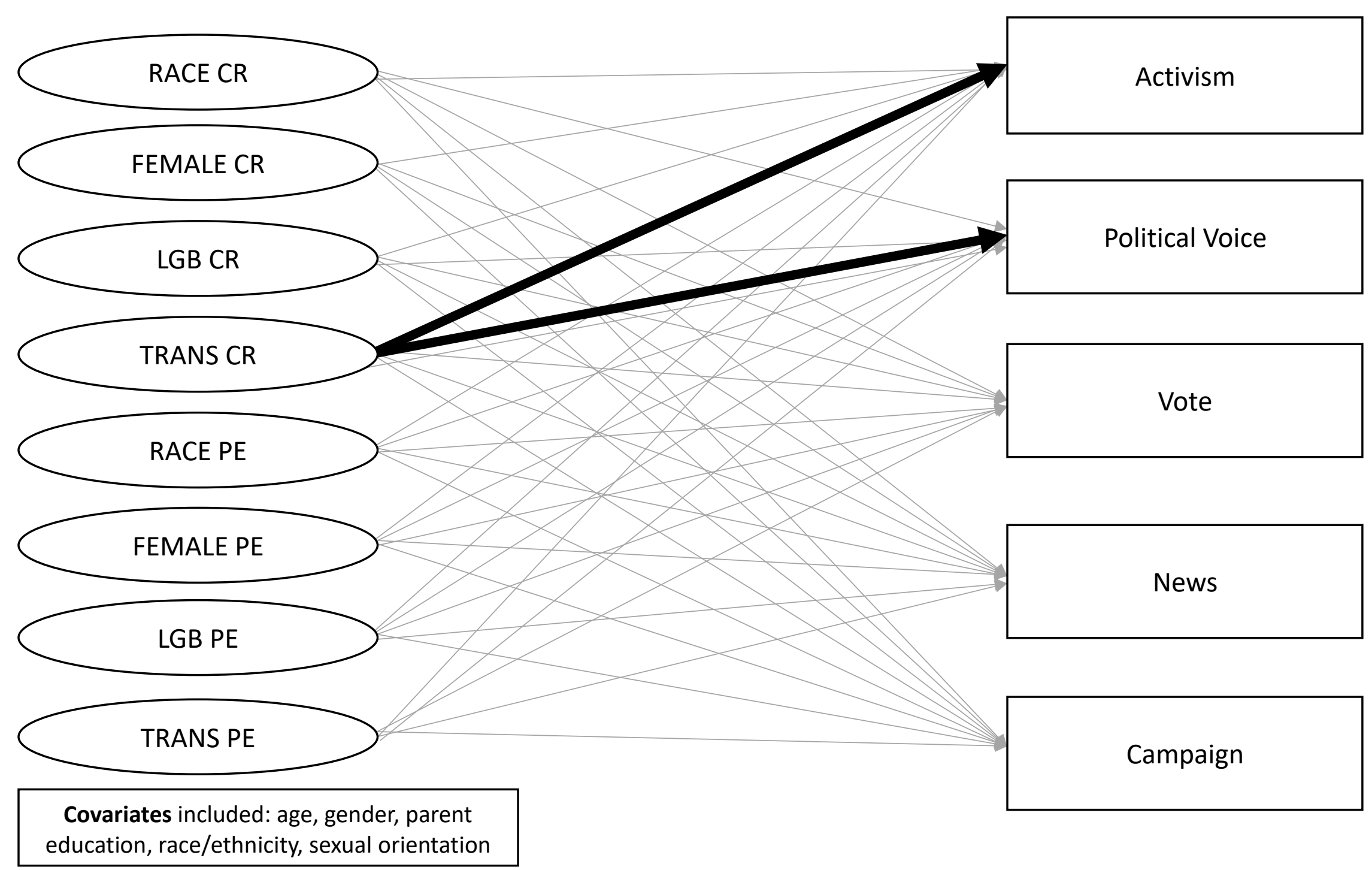

Figure 4. Significant associations among critical reflection (CR), external political efficacy (PE), and political involvement. Bold lines indicate significant associations and gray lines represent non-significant associations. 


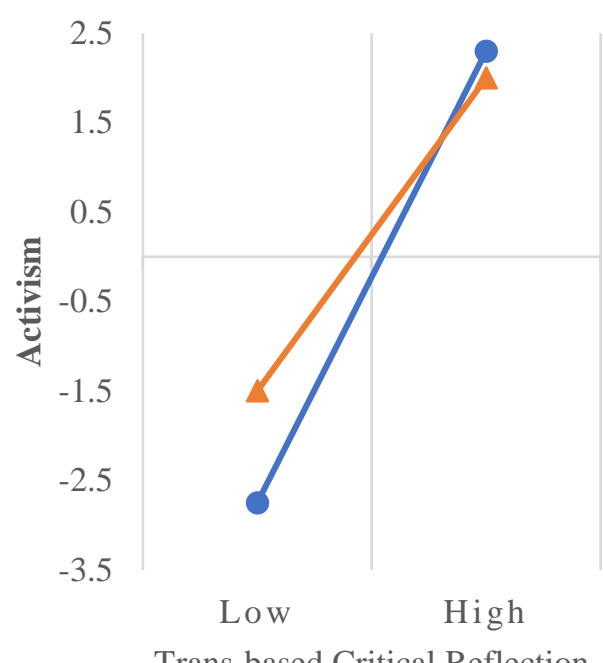

Trans-based Critical Reflection

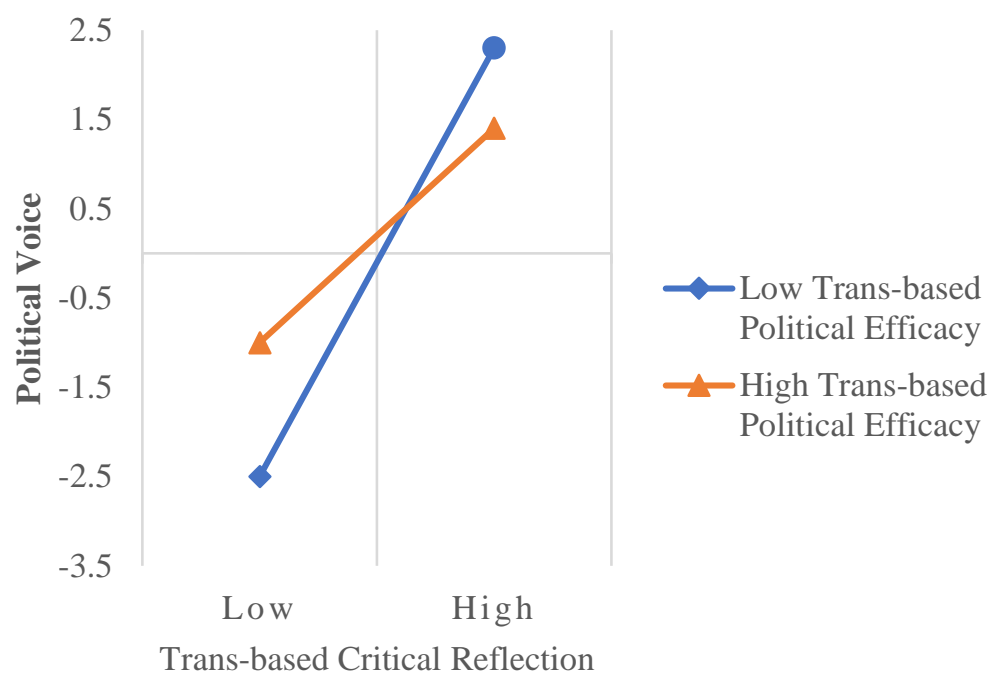

Figure 5. Trans-based critical reflection by political efficacy interaction effects on activism (left) and political voice (right). 

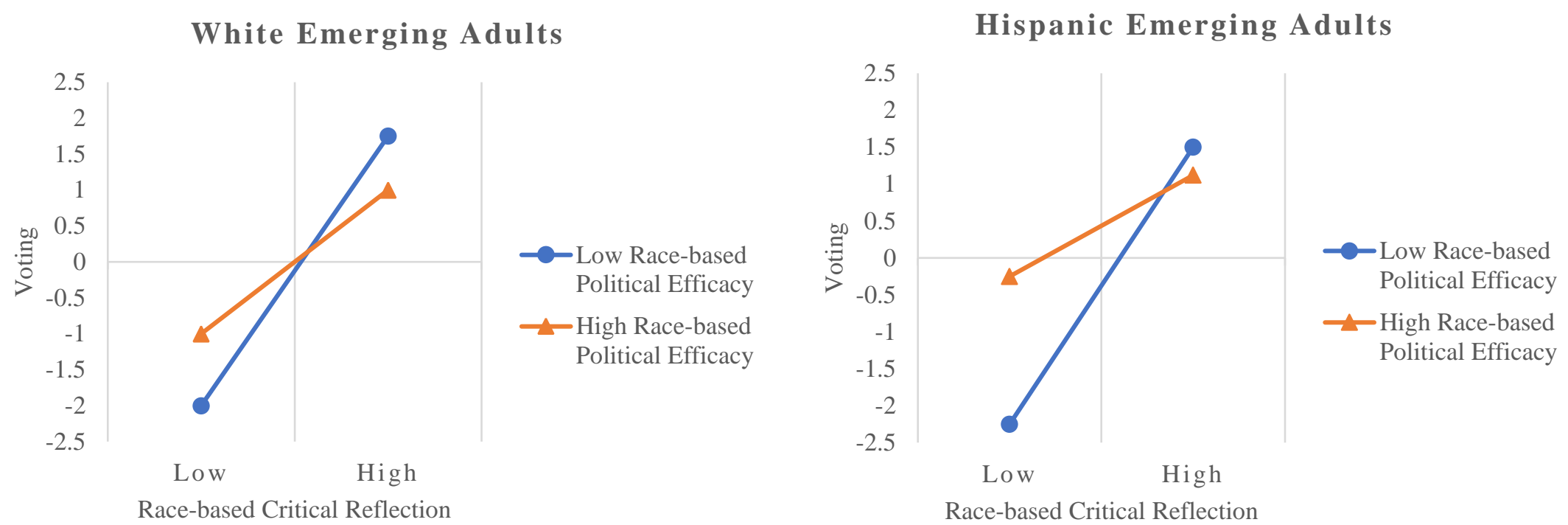

Figure 6. Race-based critical reflection by political efficacy interaction effects on voting for White (left) vs. Hispanic (right) emerging adults. 
Appendices 


\section{APPENDIX A}

Demographic Information for each University used in Participant Recruitment

\begin{tabular}{|c|c|c|c|}
\hline University & Region & $\begin{array}{l}\text { Undergraduate } \\
\text { Enrollment }\end{array}$ & Race/Ethnicity \\
\hline WVU & $\begin{array}{l}\text { Mid- } \\
\text { Atlantic }\end{array}$ & 30,000 & $\begin{array}{l}\text { 81\% Caucasian } \\
\text { 4\% Latinx/Hispanic } \\
\text { 4\% African American/Black } \\
2 \% \text { Asian American/Pacific Islander } \\
13 \% \text { Other }\end{array}$ \\
\hline UCLA & Pacific & 30,000 & $\begin{array}{l}\text { 26\% Caucasian } \\
21 \% \text { Latinx/Hispanic } \\
5 \% \text { African American/Black } \\
32 \% \text { Asian American/Pacific Islander } \\
15 \% \text { Other }\end{array}$ \\
\hline MSMU & Pacific & 2,700 & $\begin{array}{l}\text { 12\% Caucasian } \\
58 \% \text { Latinx/Hispanic } \\
7 \% \text { African American/Black } \\
15 \% \text { Asian American/Pacific Islander } \\
8 \% \text { Other }\end{array}$ \\
\hline
\end{tabular}




\section{Appendix B}

\section{Demographic Questionnaire}

How old are you?

18

19

20

21

22

23

24

25

26

27

28

29

30

Other:

What is your birth month?

$\nabla$ January ... December

What is your birth day?

$\nabla 1 \ldots 31$

What is your birth year?

$\nabla 1985 \ldots 2002$ 
What year in school are you?

t1st year

2nd year

ßrd year

74th year

5 th year

76 th year or more

Which the following best describes you? Check all that apply.

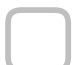

American Indian or Alaska Native

Asian

Black or African American

Hispanic or Latino/Latina

Native Hawaiian or Other Pacific Islander

White

Other: (Please specify)

If you checked "Hispanic/Latino(a)", please indicate specific ethnicity (check all that apply):

Argentinian

Colombian

Guatemalan

Nicaraguan

Puerto Rican

Bolivian

Cost Rican 


\author{
Honduran \\ Panamanian \\ Salvadorian \\ Brazilian \\ Cuban \\ Mexican/Chicano(a) \\ Paraguayan \\ Uruguayan \\ Chilean \\ Ecuadorian \\ Peruvian \\ Venezuelan
}

Other (please specify):

If you checked "Asian/Asian American", please indicate specific ethnicity (check all that apply):

East Asian (Chinese, Japanese, Korean, Okinawan, Taiwanese, Tibetan)

Native Hawaiians and Pacific Islanders

Southeast Asian (Bruneian, Burmese, Cambodian, Filipino, Hmong, Indonesian, Laotian, Malaysian, Mien, Papua New Guinean, Singaporean, Timorese, Thai, Vietnamese)

South Asian (Bangladeshi, Bhutanese, Indian, Maldivians, Nepali, Pakistani, Sri Lankan)

Middle East (Bahrain, Iran, Iraq, Israel, Jordan, Kuwait, Lebanon, Oman, Palestine, Qatar, Saudi Arabia, Syria, Turkey, United Arab Emirates, and Yemen) 
What sex were you assigned at birth, on your original birth certificate?

Male

Female

What is your current gender identity?

Male

Female

Transgender or transsexual, male to female

Transgender or transsexual, female to male

Gender non-conforming/Genderqueer

The next set of questions are about your sexual orientation, which involves who you are physically or romantically attracted to. Remember, all of your answers will be kept completely confidential and anonymous.

Do you think of yourself as:

Gay or lesbian

Straight/heterosexual

Bisexual

I prefer to self-identify:

Which of the following best describes you?

Buddhist

Christian

Hindu

Jewish

Muslim

I do not identify with any religion

Other (please specify):

Were either of your grandparents born outside of the United States?

If so, which country or countries?

No 
Yes (Please list country or countries):

Were either of your parents born outside of the United States?

If so, which country or countries?

No

Yes (Please list country or countries):

Were you born outside of the United States?

If so, which country?

No

Yes (Please list country or countries):

Does your family mostly speak English at home?

Yes

No- if NO, what language is spoken?

What grades do you usually earn in school?

Mostly As

About half As and half Bs

Mostly Bs

About half $B s$ and half $C s$

Mostly Cs

About half Cs and half Ds

Mostly Ds

Mostly below Ds

Don't know 
Which of the following statements best describes your family's financial situation?

We have a hard time buying the things we need.

We have just enough money for the things we need.

We have no problem buying the things we need, and we can also sometimes buy special things.

We have enough money to buy almost anything we want.

What is the highest level of education your mother or mother-figure has received?

78th grade or less

Jome high school

†High school graduate or equivalent

JSome college

College degree

A graduate or professional degree (e.g, masters, MD, PhD)

I don't know

What is the highest level of education your father or father-figure has received?

78th grade or less

Jome high school

THigh school graduate or equivalent

Some college

College degree

A graduate or professional degree (e.g, masters, MD, PhD)

I don't know 


\section{Appendix C}

\section{Critical Reflection Questionnaire}

The following questions ask about your beliefs about America and our society as it stands today. There are no right or wrong answers to these questions. We want to know what YOU truly think about your society and community. As a reminder, your answers will be completely confidential and anonymous, so please answer honestly. Read the following information before you begin:

-Racial and ethnic minorities include people of color or people who identify as Hispanic/Latino(a), Black or African American, Asian, American Indian, or Pacific Islander.

-Gay or lesbian refers to people who are sexually attracted to same-sex individuals and bisexual refers to people who are attracted to both opposite-sex and same-sex individuals. Heterosexual or straight refers to people who are attracted to the opposite sex.

-Transgender is an umbrella term that applies to individuals whose gender identity or expression differs from the sex they were assigned at birth.

How much do you agree or disagree with the following?

\begin{tabular}{|c|c|c|c|}
\hline $\begin{array}{l}\text { Strongly } \\
\text { Disagree }\end{array}$ & Disagree & $\begin{array}{l}\text { Somewhat Disagree } \\
\text { and Somewhat Agree }\end{array}$ & Agree \\
\hline
\end{tabular}

Certain racial or ethnic minority groups have fewer chances to get ahead.

Women have fewer chances to get ahead.

Gay, lesbian, and bisexual people have fewer chances to get ahead.

Transgender people have fewer chances to get ahead. 
How much do you agree or disagree with the following?

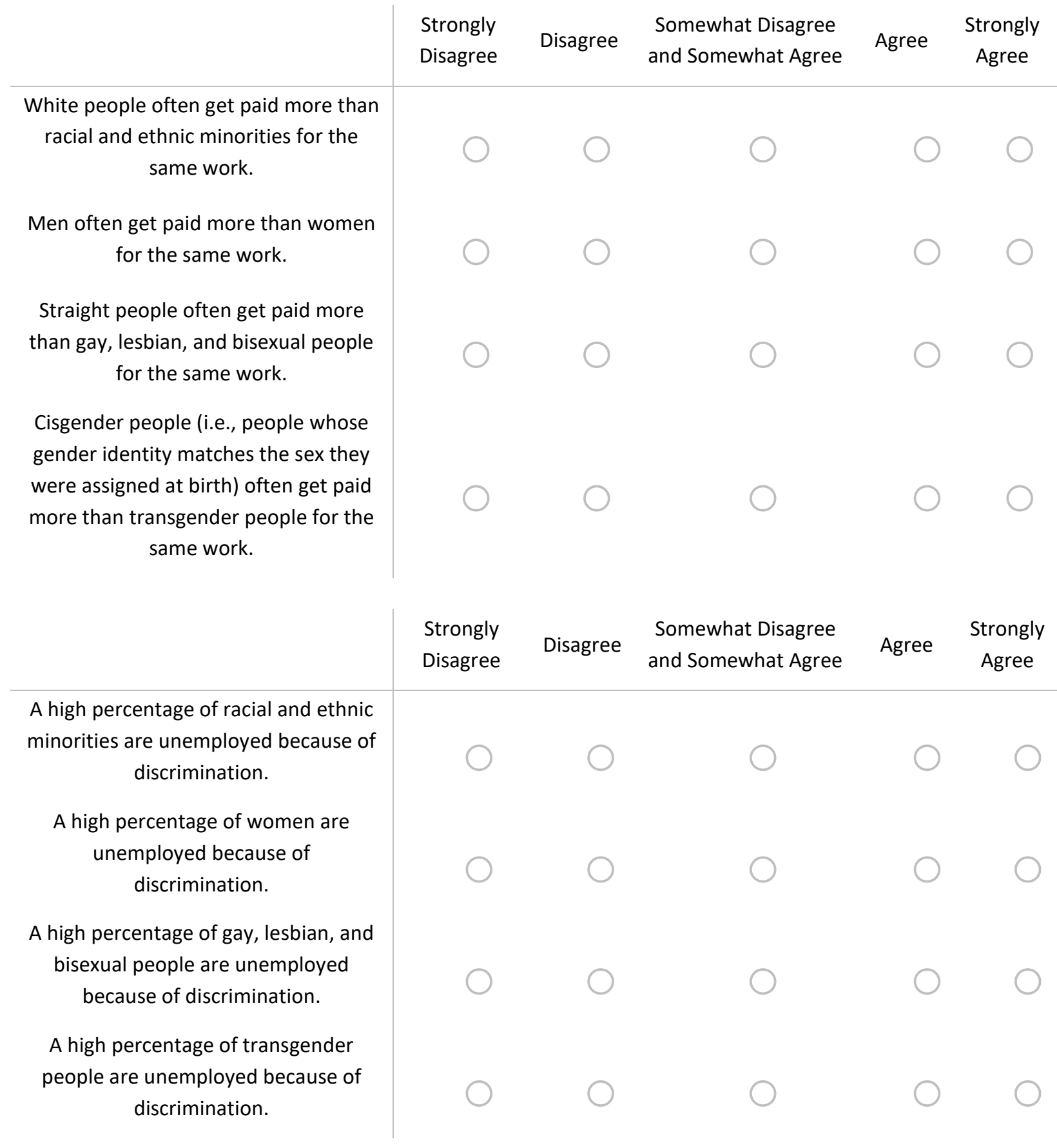


How much do you agree or disagree with the following?

\begin{tabular}{|c|c|c|c|c|c|}
\hline & $\begin{array}{l}\text { Strongly } \\
\text { Disagree }\end{array}$ & Disagree & $\begin{array}{l}\text { Somewhat Disagree } \\
\text { and Somewhat Agree }\end{array}$ & Agree & $\begin{array}{l}\text { Strongly } \\
\text { Agree }\end{array}$ \\
\hline \multirow{2}{*}{\multicolumn{6}{|c|}{$\begin{array}{c}\text { Certain racial and ethnic minority } \\
\text { groups have fewer chances to get good } \\
\text { jobs. }\end{array}$}} \\
\hline & & & & & \\
\hline \multicolumn{6}{|l|}{$\begin{array}{l}\text { Gay, lesbian, and bisexual people have } \\
\text { fewer chances to get good jobs. }\end{array}$} \\
\hline \multicolumn{6}{|l|}{$\begin{array}{l}\text { Transgender people have fewer } \\
\text { chances to get good jobs. }\end{array}$} \\
\hline & $\begin{array}{l}\text { Strongly } \\
\text { Disagree }\end{array}$ & Disagree & $\begin{array}{l}\text { Somewhat Disagree } \\
\text { and Somewhat Agree }\end{array}$ & Agree & $\begin{array}{l}\text { Strongly } \\
\text { Agree }\end{array}$ \\
\hline \multicolumn{6}{|l|}{$\begin{array}{l}\text { Certain racial and ethnic minority } \\
\text { groups have fewer chances to get job } \\
\text { promotions. }\end{array}$} \\
\hline \multicolumn{6}{|l|}{$\begin{array}{l}\text { Women have fewer chances to get job } \\
\text { promotions. }\end{array}$} \\
\hline $\begin{array}{l}\text { Gay, lesbian, and bisexual people have } \\
\text { fewer chances to get job promotions. }\end{array}$ & & & & & \\
\hline $\begin{array}{l}\text { Transgender people have fewer } \\
\text { chances to get job promotions. }\end{array}$ & & & & & \\
\hline
\end{tabular}


How much do you agree or disagree with the following?

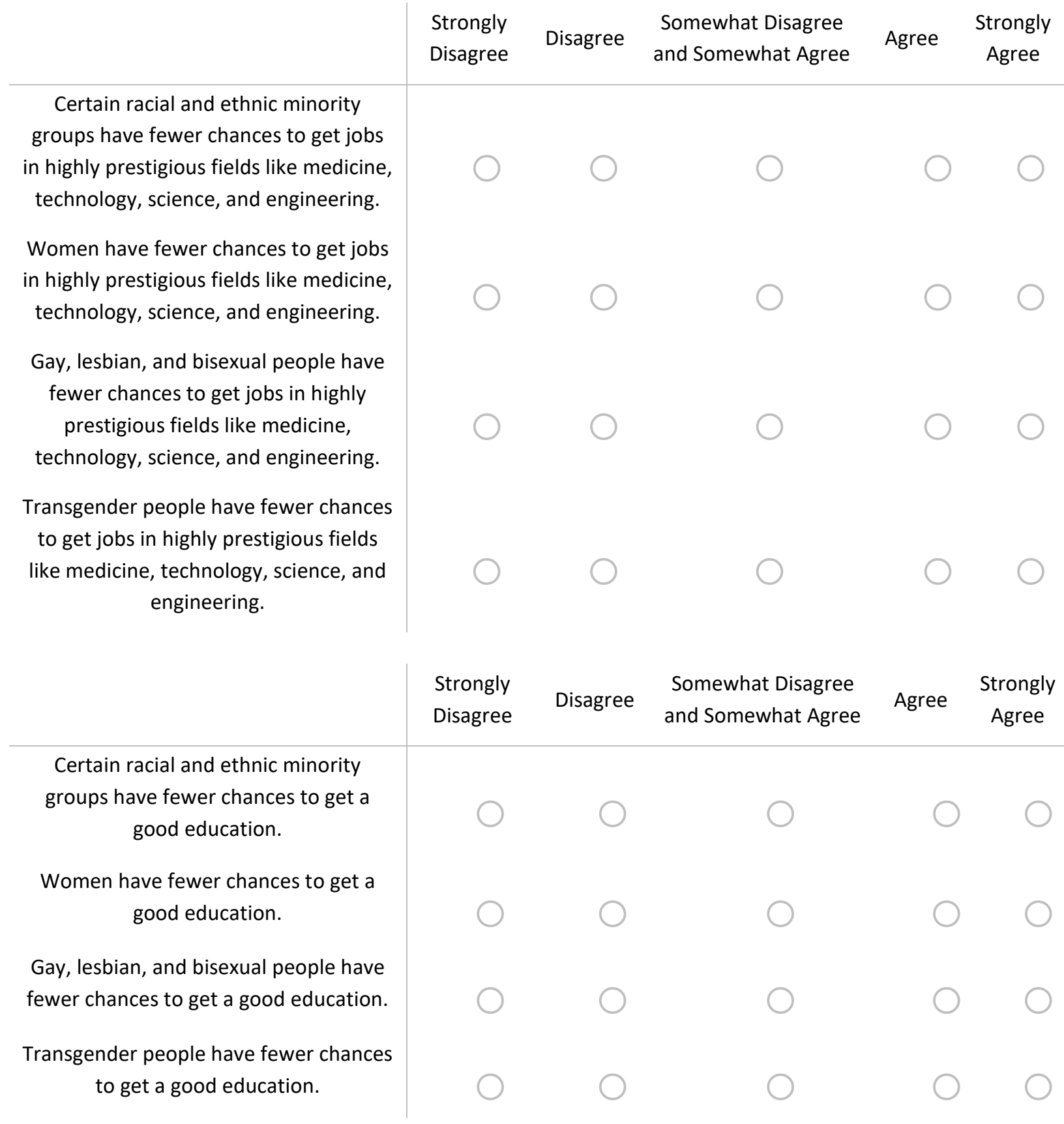


How much do you agree or disagree with the following?

\begin{tabular}{|c|c|c|c|c|c|}
\hline & $\begin{array}{l}\text { Strongly } \\
\text { Disagree }\end{array}$ & Disagree & $\begin{array}{l}\text { Somewhat Disagree } \\
\text { and Somewhat Agree }\end{array}$ & Agree & $\begin{array}{c}\text { Strongly } \\
\text { Agree }\end{array}$ \\
\hline $\begin{array}{l}\text { Certain racial and ethnic minority groups } \\
\text { have fewer chances to get a doctorate } \\
\text { degree (e.g., PhD, MD). } \\
\text { Women have fewer chances to get a } \\
\text { doctorate degree (e.g., PhD, MD). } \\
\text { Gay, lesbian, and bisexual people have } \\
\text { fewer chances to get a doctorate degree } \\
\text { (e.g., PhD, MD). } \\
\text { Transgender people have fewer chances } \\
\text { to get a doctorate degree (e.g., PhD, } \\
\text { MD). }\end{array}$ & & & 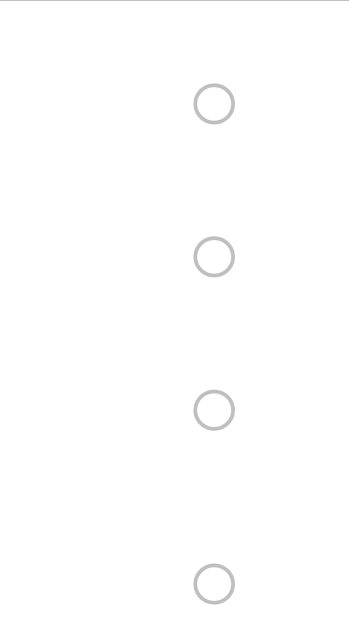 & & . \\
\hline & $\begin{array}{l}\text { Strongly } \\
\text { Disagree }\end{array}$ & Disagree & $\begin{array}{c}\text { Somewhat Disagree } \\
\text { and Somewhat } \\
\text { Agree }\end{array}$ & Agree & $\begin{array}{l}\text { Strongly } \\
\text { Agree }\end{array}$ \\
\hline $\begin{array}{c}\text { In public schools, racial and ethnic } \\
\text { minority groups are always treated fairly } \\
\text { by teachers. }\end{array}$ & & & & & \\
\hline $\begin{array}{l}\text { In public schools, boys and girls are } \\
\text { always treated fairly by teachers. } \\
\text { In public schools, gay, lesbian, and } \\
\text { bisexual students are always treated } \\
\text { fairly by teachers. }\end{array}$ & & & & & \\
\hline $\begin{array}{l}\text { In public schools, transgender individuals } \\
\text { are always treated fairly by teachers. }\end{array}$ & & & & & \\
\hline
\end{tabular}


How much do you agree or disagree with the following?

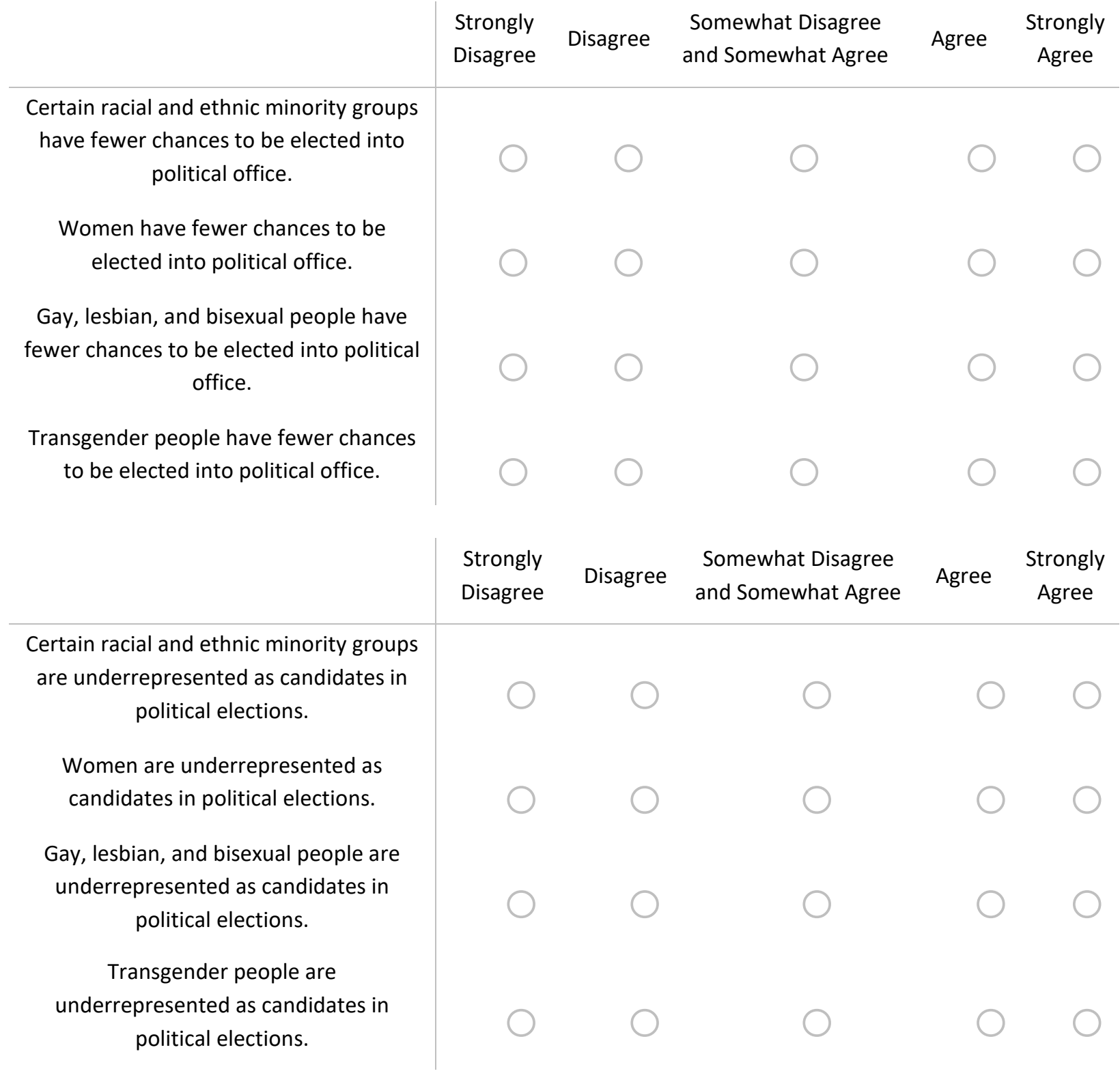


How much do you agree or disagree with the following?

\begin{tabular}{|c|c|c|c|c|c|}
\hline & $\begin{array}{l}\text { Strongly } \\
\text { Disagree }\end{array}$ & Disagree & $\begin{array}{l}\text { Somewhat Disagree } \\
\text { and Somewhat Agree }\end{array}$ & Agree & $\begin{array}{l}\text { Strongly } \\
\text { Agree }\end{array}$ \\
\hline \multicolumn{6}{|l|}{$\begin{array}{c}\text { Gay, lesbian, and bisexual people have } \\
\text { little political power. }\end{array}$} \\
\hline \multicolumn{6}{|l|}{ Women have little political power. } \\
\hline \multicolumn{6}{|l|}{$\begin{array}{c}\text { Certain racial and ethnic minority groups } \\
\text { have little political power. }\end{array}$} \\
\hline \multicolumn{6}{|l|}{$\begin{array}{l}\text { This question is to make sure you are } \\
\text { paying attention. Please select "agree" } \\
\text { and move on. }\end{array}$} \\
\hline \multicolumn{6}{|l|}{ Transgender people have little political } \\
\hline & $\begin{array}{l}\text { Strongly } \\
\text { Disagree }\end{array}$ & Disagree & $\begin{array}{l}\text { Somewhat Disagree } \\
\text { and Somewhat Agree }\end{array}$ & Agree & $\begin{array}{l}\text { Strongly } \\
\text { Agree }\end{array}$ \\
\hline \multicolumn{6}{|l|}{$\begin{array}{l}\text { The legal system is applied to all racial } \\
\text { and ethnic groups fairly. }\end{array}$} \\
\hline \multicolumn{6}{|l|}{$\begin{array}{l}\text { The legal system is applied to men and } \\
\text { women fairly. }\end{array}$} \\
\hline \multicolumn{6}{|l|}{$\begin{array}{l}\text { The legal system is applied to gay, } \\
\text { lesbian, and bisexual people fairly. }\end{array}$} \\
\hline $\begin{array}{l}\text { The legal system is applied to } \\
\text { transgender people fairly. }\end{array}$ & & & & & \\
\hline
\end{tabular}


How much do you agree or disagree with the following?

Strongly
Disagree $\quad \begin{gathered}\text { Somewhat Disagree } \\ \text { and Somewhat Agree }\end{gathered} \quad$ Agree $\quad \begin{gathered}\text { Strongly } \\ \text { Agree }\end{gathered}$

A high percentage of certain racial and ethnic minority groups are treated unfairly by police officers.

A high percentage of women are treated unfairly by police officers.

A high percentage of gay, lesbian, and bisexual people are treated unfairly by police officers.

A high percentage of transgender people are treated unfairly by police officers.

\section{Racial and ethnic minority groups face more legal obstacles because of their race or ethnicity. \\ Women face more legal obstacles because of their gender.}

Gay, lesbian, and bisexual people face more legal obstacles because of their sexual orientation.

Transgender people face more legal obstacles because of their sexual orientation.

$\begin{array}{lcccc}\text { Strongly } & \text { Disagree } & \begin{array}{c}\text { Somewhat Disagree } \\ \text { and Somewhat Agree }\end{array} & \text { Agree } & \begin{array}{c}\text { Strongly } \\ \text { Aisagree }\end{array}\end{array}$


How much do you agree or disagree with the following?

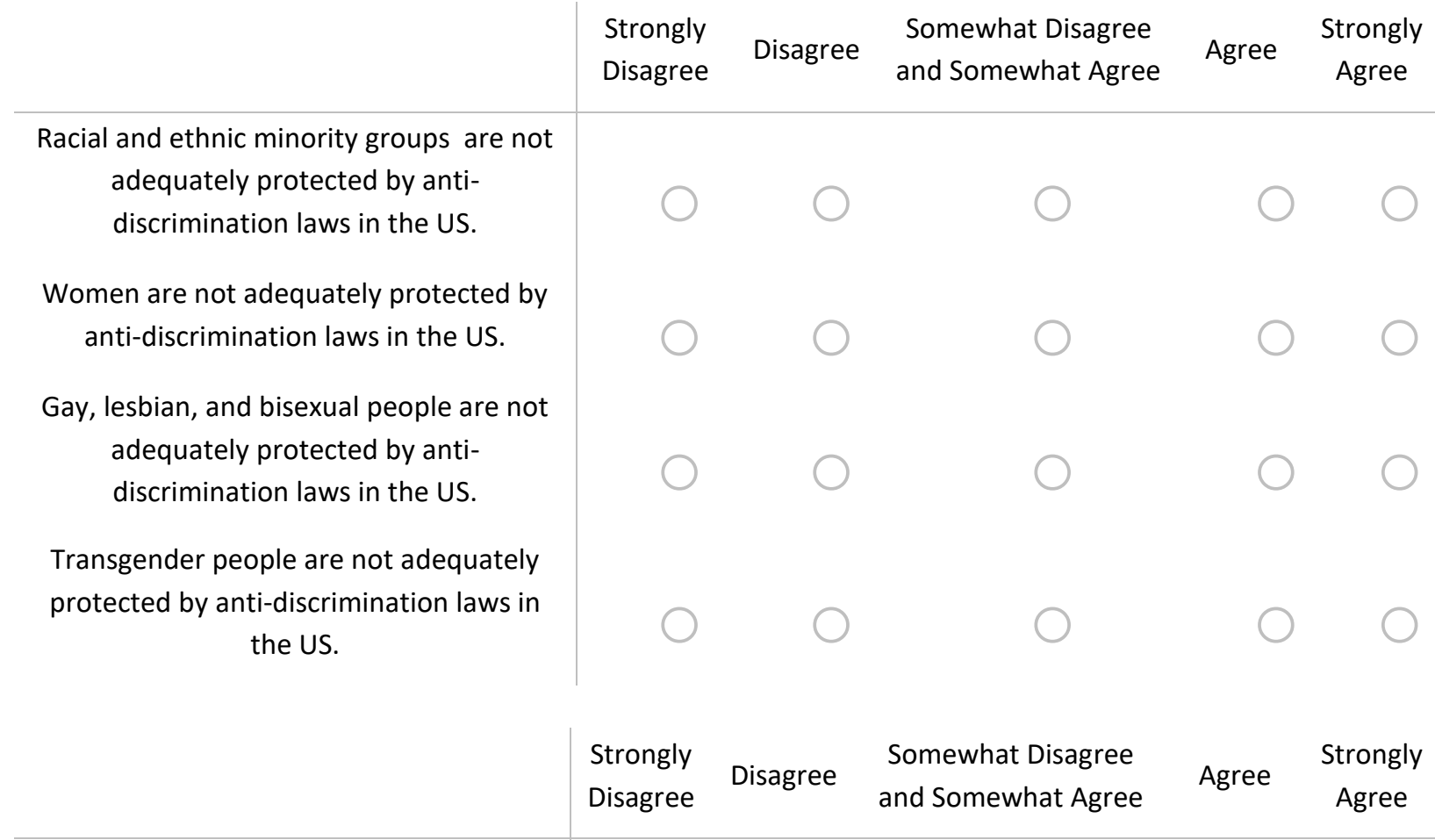

A high percentage of racial and ethnic minority groups are sexually assaulted.

A high percentage of women are sexually assaulted.

A high percentage of gay, lesbian, and bisexual people are sexually assaulted.

A high percentage of transgender people are sexually assaulted. 
How much do you agree or disagree with the following?

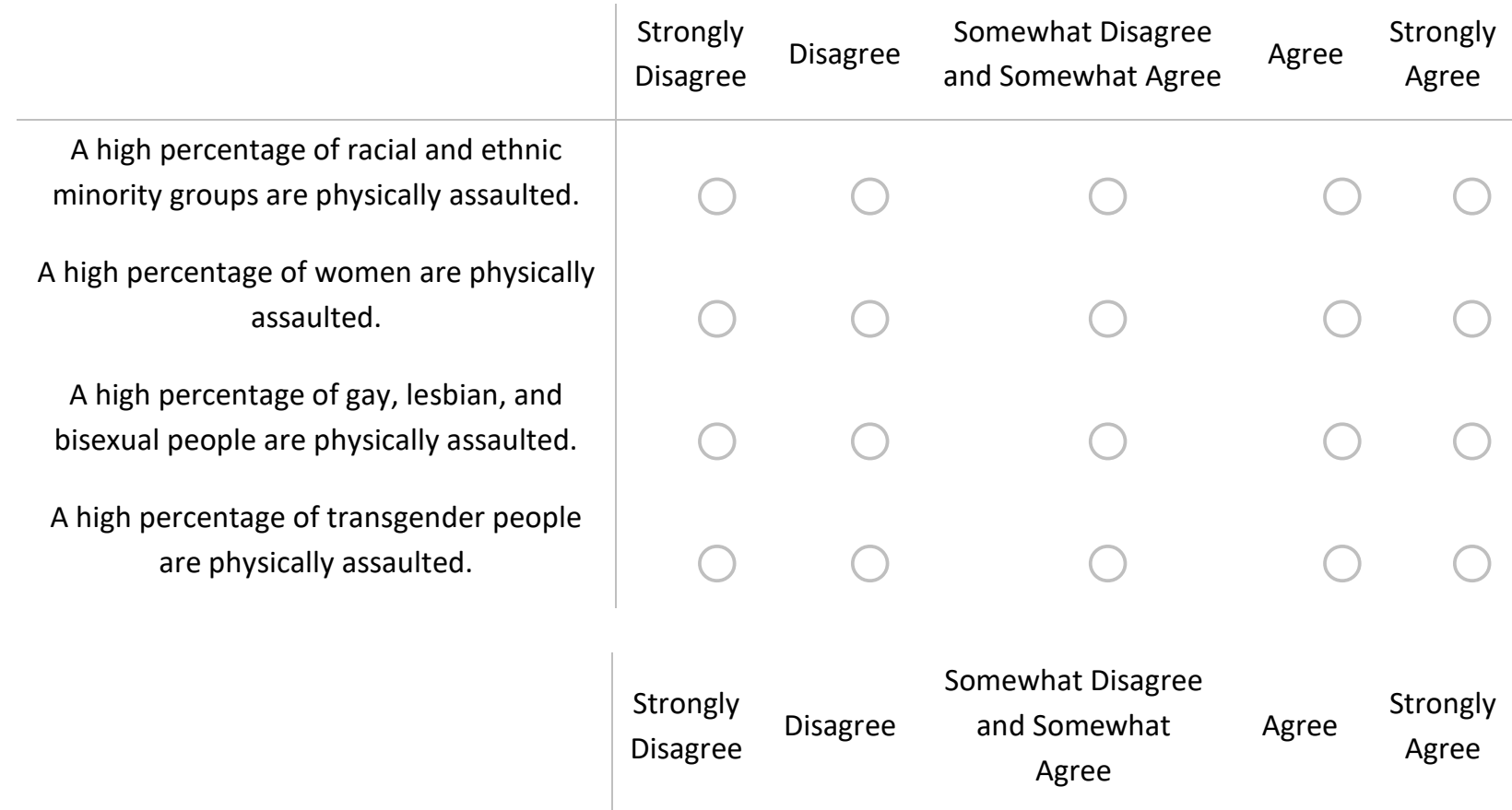

A high percentage of racial and ethnic minority groups are victims of domestic violence.

A high percentage of women are victims of domestic violence.

A high percentage of gay, lesbian, and bisexual people are victims of domestic violence.

A high percentage of transgender people are victims of domestic violence. 


\section{Appendix D \\ External Political Efficacy Questionnaire}

$\begin{aligned} & \text { How much do you agree or disagree with the following? } \\ & \text { Disagree }\end{aligned}$ Disagree $\begin{gathered}\text { Somewhat Disagree } \\ \text { and Somewhat Agree }\end{gathered}$
$\begin{gathered}\text { Three } \\ \text { The powerful leaders in government } \\ \text { racial and ethnic minorities. }\end{gathered}$
$\begin{gathered}\text { Certain racial and ethnic minority } \\ \text { groups don't have any say about what } \\ \text { the government does. }\end{gathered}$
$\begin{gathered}\text { Racial and ethnic minority groups can } \\ \text { successfully influence what the } \\ \text { government does. }\end{gathered}$
$\begin{gathered}\text { The powerful leaders in government } \\ \text { care very little about the opinions of } \\ \text { women. }\end{gathered}$

How much do you agree or disagree with the following? Note: LGB refers to lesbian, gay, and bisexual people.

\begin{tabular}{|c|c|c|c|c|c|}
\hline & $\begin{array}{l}\text { Strongly } \\
\text { Disagree }\end{array}$ & Disagree & $\begin{array}{l}\text { Somewhat Disagree } \\
\text { and Somewhat Agree }\end{array}$ & Agree & $\begin{array}{l}\text { Strongly } \\
\text { Agree }\end{array}$ \\
\hline $\begin{array}{l}\text { The powerful leaders in government } \\
\text { care very little about the opinions of } \\
\text { LGB people. }\end{array}$ & & & & & \\
\hline $\begin{array}{l}\text { LGB people don't have any say about } \\
\text { what the government does. }\end{array}$ & & & & & \\
\hline $\begin{array}{l}\text { LGB people can successfully influence } \\
\text { what the government does. }\end{array}$ & & & & & \\
\hline
\end{tabular}


How much do you agree or disagree with the following?

\begin{tabular}{l|lll} 
& $\begin{array}{c}\text { Strongly } \\
\text { Disagree }\end{array}$ Disagree & $\begin{array}{c}\text { Somewhat Disagree } \\
\text { and Somewhat Agree }\end{array}$ & $\begin{array}{c}\text { Agree } \\
\text { Agree }\end{array}$ \\
\hline $\begin{array}{c}\text { The powerful leaders in government } \\
\text { care very little about the opinions of } \\
\text { transgender people. }\end{array}$ & \\
Transgender people don't have any say \\
about what the government does. \\
Transgender people can successfully \\
influence what the government does.
\end{tabular}




\section{Appendix E \\ Political Involvement Questionnaire}

Some people seem to follow what's going on in government and public affairs most of the time, whether there's an election going on or not. Others aren't that interested.

In a TYPICAL WEEK, how often do you access information about politics and current events on TV, the radio, in the newspaper, or on news websites?

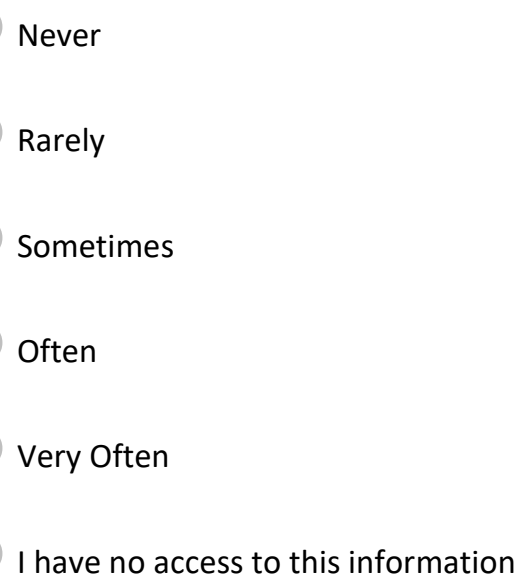


Have you ever done or plan to do the following?

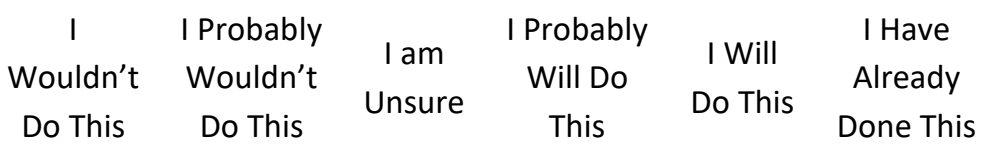

Use online communities or tools to discuss political issues or current events (Examples: Twitter, Facebook, blogs).

Share my opinions about political issues with others.

Participate in a rally or protest for a cause.

Contact politicians, governments, or authorities about issues that are important to me.

Work or volunteer to campaign for a political candidate.

Sign an email or written petition about a social or political issue.

Vote in national elections.

Refuse to buy something from a company that stands for things you don't like.

Intentionally buy a certain product or service because you like the social or political values of the company that produces it.

Participate in a political party, club or organization.

Write a letter to a school, community newspaper, or publication about a social or political issue. 


\section{APPENDIX F RECRUITMENT LOCATION DIFFERENCES IN KEY STUDY VARIABLES}

Additional analyses were performed to examine differences in variability based on recruitment location (Table 1). Results indicated that several key study variables varied by recruitment location such that participants residing in West Virginia reported lower levels of race-, gender-, LGB-, and trans-based critical reflection compared to participants from both California locations. There were no significant differences between the two California schools on levels of critical reflection. West Virginia participants reported significantly higher levels of race-based political efficacy compared to California groups and participants from the larger California university reported higher levels of race-based political efficacy than participants from the smaller California university. Participants recruited from the smaller California school reported significantly lower levels of gender- and LGB-based political efficacy compared to the other groups and lower trans-based political efficacy compared to the West Virginia group. Among the five political behaviors, only standard political involvement varied by recruitment location such that the smaller California school group engaged in significantly higher levels of standard political behavior compared to the West Virginia group. A few sociodemographic characteristics were also associated with recruitment location, such that West Virginia participants were more likely to be White and less likely to be Hispanic or Asian compared to California participants $\left(\chi^{2}(8)=423.18, \mathrm{p}<.001\right.$. Participants recruited from the smaller California school were significantly less likely to be male compared to participants recruited from the other schools $\left(\chi^{2}(2)=23.15, \mathrm{p}<.001\right)$. 
Table 1

Recruitment Location Differences in Key Study Variables

\begin{tabular}{rcccc}
\hline & WVU & UCLA & MSMU & F test \\
\hline Critical Reflection & & & & \\
Race-based & $3.46(.81)$ & $3.79(.07)$ & $3.94(.66)$ & $\mathrm{F}(2,850)=20.64, p<.001$ \\
Gender-based & $3.19(.71)$ & $3.48(.71)$ & $3.75(.67)$ & $\mathrm{F}(2,850)=22.39, p<.001$ \\
LGB-based & $3.19(.73)$ & $3.5(.70)$ & $3.66(.63)$ & $\mathrm{F}(2,850)=22.63, p<.001$ \\
Trans-based & $3.35(.76)$ & $3.70(.70)$ & $3.72(.63)$ & $\mathrm{F}(2,850)=23.76, p<.001$ \\
Political Efficacy & & & & \\
Race-based & $3.03(.83)$ & $2.85(.79)$ & $2.45(.78)$ & $\mathrm{F}(2,850)=11.54, p<.001$ \\
Gender-based & $3.45(.78)$ & $3.40(.78)$ & $2.83(.78)$ & $\mathrm{F}(2,850)=10.27, p<.001$ \\
LGB-based & $2.71(.62)$ & $3.08(.71)$ & $2.71(.62)$ & $\mathrm{F}(2,850)=6.49, \mathrm{p}=.002$ \\
Trans-based & $2.92(.81)$ & $2.81(.73)$ & $2.57(.71)$ & $\mathrm{F}(2,850)=4.15, \mathrm{p}=.016$ \\
Political Action & & & & \\
Voting & $5.09(.98)$ & $5.15(1.26)$ & $4.8(1.32)$ & $\mathrm{F}(2,850)=1.59, \mathrm{p}=.204$ \\
Campaigning & $2.97(1.23)$ & $2.97(1.10)$ & $3.62(1.30)$ & $\mathrm{F}(2,850)=8.39, p<.001$ \\
News Consumption & $3.28(1.09)$ & $3.19(1.13)$ & $3.23(1.19)$ & $\mathrm{F}(2,850)=.61, \mathrm{p}=.544$ \\
Activism & $3.95(1.28)$ & $4.03(1.26)$ & $4.34(1.56)$ & $\mathrm{F}(2,850)=1.72, \mathrm{p}=.18$ \\
Voice & $4.13(1.57)$ & $4.01(1.43)$ & $4.29(1.58)$ & $\mathrm{F}(2,850)=.89, \mathrm{p}=.54$ \\
\hline
\end{tabular}




\section{APPENDIX G}

\section{MEASUREMENT MODEL ESTIMATES FOR MODEL 1A: SINGLE FACTOR CRITICAL REFLECTION}

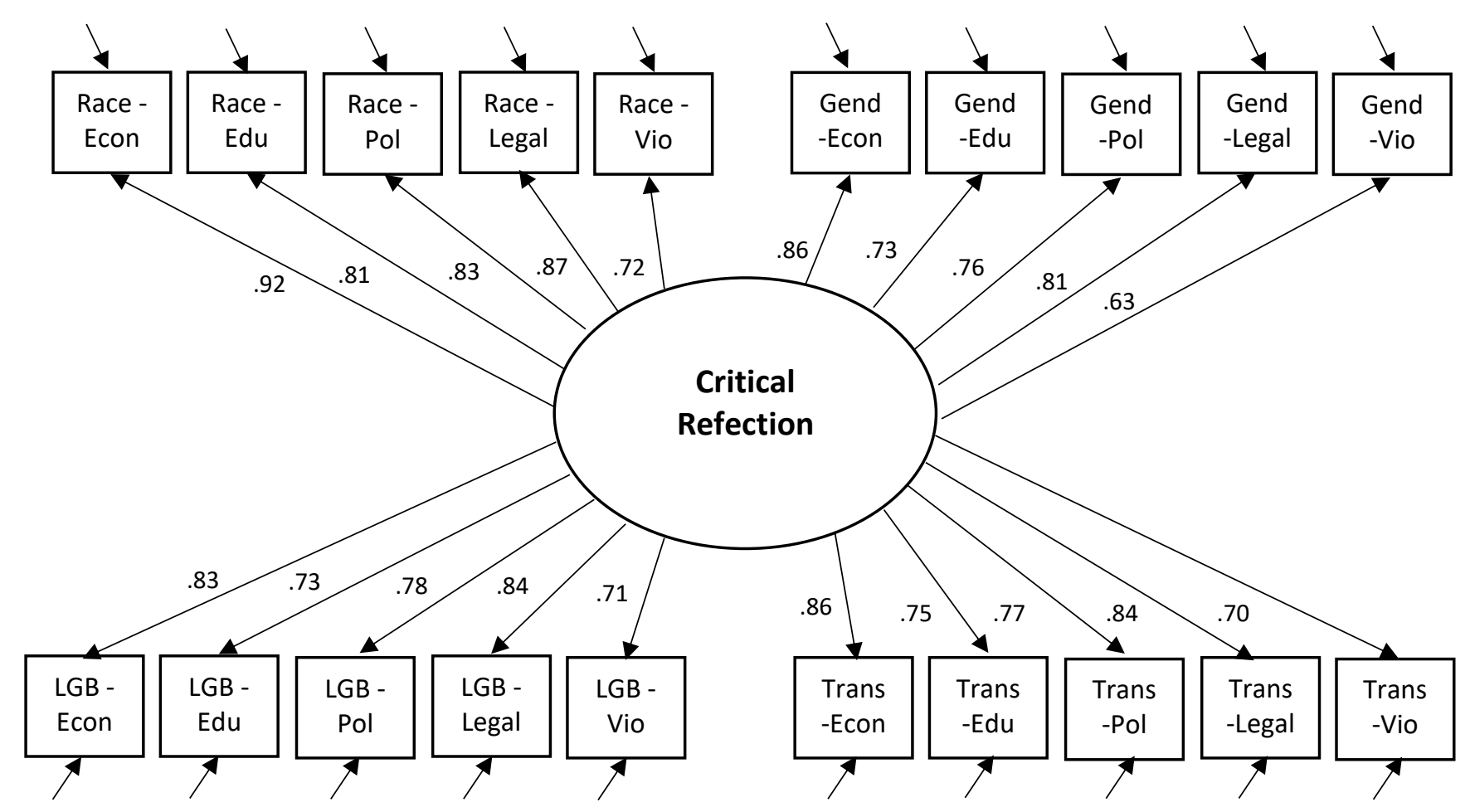

Note. Standardized estimates are reported and were all significant at $\mathrm{p}<.001$. 
APPENDIX H

MEASUREMENT MODEL ESTIMATES FOR MODEL 1C: HIGHER-ORDER FACTOR CRITICAL REFLECTION

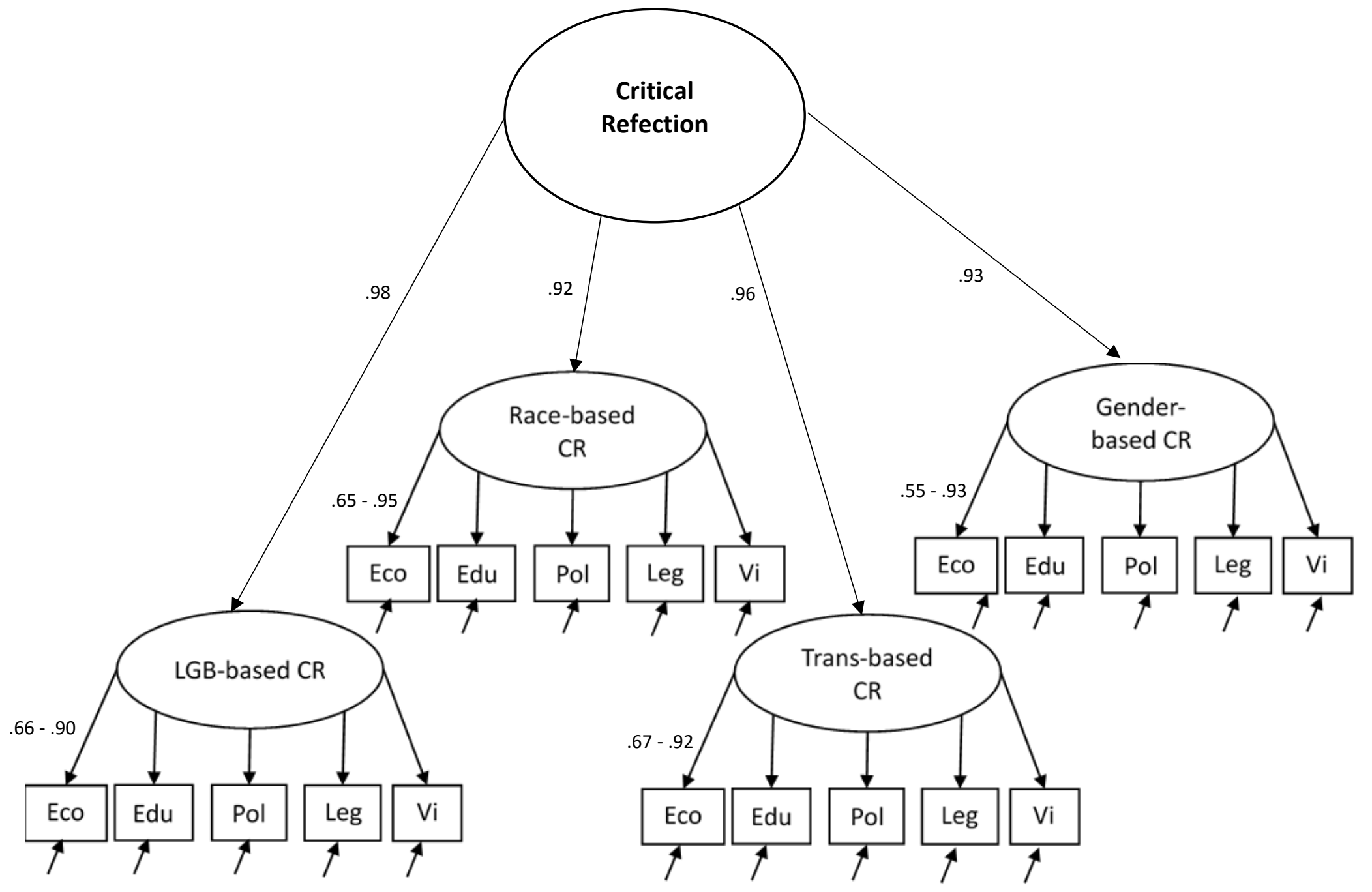




\section{APPENDIX I}

MEASUREMENT MODEL ESTIMATES FOR MODEL 2A: SINGLE FACTOR POLITICLA EFFICACY

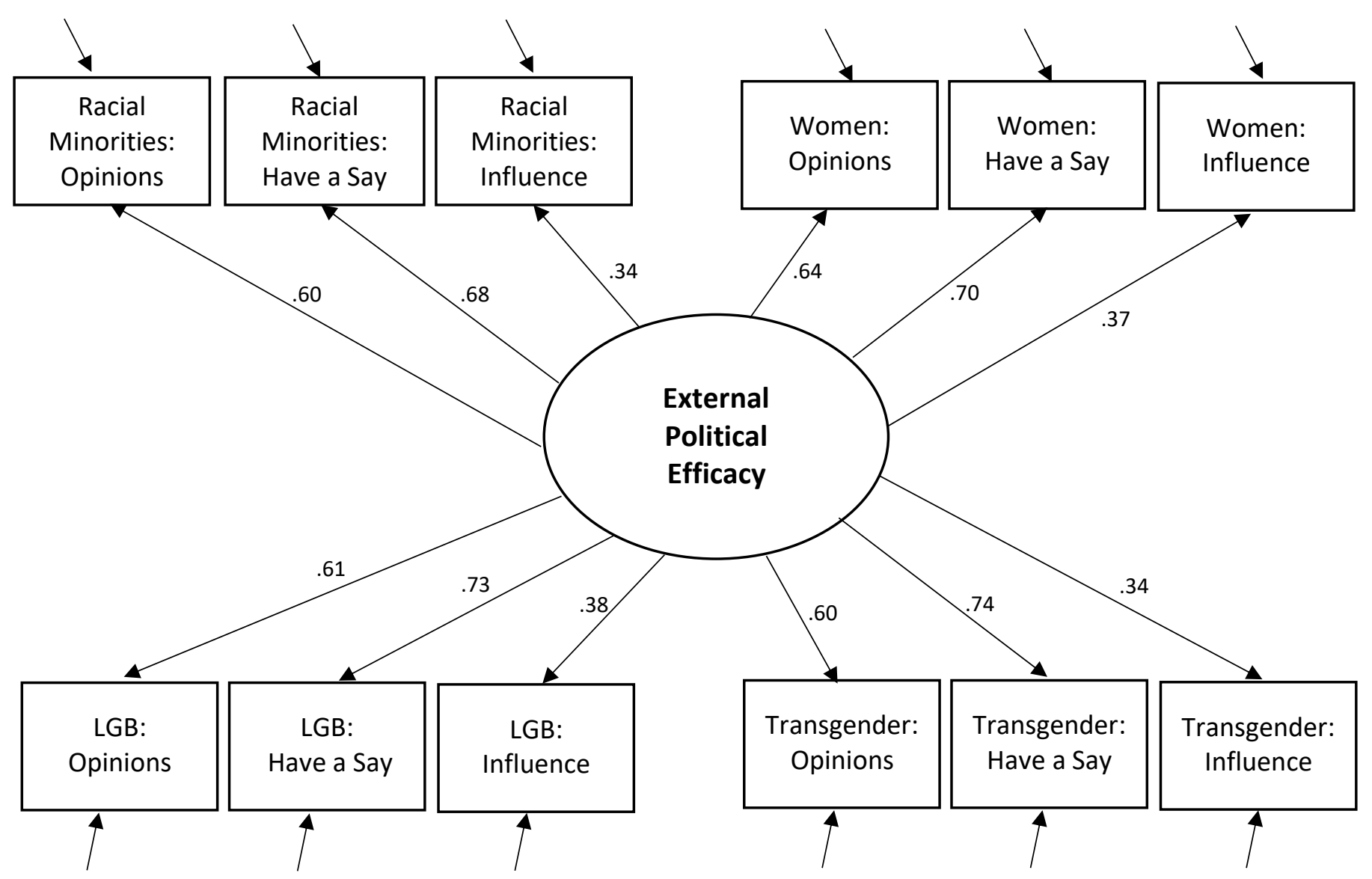


APPENDIX J

MEASUREMENT MODEL ESTIMATES FOR MODEL 1C: HIGHER-ORDER FACTOR POLITICAL EFFICACY

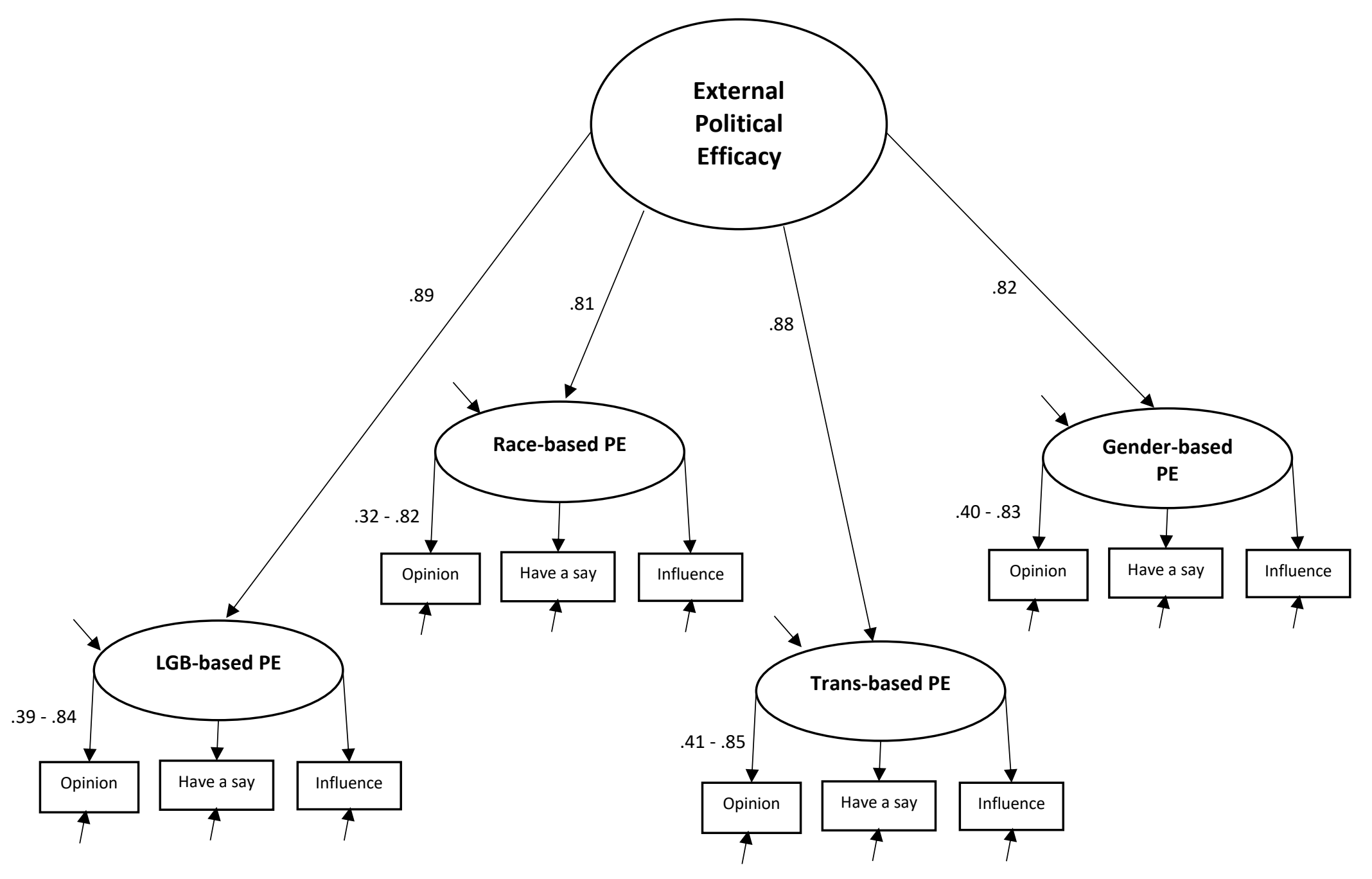




\section{APPENDIX K}

\section{SEPARATE SINGLE PREDICTOR STRUCTION MODELS}

Table 1. Unstandardized estimates for critical reflection and political efficacy as predictors of political involvement

\begin{tabular}{|c|c|c|c|c|c|c|c|c|c|c|}
\hline & \multicolumn{4}{|c|}{$\underline{\text { Social Movement }}$} & \multicolumn{6}{|c|}{$\underline{\text { Standard Political Involvement }}$} \\
\hline & \multicolumn{2}{|c|}{ Activism } & \multicolumn{2}{|c|}{ Political Voice } & \multicolumn{2}{|c|}{ Voting } & \multicolumn{2}{|c|}{ News Consumption } & \multicolumn{2}{|c|}{ Campaign } \\
\hline & $B$ & $S E$ & $B$ & $S E$ & $B$ & $S E$ & $B$ & $S E$ & $B$ & $S E$ \\
\hline \multicolumn{11}{|c|}{ Critical Reflection } \\
\hline Race-based & $.47 * * *$ & 0.04 & $.36 * * *$ & 0.05 & $.14 * *$ & 0.04 & $.17 * * *$ & 0.04 & $.21 * * *$ & 0.04 \\
\hline Gender-based & $.41 * * *$ & 0.05 & $.30 * * *$ & 0.06 & $.09 *$ & 0.04 & $.13^{* *}$ & 0.04 & $.23 * * *$ & 0.05 \\
\hline LGB-based & $.45 * * *$ & 0.05 & $.35 * * *$ & 0.06 & $.12 * *$ & 0.04 & $.16^{* * *}$ & 0.04 & $.27 * * *$ & 0.05 \\
\hline Trans-based & $.52 * * *$ & 0.05 & $.40 * * *$ & 0.06 & $.17 * * *$ & 0.04 & $.167 * * *$ & 0.04 & $.28 * * *$ & 0.05 \\
\hline \multicolumn{11}{|c|}{ Political Efficacy } \\
\hline Race-based & $-.33 * * *$ & 0.05 & $-.26 * * *$ & 0.06 & -0.02 & 0.05 & $-.10 *$ & 0.05 & $-.14 * *$ & 0.05 \\
\hline Gender-based & $-.14 *$ & 0.06 & -.06 & 0.06 & 0.04 & 0.05 & .05 & 0.05 & $-.09 \mathrm{t}$ & 0.05 \\
\hline LGB-based & $-.11 *$ & 0.05 & -.06 & 0.05 & 0.03 & 0.04 & -0.01 & 0.04 & -0.05 & 0.04 \\
\hline Trans-based & $-.16^{* *}$ & 0.05 & $-.11+$ & 0.06 & -0.03 & 0.04 & -0.01 & 0.04 & $-.08 \mathrm{t}$ & 0.05 \\
\hline
\end{tabular}




\section{APPENDIX L}

\section{SENSTIVITY ANALYSES}

Given the complexity of the latent variable interactions models and strong correlations among independent variables, additional follow-up analyses were performed to test for potential suppression effects that may have been caused by multicollinearity among the IVs. Specifically, critical reflection X political efficacy (CR X PE) interactions that yielded significant simple slopes in the full structural model were further probed by plotting and testing the significance of the simple slopes in a simplified, domain-specific model. The direction and significance of the simple slopes in a model with all forms of critical reflection and efficacy included (full model) were compared to the simple slopes in a model without the other forms of critical reflection and efficacy (simple domain-specific model). Interaction effects that were consistent across models were considered robust and reported in the main document.

Gender-based CR X PE. Gender-based critical reflection was negatively associated with news consumption for young adults with high levels of gender-based political efficacy $(B=-.37$, $S E=.18, \mathrm{p}=.04)$ and was unrelated to news consumption for young adults with low levels of gender-based efficacy $(B=-.06, S E=.19, p=.76)$. That is, for young adults who perceived the government as highly responsive to women (i.e., high efficacy), a greater awareness of genderbased inequalities was related to less frequent news consumption. However, follow-up sensitivity analyses indicate that this interaction effect may not be robust, as the pattern of significant simple slopes was not consistent in a simplified model with only gender-based CR and PE beliefs included. After trimming other forms of CR and PE from the model, gender-based critical reflection was no longer significantly associated positively with news consumption at high levels of gender-based efficacy $(B=-.02, S E=.08, p=.81)$. Instead, gender-based critical reflection 
was positively associated with news consumption at low levels of gender-based efficacy $(B=$ $.36, S E=.10, p<.001)$, which was previously nonsignificant and negative in the full model. Therefore, the effect of gender-based CR X PE on news consumption could not be interpreted likely to due to multicollinearity.

LGB-based CR X PE. LGB-based critical reflection was associated negatively with activism for emerging adults with high LGB-based political efficacy $(B=-.49, S E=.23, p=$ $.03)$, but not for emerging adults with low LGB-based efficacy $(B=-.22, S E=.24, p=.36)$. Follow-up sensitivity analyses suggest this may be due to suppression. In the domain-specific model in which all other forms of CR and PE were trimmed from the model, LGB-based critical reflection was associated positively with activism at both high $(B=.48, S E=.06, p<.001)$ and low levels of LGB-based efficacy $(B=.69 S E=.09, p<.001)$, but the association was significantly stronger for emerging adults with low LGB-based efficacy. Thus, the direction of the association between LGB-based critical reflection and activism at both high and low levels of efficacy flips from positive to negative when other forms of CR and PE are included in the model. This is likely due to the strong correlation between trans-based and LGB-based critical reflection ( $\mathrm{r}=.95)$ as well as the strong link between trans-based CR and activism. 


\section{APPENDIX M \\ LATENT PROFILE ANALYSIS}

\section{Background from Proposal Document}

The intersection of domain-specific critical reflection, domain-specific external efficacy, and social identity characteristics can also be examined utilizing a person-centered approach to identify distinct profiles. A person-centered approach (e.g., cluster analysis) may reveal unique patterns of domain-specific critical reflection and political efficacy. That is, people may vary in the extent to which critical reflection and external political efficacy align across different forms of social inequality. Some individuals may demonstrate high levels of critical awareness and external efficacy across all social issues whereas others may demonstrate high levels of critical reflection combined with low levels of external efficacy across social issues. Additionally, some individuals may show greater specificity in their beliefs about social inequality by reporting stronger beliefs about certain group-based inequalities and weaker beliefs about others. These unique patterns of domain-specific critical reflection and efficacy may be related to sociodemographic characteristics such as gender, race/ethnicity, and sexual identity. Moreover, distinct profiles of critical reflection and external efficacy may be differentially associated with engagement in social movement and standard political activities.

RQ 6: Exploratory analyses will examine whether distinct profiles of critical consciousness emerge. If unique clusters of domain-specific critical reflection and external efficacy are found, the proposed study will explore how these profiles are related to race/ethnicity, gender, and sexual identity. Additionally, we will examine how the profiles differentially predict engagement in social movement and standard political activity. 


\section{Originally Proposed Analytic Technique}

A cluster analysis will be conducted to isolate distinct profiles of domain-specific critical reflection and domain-specific external efficacy using SPSS Version 24. First, Ward's hierarchical agglomerative cluster analysis will be conducted, a technique that is commonly utilized for determining the number of clusters in a data set (Henry, Tolan, \& Gorman-Smith, 2005). The resulting dendogram, agglomerative schedule, and pseudo-F scores will be examined to identify a cluster solution. To test the stability of the resulting cluster solution, a nonhierarchical, K-means analysis will be performed. This technique allows cases to be reassigned after their initial classification. If the resulting clusters using the nonhierarchical approach substantially overlap with the resulting clusters using the hierarchical technique, this indicates the identified clusters are stable (Hair \& Black, 1998). The sample size and intuitive meaningfulness of the identified clusters will be examined. If the cluster solution points to stable and meaningful profiles of critical reflection and external efficacy, follow-up analyses will be conducted. First, a chi-square test will test whether the profiles significantly differ in their distribution of gender, race-ethnicity, and sexual orientation. Next, to test how the profiles are differentially associated with political action, a structural equation model will be conducted in Mplus with a dummy variable representing each profile predicting social movement and standard political involvement.

\section{New Analytic Technique}

Based on feedback from committee members in the proposal meeting, it was decided that a latent profile analysis (LPA) using mplus version 8 would be a more robust statistical technique to address research question 6. LPA is a confirmatory, person-centered approach that is appropriate for identifying clusters of observations that have similar values on a set of 
continuous variables (Muthen, 2001, 2004). Each cluster is based on item probability parameters, which refers to the likelihood an individual will endorse each indicator, and cluster probability parameters, which refers to the probability of individuals belonging to each cluster (Nylund, 2007). Model parameters were estimated using maximum likelihood estimation with robust standard errors (MLR). In an LPA, the number of clusters are empirically determined using fit indices, including Lo-Mendell-Rubin likelihood ratio test (LMR; Lo, Mendell, \& Rubin, 2001), Bayesian information criterion (BIC; Shwartz, 1978), AIC, and entropy (cutoff > .60). A series of models are estimated, beginning with a one-cluster solution and then increasing the number of clusters in each model. Once the fit indices level out, showing no substantive change or improvement, the resulting cluster solution is examined to ensure the profiles are intuitively and conceptually meaningful.

\section{Results}

A latent profile analysis performed on a set of eight continuous indicators including race-, gender-, LGB-, and trans-based critical reflection and external political efficacy indicated a fourcluster solution (see Table 1 for model fit criteria). Critical reflection and political efficacy means for each profile are displayed in Figure 1. A high percentage of emerging adults were classified as reflective with perceptions of moderate government responsiveness $(n=341,39 \%)$. Another profile represented emerging adults with limited critical consciousness who were slightly unaware of inequalities and slightly more efficacious $(n=267,31 \%)$. The third group consisted of emerging adults who demonstrated exceptional critical consciousness, with high perceived inequality and low perceived government responsiveness $(n=171,20 \%)$. Last, eleven percent of emerging adults $(n=93)$ displayed diminished critical consciousness, reporting the lowest levels of critical reflection and the highest levels of external political efficacy compared 
to the other profiles. It was anticipated that a person-centered approach would offer additional insight beyond the information gained from testing two-way interactions between domainspecific critical reflection and external political efficacy beliefs. However, the profiles were not distinguished by variation in group-specific beliefs. That is, the LPA results only offer insight into general combinations of high vs. low critical reflection and external political efficacy rather than showing unique patterns based on different combinations of group-specific beliefs (i.e., higher LGB-based beliefs combined with lower trans-based beliefs). Given that findings were not consistent with the goal of the proposed research question, additional follow-up analyses examining correlates of the profiles were not examined. 
Table 1

Model Fit Indices for Latent Profile Solutions

\begin{tabular}{ccccc}
\hline \# of Clusters & AIC & BIC & Entropy & $\begin{array}{c}\text { LMR p } \\
\text { value }\end{array}$ \\
\hline 2 & 13198.26 & 13317.53 & .898 & 0 \\
3 & 11855.05 & 12017.26 & .902 & .1289 \\
$\mathbf{4}$ & $\mathbf{1 1 1 0 9 . 6 3}$ & $\mathbf{1 1 3 1 4 . 7 7}$ & $\mathbf{. 9 0 4}$ & $\mathbf{. 0 1 7 3}$ \\
5 & 10686.20 & 10934.29 & .909 & .0546 \\
6 & 10458.32 & 10749.34 & .904 & .0659 \\
7 & 10300.53 & 10634.49 & .881 & .2883 \\
8 & 10162.86 & 10539.76 & .872 & .2059 \\
\hline
\end{tabular}




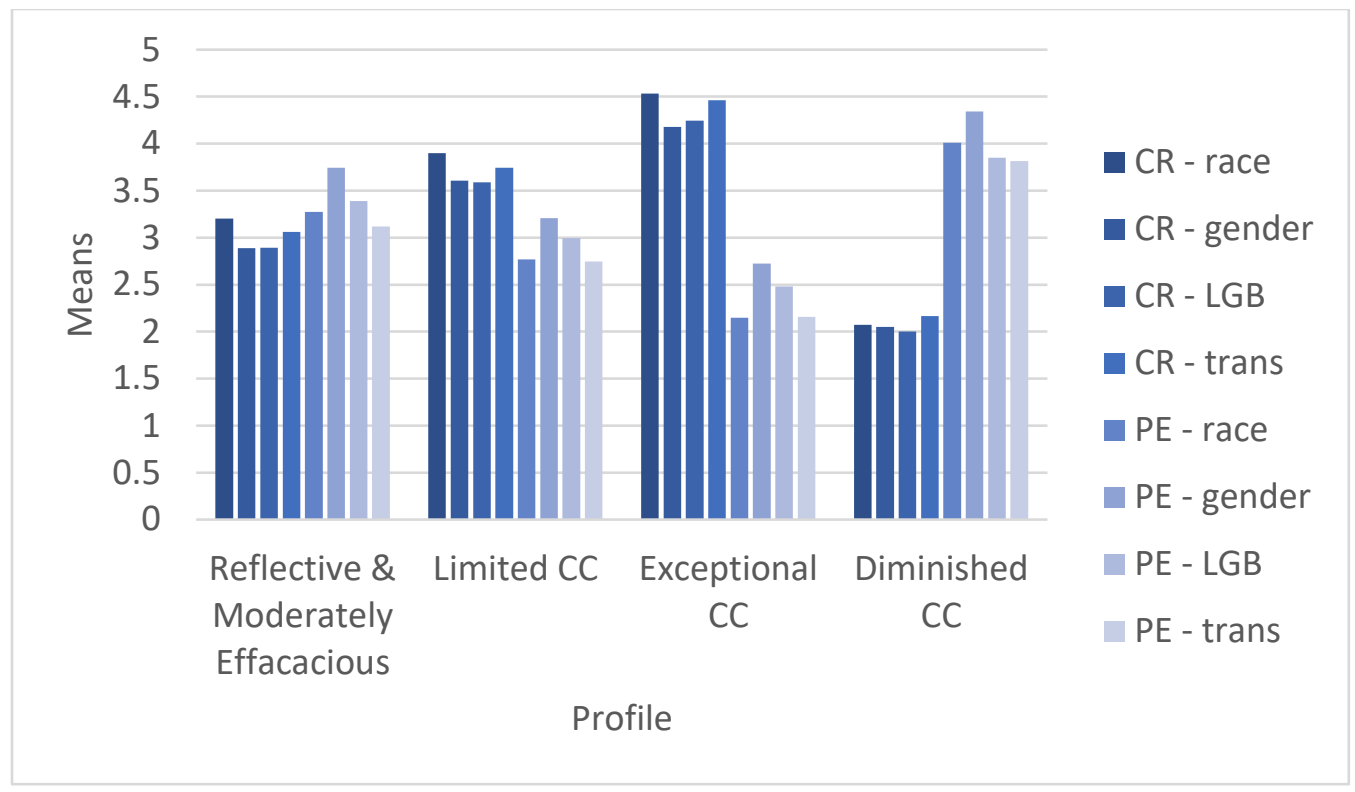

Figure 1. Profiles of Critical Reflection and External Political Efficacy Beliefs. 